\title{
An electronic patient record for stroke: development, implementation and evaluation in practice
}

Citation for published version (APA):

van der Meijden - van Buiss, M. J. (2002). An electronic patient record for stroke: development, implementation and evaluation in practice. [Doctoral Thesis, Maastricht University]. Universiteit Maastricht. https://doi.org/10.26481/dis.20021122mm

Document status and date:

Published: 01/01/2002

DOI:

10.26481/dis.20021122mm

Document Version:

Publisher's PDF, also known as Version of record

\section{Please check the document version of this publication:}

- A submitted manuscript is the version of the article upon submission and before peer-review. There can be important differences between the submitted version and the official published version of record.

People interested in the research are advised to contact the author for the final version of the publication, or visit the DOI to the publisher's website.

- The final author version and the galley proof are versions of the publication after peer review.

- The final published version features the final layout of the paper including the volume, issue and page numbers.

Link to publication

\footnotetext{
General rights rights.

- You may freely distribute the URL identifying the publication in the public portal. please follow below link for the End User Agreement:

www.umlib.nl/taverne-license

Take down policy

If you believe that this document breaches copyright please contact us at:

repository@maastrichtuniversity.nl

providing details and we will investigate your claim.
}

Copyright and moral rights for the publications made accessible in the public portal are retained by the authors and/or other copyright owners and it is a condition of accessing publications that users recognise and abide by the legal requirements associated with these

- Users may download and print one copy of any publication from the public portal for the purpose of private study or research.

- You may not further distribute the material or use it for any profit-making activity or commercial gain

If the publication is distributed under the terms of Article $25 \mathrm{fa}$ of the Dutch Copyright Act, indicated by the "Taverne" license above, 
An electronic patient recond for stroke:

Development, Implementation and Evaluation in Practice 



\section{An electronic patient record for stroke: Development, Implementation and Evaluation in Practice}

\section{Proefschrift}

ter verkrijging van de graad van doctor aan de Universiteit Maastricht, op gezag van de Rector Magnificus, Prof. Dr. A.C. Nieuwenhuijzen Kruseman, volgens het besluit van het College van Decanen, in het openbaar te verdedigen op vrijdag 22 november 2002 om 14:00 uur

door

Maria Johanna van der Meijden

geboren op 8 november 1969

te Sint Oedenrode 


\section{Promotores}

Prof.dr.ir. A. Hasman

Prof.dr. J. Troost

\section{Co-promotor}

Dr. H.J. Tange

\section{Beoordelingscommissie}

Prof.dr. F. Spaans (voorzitter)

Prof.dr. J. van der Lei

Erasmus Universiteit Rotterdam

Prof.dr. M. Limburg

Universiteit van Amsterdam

Dr. H. Schouten

Dr. G. Wesseling

Design Martien Frijns

Print PrintPartners Ipskamp

ISBN 90-9016286-0

(C)2002 Mirjan van der Meijden

The research in this thesis was conducted under the auspices of the Maastricht Health research Institute for Prevention and Care (HEALTH), which participates in the Netherlands School of Primary Care Research (CaRe), acknowledged in 1995 by the Royal Dutch Academy of Science (KNAW).

In de productiekosten van dit proefschrift werd bijgedragen door MI Consultancy (www.miconsultancy.com) en Getronics Care Services.

Daarnaast heeft ook de Stichting

BAZIS bijgedragen in de productiekosten. 


\section{Contents}

General Introduction

Chapter 1

Evaluations of inpatient clinical information systems:

Determinants of success

A literature review

\section{Chapter 2}

Situation analysis

Chapter 3

Development and implementation: how to encourage the user

Chapter 4

System description

Chapter 5

Evaluation in daily practice

Chapter 6

Two patient care information systems in the same hospital: beyond technical aspects

Chapter 7

Conclusions and General Discussion

Apendices

Summary

Samenvatting

Dankwoord

Curriculum Vitae

Publications 



\section{General Introduction}

Neurological symptoms that occur suddenly and persist for more than 24 hours or lead to death are often related to interruptions in cerebral blood circulation or to bleeding in brain tissue. Such an event, a cerebrovascular accident (CVA) or stroke, can lead to irreversible damage of brain tissue and loss of function. It is relevant for treatment to distinguish ischaemic stroke and haemorrhagic stroke. The first two weeks after the event, the acute phase of stroke, are considered to be crucial for further prognosis. In this phase, time is critically important, because adequate stroke care requires immediate diagnosis and treatment. Research presented evidence that a computed tomography $(C T)$ - scan could provide clinically relevant information concerning the type, ischaemic or haemorrhagic, size and location of the stroke lesion. There is also evidence that that a timely and adequate intervention with streptokinase can be beneficial for the ischaemic type of stroke. Therefore, an admission in the hospital immediately after the event is considered essential. At the neurology department of the Maastricht University Hospital, however, many non-acute stroke patients are occupying a hospital bed, while waiting for a place in a nursery home or revalidation clinic; institutes that are better equipped to offer adequate facilities to stroke patients in the revalidation phase. These institutes often have a waiting list that impedes an effective transmission of stroke patients. Thus, the situation is sub-optimal in two ways.

A wide range of health care providers is involved in the care for stroke patients: GPs, neurologists, nurses, physical therapists, speech therapists, revalidation physicians, etc. All these health care providers require adequate and timely information about their stroke patients. The key to improve the quality of care for stroke patients is to optimise information processing of and communication between health care providers. The patient record, the repository of information about a single patient, is most suitable to realise that [1].

Storage of patient data has always been the major function of the patient record. These patient data serve various purposes, for instance communica- 
tion, aid to memory and research. However, nowadays health care requires additional functions of the patient record like support of the care process as well as guidance of the process of clinical problem solving [1]. An electronic patient record (EPR) has more potential to fulfil these needs than a paper patient record. However, where technology advanced throughout health care, the patient record survived in its paper format. Impediments to successful computerised or electronic patient records include a lack of integration of different systems, data input by health care professionals, and the difficulty to quantify the benefits of information technology in health care [2]. To achieve all desired functions of an EPR the following aspects need to be addressed (a) the integration of different data sources with standardisation of information, (b) human-computer interfaces (c) other than technical issues including organisational and cultural issues, and (d) the organisation of the health care process $[1,2]$. Thus, challenges to surmount are numerous, while the road to success is often unpaved.

In this thesis I report on a study that aims at supporting the health care process for stroke patients with electronic record keeping in a multidisciplinary setting. The starting point of the study was as follows. Approximately $70 \%$ of all admitted patients at the neurology ward were stroke patients. To optimise the care for stroke patients inside and outside the hospital, a project had started in 1996 [3]. It implied that (1) a multidisciplinary approach was adopted to coordinate the care for stroke patients in the hospital and that (2) a stroke unit was realised at the neurology department. The fully equipped stroke unit existed of a medium care unit and two normal care wards. A number of 12-14 residents, their supervisors and 20 experienced nurses treated approximately 300 stroke patients per year.

In this setting, the need was felt for an EPR to support information exchange, but the developments toward a hospital wide electronic record system were still in a very premature stage. Hence, it was decided to develop a prototype EPR-system for stroke patients to gain experience with electronic record keeping. The implementation of an EPR was considered to be feasible, because it was expected that (1) the need for paper records at the stroke unit would be very limited when an EPR for stroke would be available and (2) consulting physicians from outside the neurology department would be easily persuaded to use the stroke EPR, because they were all familiar with an EPR-system at the intensive care unit of the hospital. It had to be a smallscale project with direct contacts with the end users to fit the specific circumstances of the stroke unit. For the users this set-up had the advantage that they would be able to discuss benefits and limitations of EPR systems 
easily. For the researchers such a small scale would provide the opportunity to study diverse aspects of the introduction and use of EPRs in daily practice without having to involve too many health care professionals.

The aims of the study were:

- To develop, implement and evaluate a prototype electronic patient record for stroke

- To investigate electronic record keeping in daily practice

These aims were translated into the following research questions:

- What does a successful approach to EPR development and implementation comprise?

- What are important aspects of an EPR evaluation study?

- What consequences does an EPR have on health care professionals and on their daily work?

\section{Overview of this dissertation}

Chapter 1 provides a literature overview of evaluations of clinical information systems, thereby concentrating on those information systems that required data entry by health care professionals. In this literature review I examined if in the literature attributes of success of clinical information systems could be identified. In addition, this chapter provides an overview of what could be evaluated when implementing information systems in a health care environment and the considerations to take into account while planning an evaluation study.

Chapter 2 examines the situation prior to the implementation of the EPR. A description of a patient's trajectory at the neurology ward provides insight in the existing work practices. The paper medical and nursing records and their role in this trajectory are analysed in detail. Then the quality of paper record keeping and the problems with these paper records are discussed.

Chapter 3 focuses on how users were involved in the process toward electronic record keeping. Their attitudes towards computers, their satisfaction with the paper records, and their expectations of electronic record keeping were very important during the whole development process. This chapter provides an overview of all these different aspects.

Chapter 4 describes the EPR developed for the specific context of stroke. 
First, the considerations in designing this EPR are discussed. Then, the structure of the database and the user interface are outlined. A brief explanation shows how data need to be entered and how data - once entered - are presented. Finally, the practical implications for record keeping are described.

Chapter 5 describes the evaluation of the EPR in daily practice. An analysis of usage behaviour, the quality of record keeping, and a quantitative and qualitative user evaluation is presented. In addition, the management's point of view on the project and the EPR is elucidated in this chapter.

Chapter 6 compares the EPR for stroke with another system in the same hospital with respect to technical issues, human factors and organisational issues. This comparison between the results of the evaluation of the EPR and those of the evaluation of the hospital-wide available clinical workstation, Mirador, aims at identifying commonalities.

Chapter 7 presents the conclusions and discusses general aspects of the study.

\section{References}

1 Dick RS, Steen EB, eds. The Computer-based patient record: an Essential Technology for Health Care. Washington DC: National Academy press 1991.

2 Kuhn KA, Giuse DA. From hospital information systems to health information systems. Problems, challenges, perspectives. Meth Inform Med. 2001; 40 (4): 275-87.

3 Transmuraal zorgmodel CVA Regio Heuvelland. Een model voor de verbetering van de kwaliteit van zorg voor CVA patiënten in de regio Heuvelland. Maastricht: Synchron; 1996. 


\section{Evaluations of inpatient clinical information systems: Determinants of success}

A literature review 


\section{Introduction}

Introducing an innovation into an organisation will evoke changes. In some cases these changes will be minor ones that hardly affect the organisation and the people working in it. In other cases, those having to use the innovation might experience major changes. Among health care professionals, new innovations are predominantly judged by their direct value for patient care [1]. Patient care information systems (PCISs) include different kinds of information systems (IS) in health care like hospital information systems (HIS), computerised or electronic medical record systems, or nursing documentation systems. ISs with a practical utility for patient care or diagnostic procedures are relatively easily accepted, sometimes even without any scientific evidence of their value $[1,2]$. However, ISs that support the process of health care without being directly relevant to patient care are less easily accepted. Particularly, attempts to introduce health care ISs that require data entry by health care providers were not always successful [3-5].

But what is successful? Complete refusal of users to use an IS is certainly a failure, but success remains often undefined. Clearly, the rate of success depends on the setting, the objectives and the stakeholders. Only a thorough evaluation study can show whether or not a specific system was successful in a specific setting. A wide range of attributes has been measured in PCISs evaluations. These attributes vary from purely technical factors to outcome measures like the quality of care, and from end user evaluation to diffusion into the organisation. Which criteria predict for success or failure is unclear, but it is very likely that not one single criterion can account for success or failure of an IS. Furthermore, not only what to assess is important, but also how to assess success is.

In 1995 van der Loo conducted a literature review to classify evaluation studies of IS in health care [6]. Primary objective of this classification was to get an insight in the variety of evaluation methods applied. In all, 76 studies published between 1974 and 1995 were included in the review. The main conclusion of that study was that the selected evaluation method and effect measures depended on the characteristics of the IS under evaluation. However, the range of identified evaluation methods and effect variables was broad for every type of system. Among the effect variables were costs, time changes for patients and personnel, changes in care process, database usage, performance of users or the system, patient outcome, job satisfaction and the number of medical test requests. Thus, many different performance measures or success factors have been applied in evaluations of clinical ISs. Several authors suggested approaches to evaluate information technology in 
health care [7-9]. These approaches concerned assessment of technical, sociological as well as organisational impacts $[7,8,10]$. A literature review of Delone and McLean in the field of management information systems (MISs) aimed at identifying determinants for IS success [11]. They presented a framework with six dimensions of success.

The purpose of our review is to analyse evaluation studies of inpatient PCISs requiring data entry and data retrieval by health care professionals, published between 1991 and May 2001, to determine the attributes that were used to assess the success of PCISs, and to use the fore mentioned framework to systematize these attributes. In addition we assessed how the attributes were measured and what study designs were applied.

\section{Methods}

\section{Selection procedure}

A PCIS was identified as a clinical information system in use in inpatient settings, requiring data entry and data retrieval by health care professionals themselves. The search in Medline included the following medical subject headings $(\mathrm{MeSH})$ terms: evaluation studies, medical record systems- computerized, and nursing records. Additionally, MEDLINE, EMBASE and Current Contents were searched with medical record*, nursing record*, evaluat*, technology assessment, electronic, computer* in all possible combinations. Exclusion criteria were guidlin* and decision support. References in English or Dutch published between 1991 (Current Contents 1998) and May 2001 were retrieved. The first author manually reviewed the titles abstracts of all journal articles and the abstracts from the1999 and 2000 Annual AMIA Symposium proceedings and the 1995 and 1998 Medinfo conference proceedings. References were selected for further analysis if the article contained (a) a short system description (b) a description of the evaluation study design (c) the data collection methods, and (d) an analysis of results. The full articles of these selected abstracts were retrieved for detailed review for further analysis. No distinction was made between articles in proceedings and regular journals and the bibliographies of selected articles were not searched for additional relevant literature. 


\section{Study designs}

Friedman and Wyatt [12] describe several evaluation study designs. They make a distinction between objectivist studies in which subjects, variables and data collection methods are selected and subjectivist studies that are conducted in the natural environment of the subjects, without manipulating it, and in which themes of interest emerge during the study [12, 13]. Objectivist studies are descriptive, comparative or correlational studies. In a descriptive study the value of an outcome variable or a set of outcome variables is measured at a certain point in time. This design is valuable for assessing predefined requirements. In a correlational study the researcher does not assign subjects to a condition, but selects variables and data collection methods. An example is a before-after design in which the introduction of the IS is preceded by baseline measurements and followed by intervention measurements. The researcher in a comparative design seeks to "create" contrasting conditions between intervention and control group. A sample of subjects is selected and assigned - randomly or not - to one of the conditions. Then, a predefined set of variables - dependent and independent - is measured. With randomly assigned subjects the study can approach a randomised controlled trial.

Subjectivist studies are for example case studies. Case studies are empirical in nature and study a phenomenon in its natural context, where the boundaries between phenomenon and environment are not absolutely clear. Evidence is collected from multiple sources - quantitatively or qualitatively. In evaluation studies of ISs, a case study can be a powerful instrument.

\section{Dimensions of success}

We decided to analyse the literature according to the approach of Delone and McLean, because in our view the success dimensions identified for MISs are valid for PCISs as well. In their review, Delone and McLean proposed to subdivide success measures of MISs into six distinct categories: (1) system quality, (2) information quality, (3) usage, (4) user satisfaction, (5) individual impact and (6) organisational impact. Within each category several attributes could contribute to success [11].

The information processing system itself is assessed with system quality attributes, which are for example usability, accessibility and ease of use. Information quality attributes concern the IS output with attributes like legibility, accuracy, and completeness. Usage refers to system usage, information 
usage or both. Examples of attributes of usage are number of entries and total data entry time. User satisfaction can concern the IS itself or its information, although both are hard to disentangle. Delone and McLean included user satisfaction additionally to usage, because in cases of obligatory use user satisfaction is an alternative measure of IS value. Individual impact is a measure for the effects of the system or the information on users' behaviour and attributes can be information recall or frequency of data retrieval or data entry. Organisational impact, the last category, refers to the effects of the IS that concern organisational performance. Thus, success measures vary from technical aspects of the IS itself to effects of large scale IS usage.

DeLone and McLean [11] concluded that success was a multidimensional construct that should be measured as such. In addition, they argued that the focus of an evaluation depended on the objective of the study, the organisational context, etc. Furthermore, they proposed an IS success model in which the interdependency - causal as well as temporal - of the six success factors was expressed. In their view, success was a dynamic process rather than a static state; a process in which the six different dimensions temporally and causally relate. System quality and information quality individually and jointly affect usage and user satisfaction. They influence each other and have a joint influence on user behaviour.

\section{Contingent factors}

The previously mentioned six dimensions of success account for effects directly relating to a system, its content or its users. However, contingencies like the process of system development, or legal issues undoubtedly have their influence [14]. Table 1 shows several factors that may affect success. In our review we included the system development process, the implementation process, and the organisational culture and characteristics, since these are specific for each setting while the other two are not.

User involvement during system development can influence the system and information quality. User involvement during the implementation can also shape user satisfaction. Management support and professional values are examples of organisational culture and characteristics that influence usage. Besides these indirect influences, organisational characteristics have also been reported to modify user assessments of IS quality directly [14]. 
Table 1

Contingencies to the six success factors of ISs. An $\mathrm{x}$ indicates that the contingent factor can influence the success factor.

Contingencies

SQ

\section{IQ}

Dimensions of Success*

Usage US II

OI

Design \& Development

$\mathrm{x}$

$\mathbf{x}$

$\mathbf{x} \quad \mathbf{x}$

Implementation

$\mathbf{x}$

x $\quad \mathbf{x}$

Organizational culture \&

characteristics

$\begin{array}{lll} & x & x\end{array}$

Issues like privacy, confidentiality

\begin{tabular}{ll}
$\mathrm{x}$ & $\mathrm{x}$ \\
$\mathrm{x}$ & \\
$\mathrm{x}$ & \\
\hline
\end{tabular}

Governmental rules

$x$

* SQ: system quality, IQ: information quality, US: user satisfaction, II: individual impact, OI: organisational impact

\section{Results}

Our search identified 1077 publications for review of their abstracts. Of the remaining 202 references, full articles were obtained, except for eleven references that were unavailable in Dutch libraries. Based on the selection criteria, the set of references was reduced to a final set of 33 articles, describing 29 different ISs. We included more than one article on a single system if the articles described distinct evaluations and we analysed them separately.

\section{Trpes of systems}

We identified general and specific systems. Hospital information systems, nursing (bedside) documentation systems, computerized medical records systems, and physician order entry systems (POE) are examples of general systems. These ISs are not necessarily limited to one ward or department. Other systems were ISs specifically designated for one type of department like intensive care unit (ICU) systems or automated anaesthesia record keeping (AARK) systems. Fourteen systems were only used by nurses, five only by physicians, and 11 were used by both nurses and physicians. The latter category comprised four order entry systems and three hospital medical record systems. 


\section{Study designs \& Data collection methods}

Table 2 shows that descriptive and correlational designs were used most frequently, whereas the comparative design with simultaneous randomised controls was applied in two studies. Data collection methods varied from chart review, questionnaires, time studies, work sampling, automated logging of user information, focus groups, observations to open-end interviews.

\section{Table 2}

Occurrences of study designs and data collection methods for each type of study.

\begin{tabular}{|c|c|c|c|c|c|c|c|c|}
\hline \multirow[t]{2}{*}{ Study Design } & & \multicolumn{6}{|c|}{ Data collection methods* } & \multirow[b]{2}{*}{ other } \\
\hline & & CR & Q & I & WS/TS & OBS & FG & \\
\hline Descriptive & [15-23] & 3 & 7 & & & & & 2 \\
\hline Correlational & [24-32] & 6 & 3 & 1 & 2 & 1 & & 2 \\
\hline \multirow[t]{2}{*}{ Comparative } & $\begin{array}{l}\text { Simultaneous non random- } \\
\text { ized controls [33-39] }\end{array}$ & 4 & 3 & 1 & 6 & & & 1 \\
\hline & $\begin{array}{l}\text { Simultaneous randomized } \\
\text { controls }[40,41]\end{array}$ & 1 & 2 & 2 & 2 & & & \\
\hline \multirow[t]{2}{*}{ Case study } & Single [42-45] & 2 & 1 & 3 & & 1 & & 1 \\
\hline & Multiple $[46,47]$ & 2 & & 2 & & 1 & & 1 \\
\hline
\end{tabular}

\section{Dimensions of success}

Information quality was evaluated in $64 \%$, system quality in $58 \%$, usage in $36 \%$, user satisfaction in $48 \%$, individual impact in $45 \%$, and organisational impact in $39 \%$ of the studies.

An overview of the data collection methods in the different studies is shown in table 3. Eight authors used multiple data collection methods to measure several attributes of the same success factor $[18,27,31,33,38,39,41,46]$. To measure system quality authors preferred questionnaires and time or work sampling techniques. Three authors combined two data collection methods. Information quality was predominantly assessed by means of chart review or 
a questionnaire. Four authors applied multiple methods and they combined chart reviews and questionnaires, in one case supplemented with interviews. Time and work sampling and content analyses were preferred to assess usage of an IS $[27,33,36,37,39,41]$. One study kept a log to investigate usage behaviour [35]. User satisfaction was most frequently measured with a questionnaire. Two authors combined interviews and questionnaires. Individual impact and organisational impact were assessed with several data collection methods. Four authors used multiple methods to assess individual impact; two of them combined a questionnaire with work sampling and the other two combined chart reviews, interviews and questionnaires. In three evaluations interviews and questionnaires were combined to assess organisational impact, supplemented with chart reviews in one case.

\section{Table 3}

Occurrences of data collection methods linked to dimensions of success.

\begin{tabular}{|c|c|c|c|c|c|c|}
\hline $\begin{array}{l}\text { Data } \\
\text { collection } \\
\text { method }^{\star}\end{array}$ & $\begin{array}{l}\text { System } \\
\text { Quality }\end{array}$ & $\begin{array}{l}\text { Information } \\
\text { Quality }\end{array}$ & Usage & $\begin{array}{l}\text { User } \\
\text { Satisfaction }\end{array}$ & $\begin{array}{l}\text { Individual } \\
\text { Impact }\end{array}$ & $\begin{array}{l}\text { Organisational } \\
\text { Impact }\end{array}$ \\
\hline Q & $\begin{array}{l}{[15,20-22} \\
33,39,41]\end{array}$ & $\begin{array}{l}{[17,21,22,} \\
27,38,39,41]\end{array}$ & {$[17]$} & $\begin{array}{l}{[15,17,21-24,} \\
27,28,33,39- \\
42]\end{array}$ & $\begin{array}{l}{[22,23,27,} \\
33,41]\end{array}$ & $\begin{array}{l}{[15,22,27,40,} \\
41]\end{array}$ \\
\hline CR & $\begin{array}{l}{[23,30,41} \\
44,47]\end{array}$ & $\begin{array}{l}{[16,18,23,27,} \\
29-32,35,38- \\
41,44]\end{array}$ & $\begin{array}{l}{[27,35,} \\
36,41]\end{array}$ & & $\begin{array}{l}{[24,27,35,} \\
41]\end{array}$ & [41] \\
\hline I & $\begin{array}{l}{[38,41,44,} \\
46,47]\end{array}$ & $\begin{array}{l}{[27,43,44,} \\
46]\end{array}$ & {$[46,47]$} & $\begin{array}{l}{[27,38,41,} \\
43]\end{array}$ & $\begin{array}{l}{[27,38,41,} \\
43,45-47]\end{array}$ & {$[27,40,41,43]$} \\
\hline TS/WS & $\begin{array}{l}{[24,26,34,} \\
36,38-41]\end{array}$ & {$[41]$} & $\begin{array}{l}{[24,33,36,} \\
37,39,41]\end{array}$ & & {$[33,38,41]$} & {$[26,34,38,41]$} \\
\hline FG & {$[46]$} & {$[46]$} & [46] & & [46] & \\
\hline OBS & {$[26,46]$} & {$[43,46]$} & [46] & {$[43]$} & {$[43,46]$} & {$[26,43]$} \\
\hline other & {$[23,25]$} & {$[18,25,31]$} & & & {$[25,34,42]$} & {$[23,25,42]$} \\
\hline
\end{tabular}


Overall, system and information quality were most frequently assessed, and the questionnaire was the preferred data collection method. Descriptive studies emphasized the technical issues, but some included the contingent factors. Organisational issues, system development process and implementation process were hardly considered in correlational and comparative studies. Those studies describing a failed or difficult implementation were all case studies - single or multiple - [42, 44, 46, 47], except one [33], and all included the contingent factors. Three authors assessed one single attribute of a single success factor $[28,32,37]$. In correlational studies relatively few attributes of the different success factors were assessed.

Table 4 shows an overview of the attributes of the dimensions of success assessed in the different studies.

\section{System Quality}

System quality attributes were evaluated in 19 studies. The most frequently addressed variables were ease of use (record keeping time), savings in documentation time and response time. In six studies ease of use, time savings and security were the single attribute of system quality [24-26, 30, 34, 36]. Several authors reported a decrease in time spent on documentation in comparison with paper $[23,25,26,36,38,39,41]$. In three studies users complained about the (complicated) methods to register patient data electronically [21, 44, 46]. Sicotte [46] and Southon [44], who conducted open-end interviews, elaborated this and found that rigidity and factors intrinsic to the system created extra work and accounted for the inconvenience. Down time and/ or system response time was a variable in six evaluations.

\section{INFORMATION QUALITY}

Information quality criteria were analysed in 21 studies. The most frequently used ones were completeness, data accuracy, legibility, and timeliness. One single attribute was measured in seven studies and in three of them that attribute was completeness. All relevant studies found an increased completeness of record content $[21,23,25-27,29,30,35,38-40,46]$. In the perception of users, availability and timeliness of information were positive aspects [27, 43]. Only for bedside nursing documentation systems an improvement of timeliness of certain types of information was observed [ 35 , 


\section{Table 4}

Attributes of different success factors.

\section{System \\ Quality Attributes \\ ease of use (record keeping time) \\ $[15,16,21,22$. \\ Information \\ Quality \\ Attributes \\ Usage \\ Attributes \\ completeness [16, number of entries \\ $21,23,25,27,29,[16,27,35,36$, \\ $30,32,38-40,46,39,41]$}

24, 34, 36, 38-40, 47

44, 46]

response time

[15, 20-23,

$33.41]$

time savings [15,

$23,25,26,38$,

41]

intrinsic features

creating extra

work $[38,44,46$,

47]

perceived ease of

use $[22,40,41]$

accuracy of data
$[16,18,22,27$,

31, 38-40]

$$
\text { 47) }
$$

Iegibility [16, 22

$38-40,44,46]$

duration of use

[24, 36, 41, 46]

frequency of use

$[27,33,37,41]$

timeliness $[22,26$, self-reported usage

$35,38,41,44$ ]

[17]

perceived useful- location of data

ness"* [22, 27, 40, entry [38] 43]

availability $[22$, $43,44]$

\section{frequency of use} of specific functions [17]

usability $[20,21$,

46]

comprehensiveness

$[21,27]$

availability (up-

consistency [27]

time) $[22,41]$

ease of learning reliability [20]

[15, 39]

rigidity of system; format [26]

built in rules [47]

reliability [33]

security[30]

easy access to help

[22]

data accuracy [23]

\section{User \\ Satisfaction \\ Attributes \\ Individual \\ Impact \\ Attributes}

user satisfaction

[17, 21-24, 27,

$33,38,40-43$ ]

attitude [15, 28,

$33,40]$

user friendliness

$[15,39]$

expectations [33]

expectations [33]

competence (com-

puters) [27] 45, 46] changed clinical communication

work patterns [24, and collaboration

$33,42,46,47]$

$[25,27,29,38$,

$40,41,43]$

direct benefits [22, impact on patient

care $[15,22,23$.

$29,34,43]$

changed docu-

mentation habits:

more adminis-

trative tasks

$[23,27,41]$

time of day for documenting

$[35,38,41]$

documentation frequency [23, 35, 38]

information use:

information

recall $[34,46]$

accurate interpretation [27, 43]

integration of information/

overview [38,

46]

information

awareness [43]

efficiency \& effectiveness of work [25]

job satisfaction [41] time savings $[23,25,26$, 41-43]

reduction of staff $[23,42]$

number of procedures reduced [43]

- Perceived ease of use (PEU) concerns a user's perception or belief. Once users believe that the IS can be helpful, the balance between the performance benefits and the efforts to invest, PEU, determines whether they will actually use a particular system [48].

** Perceived usefulness (PU) is defined as the extent to which potential users believe that a certain IS can or will support them in performing their job better. 
38]. Order entry systems improved timeliness and increased the availability of orders by reducing the time between sending the order and having the results available or the orders executed $[22,41]$.

\section{UsAGE}

Thirteen authors analysed the usage of a specific IS. The number of entries, frequency of use and the duration of use were the preferred attributes. Ambiguous results were reported for frequency of use. In three studies of bedside nursing documentation systems chart reviews showed a significant increase in number of entries and frequency of use $[16,27,36]$. In contrast, three other studies identified no significant change in frequency of use [ 33 , $37,41]$.

\section{USER SATISFACTION}

In 16 studies the authors were interested in user satisfaction, and five of them combined two or more attributes. Overall satisfaction, user friendliness and attitude were user satisfaction attributes.

Overall user satisfaction was rather high in most studies, except one [42]. In one of the studies, physicians attributed their satisfaction to patient care benefits, like improvement of clinical communication, improvement of medical record keeping and decision-making, and educational benefits like improved supervision of students and residents [43]. In one evaluation study, staff cited a positive influence of their bedside documentation system on work efficiency and effectiveness. In addition, they promoted the system throughout the whole organisation [27]. Overall satisfaction correlated strongest with ease of use, productivity or impact on patient care in case of an order entry system [17]. In this study, dissatisfaction was strongly correlated with perceptions of a negative impact of the system on patient care. In answer to the open-ended questions, more than half of the respondents indicated that the most positive aspect of the system was remote access. Nurses, however, considered the legibility of orders the most positive aspect. Low response time and too many screens or steps to complete order entry were important drawbacks for both nurses and physicians. Those systems that were withdrawn were so predominantly because of user resistance and user satisfaction was not measured $[33,46,47]$. 


\section{INDIVIDUAL IMPACT}

Fifteen authors evaluated individual impact on users with many different attributes. Five attributes - in ten studies - related to changed work practices, varying from a change in frequency of documentation to shifts in responsibilities for certain tasks. Direct benefits, changed documentation habits and information use in daily practice were the other main aspects. Spontaneous adaptations of documentation habits were investigated by analyses of location and time of day of documentation [24, 35, 38, 41]. Hammond [24] reported that nurses started entering data upon the occurrence of an event, rather than at the end of each shift like in the paper situation. Others reported that the terminal at a patient's bedside was only used to enter specific data, like medication. Other relevant information was entered elsewhere, because the patient and/ or his or her family distracted the nurse too much [35, 38]. As a consequence, bedside documentation showed no effect on completeness and timeliness of data [35].

In contrast to this voluntary change in documentation habits, in four studies the system was reported to enforce users to change their work practices $[33,42,46,47]$. This led to problems with the acceptance of the systems. Only one of these systems survived, after adaptations [42]. Two studies showed that those who perceived a higher workload judged a shift in responsibilities negatively by $[42,47]$.

Another aspect of individual impact is the ability to adequately use the information in daily work. Several authors evaluated this [27, 34, 41-43, 46, 47]. The single study that assessed information recall reported no difference between manual and automated record keeping in an ICU setting [34]. Improved awareness of information and more accurate interpretation of data were reported by users of a CPR and a bedside nursing documentation system $[27,43]$. Users cited more comprehensive records due to better documenting, and the integration of images and written notes as examples of the improvement.

An information overload due to the design of the system negatively influenced the awareness of available information by users of one computer-based patient record [46].

\section{OrgaNisationaL IMPACT}

Thirteen authors evaluated organisational impact by assessing communication/ collaboration with other disciplines, direct or indirect impact on 
patient care, and costs. An improvement of the communication between professionals or departments was reported in two studies [27, 43]. Users perceived that ISs reduced the number of phone calls to request tests/examinations and their results $[41,43]$. In one study, however, the real number of phone calls did not decrease [41].

Seven studies assessed the impact on patient care $[15,22,23,29,31,34,41$, 43]. In two studies, time saved from documenting increased time spent on patient care $[23,37]$. In one study the physicians saved time documenting, but lost time due to technical difficulties with the IS or coupled systems [34]. According to users, good accessibility of information, and a reduced number of repeated examinations had a positive impact on patient care [43]. Furthermore, a quicker availability of test results was perceived to have a positive impact as well $[41,43]$. Other POEs were shown to improve correct documentation of orders $[29,31,41]$.

A third aspect of organisational impact related to costs. They were measured by time savings, reduced overtime, savings in personnel or less requested tests $[23-25,27,38,41]$. One study observed considerable time savings because of more efficient work routines [25]; others reported a reduction in the number of redundant examinations $[26,41,43]$.

\section{Contingent factors}

The system development and implementation process, and the organisational characteristics of the organisation were mainly assessed in evaluations of failed initiatives. Table 5 shows the attributes of the contingent factors and in which studies they were identified.

\section{SyStem DEVELOPMENT}

Key decisions during system development of two systems were evaluated (by independent researchers) $[42,45-47]$. Both systems were withdrawn and the failure was partly explained by the choices made during development. These choices were: (1) technological choices, (2) user involvement, (3) intended redesign of work practices, and (4) a reconstruction of the record format. In these studies data were collected with interviews and questionnaires. In one study, the choice of a touch screen resulted in a menu- driven input, which resulted in a structured questionnaire to capture data [46]. This made the system merely a data collection tool that did not fit the documentation prac- 


\section{Table 5}

Attributes of different contingent factors.

24

\section{System Development Attributes}

user involvement $[42,46,47]$

redesign work practices [47]

reconstruction of content/ format [46]

technical limitations $[45,46]$

\author{
Implementation Attributes \\ communication (frequency, two \\ way) $[19,42,45-47]$ \\ training $[21,23,25,29,41]$ \\ priorities chosen $[46,47]$ \\ technical support $[21,25]$ \\ user involvement [46]
}

\section{Organizational Aspects Attributes}

organizational culture

control and decision-making $[19,41,42,45,47]$

management support $[19,44$, $45,47]$

professional values $[19,42,45]$

collaboration/ communication [42]

support and maintenance $[20,21$, $25,44]$

champions [19]

rewards [42]

tices of physicians. In addition, developers approached the IS development in a logical fashion and started with the first data that were collected. Although these were the first data to collect in a patient's trajectory, entering this information in an IS was cumbersome and offered no benefits. Thus, as a result of insufficient communication and insufficient user involvement, the wrong priorities were chosen.

Strict interpretation of rules for work practices made work difficult [42]. For example, a POE system required signing of verbal orders. When the number of unsigned orders increased gradually, management decided that new orders could only be entered after the unsigned ones were removed. This requirement was eliminated because of resistance of the residents, whose workload had increased drastically. Also in other studies, required alterations in established work practices provoked resistance [42], or led to an increase in time spent on documentation [46]. 
The implementation process was evaluated in nine articles $[19,21,23,25$, $29,41,42,46,47]$. Communication, education and technical support were the main issues concerning the implementation process. Communication was included in five studies [19, 42, 45-47]. Education was only described in terms of hours of education and the organisation of technical support, but not analysed [21, 23, 25, 29, 41].

Insufficient two-way communication, about for example the progress of the implementation or the expected benefits of the IS, had a negative influence on the adoption of ISs $[42,45,47]$.

\section{Organisational culture and characteristics}

Different aspects of the organisational culture were evaluated in several studies $[19,42,45-47]$. In the study of Ash, frequent communication was associated with better diffusion of CPRs [19]. Visible management support is essential, as are the lines of authority. In two studies, the persons responsible for implementing an IS did not have decision-making authority [42, 45]. This misfit between organisational structure and IT implementation strategy largely complicated the implementation. Another example of a misfit was reported by Lehoux et al [47] with physicians asking nurses to warn them when vital signs exceeded certain values, while they had been expected to check vital signs themselves [47].

\section{Discussion and Conclusions}

Evaluations of PCISs requiring data entry by health care professionals are relatively scarce. Thirty-three contributions meeting our criteria in ten years is not much. Yet, these 33 references showed that evaluations are valuable for other designers, implementers, and researchers. Contrary to our expectations, famous systems, like the Regenstrief system, were not among the references. No evaluation studies of these systems were found in the past ten years. However, we found several detailed descriptions of the functionality of these systems $[49,50]$. The most important limits in our search were: a ten year period, inpatient PCIS, no decision support systems and data entry and retrieval by health care providers. Were these useful restrictions? It can be argued that inpatient PCISs are more difficult to implement than outpatient 
systems, since the patient trajectories make health care work less predictable there and the same can be added for direct data entry and retrieval by health care workers. To show the added value of these PCISs, careful evaluations are important. Particularly, PCISs that have been running for years can be a source of helpful information to others.

Further, some of the choices we made while systematizing the attributes of the evaluation studies are debatable. Perceived ease of use (PEU) for example is marked as a system quality attribute, while it could also be marked as an attribute for user satisfaction. This shows, however, the need for further research in this area.

\section{What is success?}

We did not find any explicit definition of success in the studies we reviewed. The value of an IS was often measured against the value of the familiar paper based systems, assuming that paper based systems are the 'gold standard'. Clearly, paper based documentation systems have many virtues, like portability and familiarity, but probably have even more disadvantages such as illegibility and unavailability. ISs are expected not only to overcome the disadvantages, but to offer more than that. Hence, the choice for paper based records as a gold standard is a pragmatic one. This choice is questionable, since the benefits of an IS differ from those of paper based systems. Moreover, ISs will interact differently with their users than their paper counterparts.

The definition of success remained undefined and also the stakeholders of the IS were not clearly identified. If the main stakeholder is the manager who wants to cut costs, a documentation system is unsuccessful since staff spends more time entering data. The physician, in contrast, may regard the same bedside nursing documentation system very successful, because vital signs are readily available and legible without the need to consult a nurse or the paper records. Thus, this documentation system can be regarded as a failure or as a success, depending on the point of view.

It is plausible that also the timing of assessing success influences the results. Technical criteria can be assessed already before the implementation, while a useful assessment of organisational impact can only occur after a reasonable period of daily use. Our review, however, showed that many evaluations finished within half a year after the introduction of the IS, whereas many started only after the implementation. To make it even more complex, definitions of success fluctuate over time [51]. A success today may be considered a failure in a decade due to technical limitations or changed demands and expec- 
tations. All this means that a good evaluation should include multiple, carefully selected periods of data collection and should include all stakeholders. Another complicating matter is the organisation in which the IS functions. Repeatedly, researchers stressed the importance of incorporating contextual information in an evaluation of an IS [52-57]. Contextual information and organisational impact were included in many evaluations. Organisational culture, like professional values, however, was seldom taken into account. In contrast to successes, failures were clearly identified by the authors. However, we found only few references concerning failed initiatives [44-47]. Possibly, failed implementations are less easily accepted, or are not offered for publication or are not often evaluated [58]. Yet, particularly the evaluations of failed initiatives that we found were rich and detailed descriptions of the design, implementation, and effects of ISs, carefully considering those aspects that contributed to the failure.

\section{What to evaluate?}

Despite the ever-increasing number of health care ISs, published evaluation studies are scarce. Nevertheless, health care needs thoroughly evaluated ISs to ensure that those ISs better support the daily work of health care workers. To our knowledge, no framework existed to evaluate PCISs. Our review showed that the dimensions of success, as defined by Delone and McLean were applicable to inpatient PCISs [11]. In addition, the contingent factors were helpful to explain the failures of PCISs.

The literature provided a wide range of attributes to choose from when evaluating PCISs (table 5). Not all attributes need to be measured in every evaluation. However, a framework is indispensable to be able to assess the quality of PCISs and to compare different PCISs. We tested the usability of a framework in this review. Further research is needed to determine what attributes are most relevant to success and if different attributes should be assessed for different types of PCISs. In addition, it is unlikely that one single dimension is decisive in system success. Rather, a multidimensional construct, as proposed by Delone and McLean, is more likely. After all, if for example the documentation time is burdensome (system quality), it is plausible that actual usage, user satisfaction as well as the behaviour of the user (individual impact) are influenced. Therefore, we suggest that the framework presented here, will be further explored in future research.

Important contingencies that can influence success of an IS are key decisions, for instance technological choices, and user involvement during system devel- 
opment and implementation. Furthermore, also the way things are done organisational culture - is important for the success of an IS. Since there was little information in the literature about the contingent factors of the non-failures, the contingent factors should be included in future research as well.

\section{How to evaluate?}

The results showed that evaluations of ISs in health care often were descriptive or correlational studies. We found only two studies with a comparative design with simultaneous randomised controls. Such comparative design is generally considered to be best, but it requires a clear definition and operationalisation of variables beforehand. Also the possibility to create two or more independent conditions often lacks in evaluation studies of ISs. In case studies, a more flexible approach allows the research questions to evolve and also includes the context of the ISs and the interactions between user and IS. Both approaches can be valuable, depending on the objective of the evaluation and the stakeholder(s). Methodological guidelines for evaluation have been suggested by Kaplan [9]. She suggested (1) to focus on a variety of concerns, (2) to choose a longitudinal study design, (3) to use multiple methods, (4) to choose a study design that can be adapted to the study findings whenever necessary, and (5) to be both formative and summative, that is, to evaluate and with the results further develop the IS. Albeit somewhat general and certainly ambitious, these guidelines are valuable in designing evaluation studies. Our review showed that evaluations assessing several attributes of different factors were more informative.

A thorough evaluation should include all success factors, but the moment to measure each varies from factor to factor. An evaluation should start before the development and should have no fixed end. One could think of a kind of post-marketing surveillance as is usual in medication registration procedures. The integration of qualitative (observations, interviews) and quantitative (questionnaires, work sampling) data collection methods provides an opportunity to improve the quality of the results through triangulation [59]. In evaluations of ISs multiple methods the data of different sources complemented each other, to provide a more complete picture. Formative evaluations - aiming at improving the IS during development or implementation - were hard to find in the reviewed literature. Most evaluations concerned systems in use and these were summative evaluations.

In short, for evaluation studies of PCISs we suggest to evaluate in multiple periods of time, to use multiple data collection methods, to take different points of view and to share results with others. 


\section{References}

1 Banta HD. Embracing or rejecting innovations:clinical diffusion of health care technology. In: Anderson JG, Jay SJ, eds. Use and impact of computers in clinical medicine. New York: Springer Verlag 1987.

2 Fineberg $\mathrm{H}$, Hiatt $\mathrm{H}$. Evaluation of medical practices. The case for technology assessment. N Engl J Med. 1979; 301 (20): 1086-91.

3 Schoenbaum SC, Barnett GO. Automated ambulatory medical records systems. An orphan technology. Int J Technol Assess Health Care. 1992; 8 (4): 598-609.

4 Sittig DF, Stead WW. Computer-based physician order entry: the state of the art. JAMLA. 1994; 1: 108-23.

5 Wyatt JC. Clinical data systems, Part 3: Development and evaluation. Lancet. 1994; 344 (8938): 1682-8.

6 van der Loo RP, Gennip EMSJ, Bakker AR, Hasman A, Rutten FFH. Evaluation of automated information systems in health care: an approach to classify evaluative studies. Comput Methods Programs Biomed. 1995; 48: 45-52.

7 Anderson JG, Aydin CE. Evaluating the impact of health care information systems. Int J Technol Assess Health Care. 1997; 13: 380-93.

8 Grémy F, Degoulet P. Assessment of health information technology: which questions for which systems? Proposal for a taxonomy. Medical Informatics. 1993; 18: 185-93.

9 Kaplan B. Addressing organizational issues to the evaluation of medical systems. JAMLA. 1997; 4: 94-101.

10 Goodman EC. A methodology for the 'user-sensitive implementation' of information systems in the pharmaceutical industry: a case study. Int J Inform Manag. 1998; 18 (2): 121-38.

11 DeLone WH, McLean ER. Information systems success: the quest for the dependent variable. Inf Sys Res. 1992; 3 (1): 60-95.

12 Friedman CP, Wyatt JG. Evaluation methods in medical informatics. New York: Springer-Verlag 1997.

13 Yin RK. Applications of case study research. Newbury Park, CA: SAGE publications 1993.

14 Franz CR, Robey D. Organizational context, user involvement, and the usefulness of information systems. Decision Sciences. 1986; 17: 329-56.

15 Abenstein J, DeVos C, Abel M, Tarhan S. Eight year's experience with automated anesthesia record keeping: Lessons learned - New directions taken. Int J Clin Monit Comput. 1992; 9 (2): 117-29.

16 Hammond J, Johnson H, Varas R, Ward C. A qualitative comparison of paper flowsheets vs a computer-based clinical information system. Chest. 1991; 99 (1): 155-7.

17 Lee F, Teich JM, Spurr CD, Bates DW. Implementation of physician order entry: user satisfaction and self-reported usage patterns. JAMIA. 1996; 3 (1): 42-55. 

gy examinations on the transmission of clinical information. Acad Radiol. 1997; 4 (2): 154-6.

19 Ash J. Organizational factors that influence information technology diffusion in academic health sciences centers. JAMIA. 1997; 4 (2): 102-11.

20 Meyer KE, Altamore R, Chapko M, Miner M, McGann M, Hill E, C. VDL, Bates M, Weir C, Lincoln T. The need for a thoughtful deployment strategy: evaluating clinicians' perceptions of critical deployment issues. Medinfo. 1998; 2: 854-8.

21 Urschitz M, Lorenz S, Unterasinger L, Metnitz P, Preyer K, Popow C. Three years experience with a patient data management system at a neonatal intensive care unit. J Clin Monit. 1998; 14 (2): 119-25.

22 Weiner M, Gress T, Thiemann DR, Jenckes M, Reel SL, Mandell SF, Bass EB. Contrasting views of physicians and nurses about an inpatient computer-based provider order-entry system. JAMIA. 1999; 6 (3): 234-44.

23 Allan J, Englebright J. Patient-centered documentation: an effective and efficient use of clinical information systems. J Nurs Adm. 2000; 30 (2): 90-5.

24 Hammond J, Johnson H, Ward C, Varas R, Dembicki R, Marcial E. Clinical evaluation of a computer-based patient monitoring and data management system. Heart Lung. 1991; 20 (2): 119-24.

25 Harrison GS. The Winchester experience with the TDS hospital information system. Br J Urol. 1991; 67 (5): 532-35.

26 Kahl K, Ivancin L, Fubrmann M. Automated nursing documentation system provides a favorable return on investment. J Nurs Adm. 1991; 21 (11): 44-51.

27 Dennis K, Sweeney P, Macdonald L, Morse N. Point of care technology: impact on people and paperwork. Nurs Econ. 1993; 11 (4): 229-37.

28 Murphy CA, Maynard M, Morgan G. Pretest and post-test attitudes of nursing personnel toward a patient care information system. Comput Nurs. 1994; 12 (5): 23944.

29 Sulmasy DP, Marx ES. A computerized system for entering orders to limit treatment: implementation and evaluation. J Clin Ethics. 1997; 8 (3): 258-63.

30 Nielsen PE, Thomson BA, Jackson RB, Kosman K, Kiley KC. Standard Obstetric Record Charting System: Evaluation of a new electronic medical record. Obstet Gynecol. 2000; 96 (6): 1003-8.

31 Bates D, Teich J, Lee J, Seger D, Kuperman G, Ma'Luf N, Boyle D, Leape L. The impact of computerized physician order entry on medication error prevention. Obstet Gynecol. 1999; 6 (4): 313-21.

32 Larrabee J-H, Boldreghini S, Elder-Sorrells K, Turner Z-M, Wender R-G, Hart J-M, Lenzi P-S. Evaluation of documentation before and after implementation of a nursing information system in an acute care hospital. Comput Nurs. 2001; 19 (2): 56-65. 

tems in an university hospital. Meth Inform Med. 1999; 38: 9-15.

34 Allard J, Dzwonczyk R, Yablok D, Block J-F, McDonald J. Effect of automatic record keeping on vigilance and record keeping time. Br J Anaesth. 1995; 74 (5): 619-26.

35 Marr PB, Duthie E, Glassman KS, Janovas DM, Kelly JB, Graham E, Kovner CT, Rienzi A, Roberts NK, Schick D. Bedside terminals and quality of nursing documentation. Comput Nurs. 1993; 11 (4): 176-82.

36 Minda S, Brundage DJ. Time differences in handwritten and computer documentation of nursing assessment. Comput Nurs. 1994; 12 (6): 277-9.

Marasovic C, Kenney C, Elliott D, Sindhusake D. A comparison of nursing activities associated with manual and automated documentation in an Australian intensive care unit. Comput Nurs. 1997; 15 (4): 205-11.

Pabst MK, Scherubel JC, Minnick AF. The impact of computerized documentation on nurses' use of time. Comput Nurs. 1996; 14 (1): 25-30.

39 Wang X, Gardner RM, Seager PR. Integrating computerized anesthesia charting into a hospital information system. Int J Clin Monit Comput. 1995; 12 (2): 61-70.

Ammenwerth E, Eichstadter R, Haux T, Pohl U, Rebel S, Ziegler S. A randomized evaluation of a computer-based nursing documentation system. Meth Inform Med. 2001; 40: 61-8.

41 Ostbye T, Moen A, Erikssen G, Hurlen P. Introducing a module for laboratory test order entry and reporting of results at a hospital ward: an evaluation study using a multi-method approach. J Med Sys. 1997; 21 (2): 107-17.

42 Massaro TA. Introducing physician order entry at a major academic medical center: I. Impact on organizational culture and behavior. Acad Med. 1993; 68: 20-5.

43 Kaplan B, Lundsgaarde $\mathrm{H}$. Toward an evaluation of an integrated clinical imaging system: identifying clinical benefits. Meth Inform Med. 1996; 35 (3): 221-9.

44 Southon FCG, Sauer C, Dampney CNG. Information technology in complex health care services: organizational impediments to successful technology transfer and diffusion. JAMLA. 1997; 4: 112-24.

45 Southon G, Sauer C, Dampney K. Lessons from a failed information systems initiative: issues for complex organisations. Int J Med Inf. 1999; 55: 33-46.

46 Sicotte C, Denis J, Lehoux P, Champagne F. The computer-based patient record challenges towards timeless and spaceless medical practice. J Med Sys. 1998; 22 (4): 237-56.

47 Lehoux P, Sicotte C, Denis J. Assessment of a computerized medical record system: disclosing scripts of use. Evaluation And Program Planning. 1999; 22 (4): 439-53.

48 Davis FD. Perceived usefulness, perceived ease of use and user acceptance of information technology. MIS Quarterly. 1989; 13: 319-39. 

A, Schadow G, Blevins L, Glazener T, Meeks-Johnson J, Lemmon L, Warvel J, Porterfield B, Warvel J, Cassidy P, Lindbergh D, Belsito A, Tucker M, Williams B, Wodniak C. The Regenstrief Medical Record System: a quarter century experience. Int J Med Inf. 1999; 54: 225-53.

50 Scherrer JR, Baud R, Borst F. Integrated computerized patient records: a two-year Geneva experience. Int J Biomed Comput. 1996; 42: 123-8.

51 Berg M. Implementing information systems in health care organizations: myths and challenges. Int J Med Inf. 2001; 64: 143-56.

52 Kaplan B. Evaluating informatics applications - some alternative approaches: theory, social interactionism, and call for methodological pluralism. Int J Med Inf. 2001; 64: 39-56.

53 Forsythe DE, Buchanan BG. Broadening our approach to evaluating medical information systems. Proc 15th Annu Symp Comput Appl Med Care. 1991;: 8-12.

54 Kaplan B. Culture counts: how institutional values affect computer use. MD Comput. 2000; (jan/feb): 23-6.

55 Heathfield H, Pitty D, Hanka R. Evaluating information technology in health care: barriers and challenges. BMJ. 1998; 316: 1959-61.

56 Heathfield HA, Peel V, Hudson P, Kay S, Mackay L, Marley T, Nicholson L, Roberts $\mathrm{R}$, Williams J. Evaluating large scale information systems: from practice towards theory. In: Proceedings of the 21th AMIA Annual Fall Symposium; 1997 1997; 11620.

57 Anderson JD. Increasing the acceptance of clinical information systems. MD Comput. 1999; (1): 62-5.

58 Friedman CP, Wyatt JC. Publication bias in medical informatics. JAMIA. 2001; 8 (2): 189-91.

59 Kaplan B. Combining qualitative and quantitative methods in information systems research: a case study. MIS Quarterly. 1988; (12): 571-86. 


\section{Situation analysis}

PUBLISHED AS

M.J. van der Meijden, H.J. Tange, J.Boiten, J.Troost, A.Hasman. An experimental electronic patient record for stroke patients Part 1 . Situation analysis. International Journal of Medical Informatics (2000) 58/59 pp 111-125 


\section{Introduction}

Started as an aide mémoire for the individually working physician, the clinical record gained significance as a means of communication between care providers of (different) disciplines. Poor legibility, limited availability, poor organisation and incompleteness are some of the problems with the paper record [1]. These and other shortcomings of paper medical and nursing records are well recognised and the electronic patient record (EPR) is believed to be the solution. The department of Neurology of the Maastricht University Hospital collaborated with the department of Medical Informatics of Maastricht University in a project to develop an EPR for stroke patients. At the Neurology department many health care workers collaborate in a multidisciplinary team to treat stroke patients. This team was founded, because the Neurology department participates in a special project (concerning transmural care for stroke patients) to improve the treatment of stroke patients. In this project GPs in the region also participate. They refer every patient they suspect of having had a stroke immediately to the hospital. Accurate and timely information exchange is a prerequisite for a good functioning team. In daily practice it appeared that the current paper records did not always fulfil the information needs. It was suggested that the use of an EPR could contribute to optimising care. Therefore, the current project was initiated between the department of Neurology and the department of Medical Informatics to study the benefits of an EPR for stroke patients. This EPR is described in Chapter 4. The main goal of this EPR is to support daily practice with complete, accurate and timely information. We presumed that the stroke unit would be a well-defined field with a limited number of users and would therefore be suitable for evaluating the EPR. The purpose of this chapter is to analyse the problems that arise with the paper records in general and those that arose in this specific setting, and to obtain the requirements for an EPR that overcomes these problems. In addition we describe (potential) problems and advantages of an EPR in a smallscale, experimental setting as the Maastricht stroke unit.

\section{Health care and EPRs}

The use of information and communication technology (ICT) in the primary process of health care institutions is not widespread. The first paragraph will briefly describe the role of paper records in the care process. In the second paragraph the focus is on the acceptance of innovations like for example an EPR. 


\section{Health care and the paper record}

The chaotic nature of health care work originates in the patient's trajectory [2]. Medical and nursing records are merely a tool in the process of managing that trajectory, not more and not less. As such they should support the health care workers in 'doing the job'. Notwithstanding the weaknesses of paper records as illegibility, incompleteness, not available when needed, inaccuracies and difficulties with data retrieval $[1,3]$, the paper record supports health care workers in their work. In the acts of reading and writing this support becomes clear. Research on the use of paper records reveals some interesting features of these records. To begin with, the medical and nursing record are not an exact representation of what happened to the patient. Nevertheless, the competent reader knows how to read and interpret the seemingly chaotically and unmanageably presented information in paper records. All entries in a record serve a purpose and ideally, they meet with expectations of readers [4-7]. Readers not only expect to find specific items in the record, but they also expect them at a specific place in the record [8]. Results of history taking and medical examination for instance, are expected to be reported at the beginning of the record and in a certain order. Medical data obtain significance in relation to the context in which they were created. Moreover, while one simple entry of its own has hardly any significance, a pattern of entries emerging over time assigns a meaning to each individual entry [5, 6]. For instance, consider the following temperature curve: at $8 \mathrm{AM}$ 38.4 , at 12 PM 38.3 and at 2 PM 38.5. The physician would respond differently to the temperature of 38.5 at $2 \mathrm{PM}$ if the preceding registrations were 37.1 and 37.6.

Many previous studies concentrated on either the (content of) records [912], the technical aspects of electronic record systems [13] or on the users solely $[11,14,15]$. However, it is hard to disentangle the workers in health care from the organisation they work in. Hence, more and more the position of the EPR system within the organisation of people that use the EPR is regarded important [16]. Clearly, the consequences of transforming record keeping from paper based to electronic record keeping are not limited to the individual health care worker. Work in a hospital can be characterised as coordination and collaboration between individual health care workers, ancillary departments and other specialties [17-19]. Therefore, the collaborative character of health care work is gaining interest and is regarded as an important aspect in building EPR systems. Logically, EPR systems should fit into daily practice [20]. The social technical approach, advocated by Berg, takes a social network as a starting point. Technology should be supportive 
to this social network. Hence, a system to be developed should be moulded more to the existing working practices rather than the other way around. Nevertheless, introducing information technology will affect the daily routine that much is clear. Atkinson drafts a scenario in which hospitals change along with their EPR system [21]. Since the current, preliminary systems will lead to new desires that cannot be foreseen, these systems are only a starting point. An EPR system should grow gradually to a mature system. During the process of maturation clinical practice and the information systems will mutually affect each other.

A recurring theme in the discussion of ICT and health care is the resisting, autonomously working, health care workers. Attitudes of health care workers towards ICT in health care have been studied thoroughly [15, 17, 22-31]. Predominant factors that are suggested to influence attitudes include age, previous experience with computers, perceived usefulness, perceived ease of use and perceived (change of) professional status. After implementation of an EPR, also the user's social world and occupational world influence attitudes to a large extent $[17,22]$.

\section{Innovations: acceptance and effects}

Empirical research on innovations and the diffusion of innovations has indicated five attributes that highly influence the success of an innovation: (1) relative advantage: the perceived usefulness of the new idea, (2) compatibility: the extent to which an innovation matches with social cultural ideas and beliefs, previously introduced ideas or the needs for such an innovation; (3) complexity: the perceived difficulty of using of the innovation (4) trialability: the extent to which an innovation can be experimented with safely, on a small scale and (5) observability: the visibility of the results of the innovation [32]. In general terms, the degree of acceptance increases when the perceived relative advantage, compatibility and observability are high, when the innovation seems simple and experiments on a small scale are possible. The rate of adoption, however, depends not only on the five attributes mentioned. Rogers [32] suggests that the decision process also influences the rate of adoption of an innovation - whether the decision was made top-down or bottom-up -, the communication channels, the nature of the social system and the extent of promotion efforts. While Rogers focuses on individual care providers and their networks, organisational factors seem to influence the diffusion rate of an innovation as well [33].

Many of the factors mentioned by Rogers [32] are described implicitly in 
studies of the use of information systems in health care. Obviously, an electronic record system needs to be tailored to its goal and users. An EPR has to be easy to work with, has to contain all necessary information, has to present information clearly, etc. The necessity of these features is widely accepted. To successfully build an EPR that fits neatly into daily routines and work practices is difficult. This is illustrated by a publication about an EPR system that was designed and implemented to change work processes; it did not succeed. According to the authors, changes in work processes should have preceded the implementation of the EPR system [34]. Hence the use of ICT as a tool to realise organisational changes is hardly recommendable, but in many cases the introduction of ICT encompasses much more than replacing existing procedures, documents or tasks. Reported consequences of EPR systems include shifts in roles and responsibilities, increase of visual accountability and various unanticipated consequences $[22,35,36]$. Shifts in roles and responsibilities occur due to proceduralising existing tasks. Hebert [36] states:

\section{Once proceduralised, these [tasks] could be monitored by people with less training than the professional.}

On the other hand, she reported that certain administrative tasks can easily be performed by professionals, because those tasks require not much time anymore and direct data entry by the professional may be beneficial in the care process. Direct order entry is an example of this [10]. The increase of visual accountability may be perceived as an intrusion to the professional autonomy and may invoke resistance $[22,36]$. Unanticipated effects may comprise that tasks require more instead of less time, that time spent with patients did not increase [28, 36, 37].

In addition, a system may affect occupational groups and departments each in a different way. Influential factors comprise differences between social worlds each having their own set of values and practices, the (perceived) impact of a system on the daily work of professionals, changing relationships within and between professional groups and changing relationships between departments [17, 22, 36, 38-42]. The study of Kaplan serves as an illustration of how people performing the same job can perceive an innovation entirely different. Kaplan studied how an information system, replacing a manual operation, affected the laboratory technicians who worked with the system. There appeared to be two ways of seeing the job of laboratory technician. Those technicians who saw their jobs as a service and aimed at results assessed the computer application positively, whereas those who saw their 
jobs as bench work felt a higher workload and assessed the computer application negatively [43].

From the above we concluded the following to apply in the EPR's design process. Notwithstanding the problems of the paper records, the positive aspects of paper records should be valued whilst developing an EPR. The order of appearance of information and the context in which medical data are generated are such important aspects that need to be considered in designing and developing the EPR. In addition, the users' perception of the EPR itself and of the EPR in work practices will greatly influence the success of the EPR. Hence, early user involvement and active participation cannot only contribute to the system itself, but to the degree of acceptance as well.

\section{Insight in the work place}

In our project we design an electronic patient record system. We based our design principles and decisions on data about work practices of nurses and physicians and their paper records. We collected these data with qualitative and quantitative methods.

\section{Methods}

Prerequisite for developing a useful EPR system is knowledge of the work practices. We analysed paper records to track possible problems with paper records like incompleteness, poor legibility, poor availability and inaccuracies. To investigate the extent of potential problems the paper records of all discharged and deceased stroke patients were analysed during four months. In all, 48 paper records were included in this analysis. The attributes rated were completeness of the admission form, inconsistencies in information, missing data and type of data recorded. We concentrated on a list of 35 items that was selected beforehand in close consultation with a senior neurologist (table 1 lists the 15 items that were missing most frequently). The set of clinical items was the minimum necessary for (diagnostic) treatment of stroke patients. 


\section{Table 1}

Numbers of missing clinical items, sections, test requests or results in 42 paper records.

\begin{tabular}{|c|c|c|c|c|c|}
\hline \multirow[t]{2}{*}{ Clinical Item } & \multicolumn{2}{|c|}{ missing } & \multirow[t]{2}{*}{ Sections missing } & \multicolumn{2}{|c|}{ missing } \\
\hline & number & $\%$ & & number & \% \\
\hline RR Left & 39 & 93 & Neurol.situation after & & \\
\hline Pulse regularity & 22 & 52 & $24 h-48 h$ & 39 & 93 \\
\hline Pulse frequency & 19 & 45 & Summarised & & \\
\hline Time onset CVA & 13 & 31 & Progress notes & 39 & 93 \\
\hline Rankin & 12 & 29 & Information at & & \\
\hline Location CVA & 12 & 29 & Discharge & 39 & 93 \\
\hline Date onset CVA & 6 & 14 & test request/ & mis & \\
\hline Smoking & 6 & 14 & test result & number & $\%$ \\
\hline Neglect & 6 & 14 & $\mathrm{X}$ thorax & 34 & 81 \\
\hline Lowered consc. & 5 & 12 & Glucose & 15 & 36 \\
\hline Drinking & 5 & 12 & Fat & 11 & 26 \\
\hline Clinical syndr. & 5 & 12 & Duplex/HTG & 4 & 10 \\
\hline RR Right & 4 & 10 & & & \\
\hline
\end{tabular}

These findings were supplemented with direct information from users in face-to-face interviews. Three nurses, the head nurse, two residents, the ward's secretary and the care coordinator were questioned in a one hour interview about their daily work, the role of the records in their work, the communication between health care providers and their expectations of an EPR. Two periods of observation completed the picture of daily work practices. In these observations daily routines and communication between nurses and physicians were subject of study. Observation results were processed to an extended report after each day of observation. All information was collected and analysed by the first author. Full-text transcripts of the audio taped interviews and the observation reports were used to analyse data qualitatively.

\section{The stroke unit: an overview}

The study was performed in the inpatient neurology clinic of a university hospital that has a regional function as well. The inpatient clinic is divided into two normal wards with in all 26 beds and a medium care unit with seven beds. Part of the beds at the ward is reserved primarily for stroke patients, the stroke unit. More than half of the patient population of the 
department consists of stroke patients and the study was concentrated on this group of patients.

For some years now the department has been participating in a project to improve treatment and care of stroke patients. Improvement of coordination and communication was believed to be a prerequisite for improvement of care. From admission to discharge a multidisciplinary team takes responsibility for the stroke patient. This team consists of specialised, highly skilled nurses, the responsible resident, his/her supervisor (a senior neurologist), a physical therapist, a speech therapist, an occupational therapist, a rehabilitation doctor, a social worker and a special care coordinator. Each of these professionals contributes with his/her specific knowledge and background to the treatment and care process. The care coordinator has to survey the progress of the care process. Twice a week the team meets to discuss the situation of each stroke patient and to evaluate the actual treatment policy.

\section{A typical patient's route}

Once a GP suspects a patient of having had a stroke, s/he immediately contacts the resident at the medium care unit. Briefly, the situation of the patient is discussed by telephone and if possible the resident awaits the patient at the first aid department. Usually, however, the first aid department personnel has already sampled blood and taken the ECG before the resident freed himself/herself to investigate the newly arrived patient. After medical intake, the physician has to decide whether or not to admit the patient. Meanwhile s/he can connect to the hospital information system (HIS) workstation to check the results of blood tests that were already processed.

In case s/he decides to admit the patient, the big paper work starts. First of all, the medical record needs to be filled in. Furthermore, there is the orders list to communicate with the nursing personnel at the medium care, the admission form and request forms for additional laboratory and other diagnostic tests. Simultaneously, the resident starts arranging a bed for the patient and although $s /$ he already filled in an orders list, $s /$ he also calls the nurses at the medium care to inform them about the arriving patient.

Upon arrival at the stroke unit the patient is monitored carefully. One or two nurses (depending on the shift) are responsible for seven beds and the room is arranged in a way that every patient is visible from the nurses' unit. This unit is located in the centre of the room for observational reasons, but it also functions as a centre for information processing and decision-making. The nursing records are always available here, as well as a telephone, a HIS ter- 
minal, and the systems to monitor patients. Furthermore the daily ward round takes place here, the information exchange between shifts and a lot of informal communication. Since only few and mainly experienced nurses work at the stroke unit, their lines of communication are short. One of the nurses stated that

We communicate constantly with each other. Not that we are afraid to forget something, but more that both of us know exactly what was done and why. Besides, with most colleagues I have been working for years, so I know how they work.

Once a day, usually in the morning the responsible resident and one of the nurses do the ward round. Often, a senior neurologist is also present. This formal meeting of physician and nurse is used to exchange information about the status of the patients, and to (re)establish the policy concerning the patient's treatment. Information and opinions are exchanged, rather than the doctor telling the nurse what to do. In an interview a nurse explained

and then they ask for your opinion about the patient. How is it going? Did you encounter anything? Is there anything to arrange or to order? Should we reduce the frequency of checking the clinical parameters, change the medication, stop the infusion etc.?

During the first days of admission most of the necessary diagnostic and other tests are running and if the patient's condition is stable, the patient is transferred to the normal ward. Both nurses and residents have to write a summary of the patient's stay at the medium care unit. In general, however, at the moment a patient is transferred there is only time for a short verbal summary.

\section{The paper work}

A patient at the inpatient department is dependent on the collaboration of his/her specialist with many ancillary departments, other specialists and paramedical personnel. In general, a pile of forms circulates in this network of health care workers. Nurses and physicians report their findings in their respective paper records (figure 1). The analysis of the paper records in this study was limited to the medical and the nursing record. 


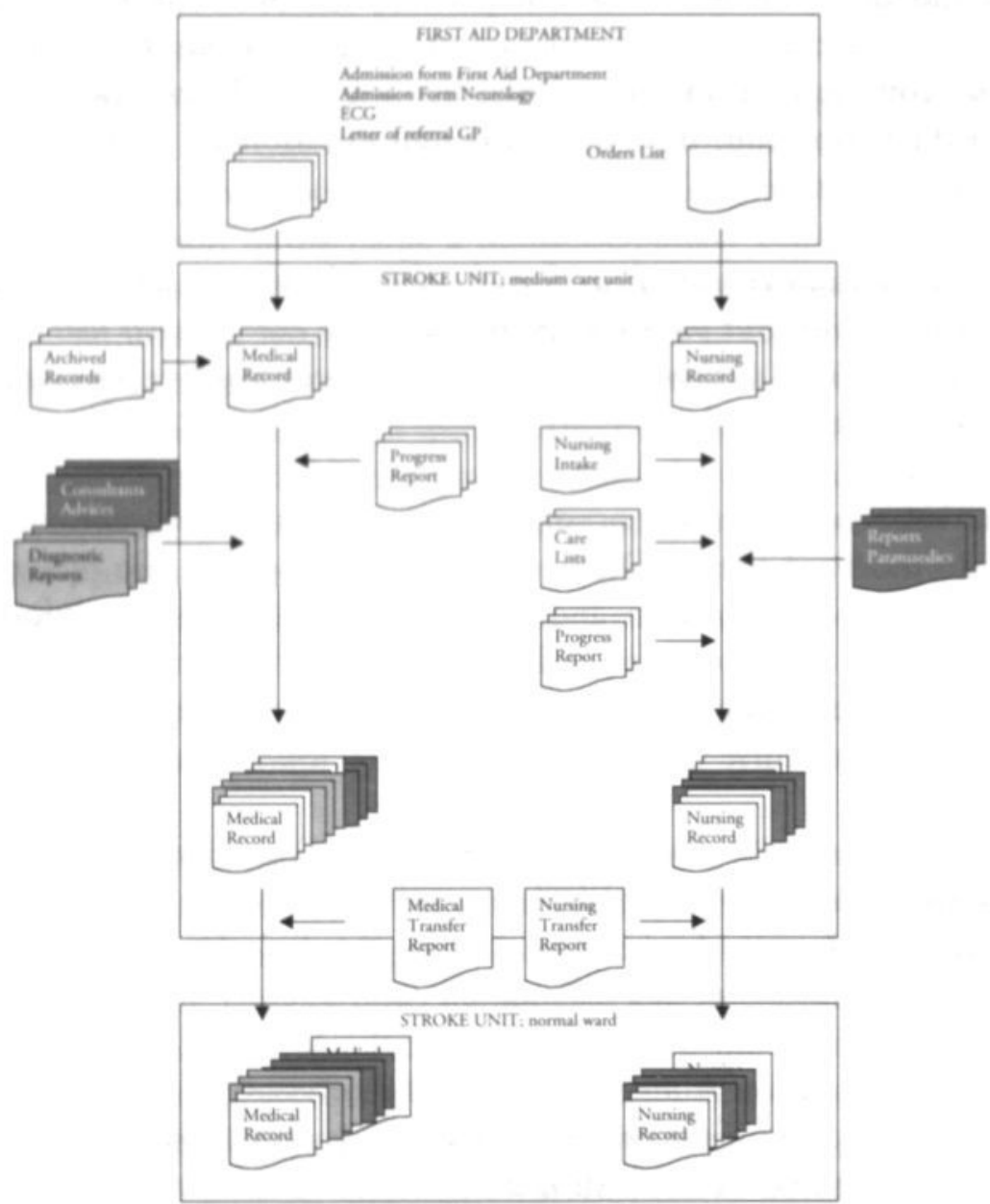

Figure 1

Composition of the medical and nursing paper records of the stroke unit.

\section{Paper medical records}

Each discipline in the hospital has a separate clinical record. After discharge, the nursing and the medical record are put together for storage and future use (at a next admission, the old paper record is added to the actual medical - specialism specific - record). Some general characteristics of the paper records are that they are organised by source, that summaries were found from time to time, as well as report forms with distinct colours and occa- 
sionally notes in the margin. Moreover, different physicians use different (colours) of ink, and have, naturally, different handwriting. At the start of the project several parts of the paper records had already been structured. The medical admission form is structured to a large extent. However, the progress notes consist completely of free text. Consulting physicians report on the request form they receive and a copy of this form is added to the medical record. New laboratory results arrive by mail from the laboratory. The responsible resident initials these results and subsequently they are added to the medical record. Narrative, authorised reports of other diagnostic tests arrive - in general - days or sometimes weeks afterwards, and upon arrival they are added to the medical record. Results of those tests are acquired by telephone long before the official report arrives and an annotation of them is made in the medical progress notes. During the patient's stay the progress notes grow thicker and thicker.

In the analysis of the paper records we found that in six cases the standard admission form was used instead of the stroke admission form. These six records were excluded from the analysis. The analysis of the remaining 42 paper medical records revealed further that several sections of the admission form were hardly ever filled in. Table 1 shows the number of times a clinical item was not filled in the remainder of the admission form. Only items that were missing more than three times are presented in table 1.

Requests and results of lab tests or other diagnostic tests were at times difficult to find or were lacking at the time the patient was discharged. We concentrated on other diagnostic tests, for lab results are always available in the HIS. In $10 \%$ of the cases a request was repeated once or more times before the test was performed. Test results were repeatedly not reported in the progress notes and thus it could not be traced in the medical narratives whether or not a test took place (19\%). In several of these cases even the residents were not informed as was indicated by questions about diagnostic test requests or results in the progress reports or repeatedly requested tests. Sometimes in the nursing record a note was found about a patient having had a test $(12 \%)$ and in three cases $(7 \%)$ only in the nursing record the test was mentioned. All these problems occurred more often in periods when the responsible residents changed frequently, for example in periods of holidays or in periods of many vacancies. A complicating matter was that a test was requested at day 1 , performed at day 3 and that the results were available at day 5 . In three records the decision not to reanimate the patient was documented poorly or even missing in the medical record. In an interview a resident made the following remark 
..It [the medical record] plays an important role [when a patient is transferred to the normal ward]. It is very important if your patient goes to the normal ward that you write down the (diagnostic tests) requested with their status and the tests to request.

Later in the interview the same resident concluded that writing a report before transferring a patient slipped through regularly, as well as a verbal transfer report.

\section{PAPER NURSING Records}

The paper nursing record of the stroke unit consists of a nursing history form, daily progress report forms, the care list and an orders list. The nursing history form and the care list are partly structured. The front page of the care list gives an overview of the policy for that patient, pages two and three of the list contain a flow sheet to record vital signs and neurological examinations. The daily progress report is entirely written in free text and different shifts use different colours. Day shifts report in blue, evening shifts in green and night shifts in red. All physician-generated orders (test requests, frequencies of vital signs checks, request for a consulting physician) are written down chronologically and are signed by the person that processed the order. A lot of information is written down manifold and some data have to be copied daily to a new care list. Nurses commented

.... at the medium care unit, we write down everything three times: on the orders list, on the care list and in the daily progress report.

Clearly, this is a potential source of errors and loss of information, illustrated with the following finding. Five of the 42 patients were reported to have a medication allergy. In two cases the allergy disappeared from the nursing care list during the patient's stay.

\section{HOW DO THESE RECORDS FIT INTO DAILY PRACTICE?}

For the seven beds at the medium care unit, seven medical records and seven nursing records are stored at the central nurses' unit. Additionally, a care list for every bed lies on the desk. All information is available. The ward round takes place at approximately the same time every day. Nurse and resident 
then sit together, each with their own record. While the HIS terminal at one side shows lab results of the patient, the care list on the other side gives an overview of neurological and vital signs. The resident writes requests for consulting specialists, decides to change the frequencies of checking the clinical parameters, decides whether or not the patient is ready to be transferred to the normal ward, all in consultation with the nurse, who writes down these orders and decisions on the orders list. Thus, nurses play an important role in the decisions made during a patient's stay at the stroke unit.

Several diagnostic tests, like a CT scan, cannot be performed at the neurology ward. When a patient is scheduled for a CT scan, the medical record is sent with the patient to the radiology department, because the radiologist may need to check medical information. After the test both the patient and the medical record return to the neurology ward.

A consulting physician comes in and browses through the medical record, asks the nurses about the condition of the patient, test or laboratory results, examines the patient and writes his/her findings on the request form. Occasionally a few lines are written in the medical record.

Nursing records are readily available. Before the end of the shift the progress reports are written, three or four by each nurse. During the day vital signs are reported on the flow sheet in the care list. At preset time intervals these signs are measured on each patient. The nurse writes down the values on a small piece of paper and copies all values at once to the care lists of the patients. Every morning lab results are checked in the HIS workstation. In case of abnormal, unexpected values the resident is warned as a nurse mentioned in an interview:

We often check lab results and we warn the resident: "Sodium is too high, or too low. Take a look at it, then we can treat that".

Occasionally the nurses already start a treatment without awaiting the responsible resident. Then, the order will follow the action. Officially, this procedure is not allowed, but in daily practice it is unavoidable.

Transfer of information from one shift to the other occurs with the help of the records. Usually the nurses sit two by two at the desk. The leaving shift reads the daily report aloud and adds -verbally- relevant, missing information.

Still, too much information gets lost in the circuit of verbal communication instead of being documented on paper. 
was commented by a head nurse in answer to a question about verbal transfer of information.

\section{OTHER PAPER WORK}

Besides the medical and nursing records a lot of forms circulate in the hospital. For laboratory tests, CT scans, MRI scans, for consulting physicians and paramedical personnel, standard order forms exist. At the stroke unit nurses and physicians fill in these forms, at the normal ward the secretary does.

\section{Discussion}

The main goal of the implementation of the EPR in this project is to improve record keeping and to improve communication. Adequate documentation and communication between nurses and physicians is very important in daily practice. We will discuss the problems with paper-based records at the stroke unit. Then different aspects of communication are subject of discussion and finally we argue why we expect the EPR to be a successful innovation.

\section{Problems with paper based records}

Commonly described shortcomings of the paper records are poor legibility, poor availability, poor organisation and incompleteness. In table 2 the problems found in our study are matched with those described in the literature. In the Maastricht situation problems with legibility were limited to the medical and nursing progress notes, since the other forms required mainly structured documentation. Another frequently mentioned shortcoming of paper records, poor availability, is not a real problem at our research site, since all information and information exchange is located and performed at the central nurses' unit. Only when the patient is away for a diagnostic test the paper medical record leaves the stroke unit to go with the patient. Those ancillary departments often require medical data and therefore the medical record. That, however, caused some unforeseen problems. 


\section{Table 2}

Comparison between the problems of the paper records in the literature and at the stroke unit of Maastricht University Hospital.

$M R=$ medical record, $N R=$ nursing record

\section{Problems of paper records according to the literature}

Illegibility

Poor availability

Incompleteness

Poor organisation
Parts of records in our study with distinct problem

Progress notes MR and NR

MR when contact outside of neurology is required

Entire records MR and NR

Progress notes MR and NR

Completeness, one aspect of adequate documentation, is an important issue for medical record keeping. This is illustrated with the case of the decision not to reanimate a patient that was not clearly documented in several records. This is a remarkable finding since this may have legal implications. But what is a complete record? The medical record is not a log in which all things said and done are recorded chronologically, but it contains information that is (thought to be) relevant for a proper diagnosis and treatment [4-7]. Additionally, the information in the record greatly influences the information yet to be collected. Although some data are expected to appear in a record, the requirements for a complete record are difficult to define. Such a definition depends on the perception of the reader. For a clinician a medical record plays a constitutive role in the patient's treatment, while the management of a hospital wants to extract exact figures and facts from the records. In our analysis of paper records we defined three sources of incompleteness. First of all, medical paper records revealed that several clinical items were consistently not filled in on the admission form. Residents explained that a lot of clinical information required on the admission form was not relevant for clinical use, only for scientific research. Thus, here we have two conflicting scopes on medical data. Second, copying of information leads to loss of data. We mentioned the medication allergies of two patients as an example. Third, results of diagnostic tests were in several cases difficult to trace in the progress notes. The exchange of information was insufficient at times that residents changed often. In addition, the time-lapse between request and results of a test, makes surveyable record keeping complex. In the chronologically ordered progress notes, the information will be scattered between other notes. 
Developing an EPR also involves structuring of clinical information. The paper records were organised by source. Free-text progress notes in the paper records may have an informal structure by the use of bright coloured memo stickers, notes in the margins, use of different colours of ink, coloured standard forms, summaries from time to time. Those parts of the paper records that were pre-structured resulted from prior initiatives. The medical admission form was structured for research purposes and the nursing record because of time pressure. Nurses had such a high workload that proper record keeping was difficult. Therefore a standardised, structured form was developed. This form gives a quick overview of the patient's situation and is easy and quick to fill in. Nevertheless, good documentation starts with the users. In an interview a nurse sighed - while talking about filling in forms and completeness of the record -

..provided it [a daily report form] is filled in correctly. And that, .. that's the problem.

Thus the users are a crucial factor in completeness of records.

\section{Communication aspects}

Communication between health care workers becomes increasingly important for several reasons. In the Netherlands working hours of physicians decrease, due to new legislation and due to changing social values. In practice, this means that one patient sees more doctors and these doctors have to hand over their patients more often. Moreover, physicians are formally responsible for their patients. In practice they do not simply order nurses. As is also described in the literature, inexperienced residents communicate frequently with the - mostly very experienced - nurses who know the condition of the patient exactly and can give advice about treatments [44]. Consequently, nurses and physicians need (read) access to both the nursing and the medical electronic record. Although previous research indicates that health care professionals prefer verbal conversation to collect information [45], data in medical and nursing records need to be readily available. Moreover, to enable good communication via the patient record, an EPR needs to have a transparent structure. Therefore, in the EPR for stroke patients the medical progress notes are subdivided into familiarly named chapters to increase transparency and to allow follow up of information in time. For instance, an ordered diagnostic test can be recorded at day one, the 
test results can be added later and, clearly visible, connected to that same test. In addition, highly specialised care means that many different disciplines are involved in the care process of patients. At the neurology ward, the multidisciplinary treatment team requires adequate information exchange to provide good care. Another problem related to the collaborative character of health care work is that different health care workers have different information needs. In EPRs a distinction might be made between general information and specialism specific information [46]. Another solution may be to offer different views on information depending on the information need of the professional [47].

\section{The EPR for stroke: A potentially successful innovation?}

Rogers mentioned five attributes that influence the rate of adoption of an innovation: relative advantage, compatibility, perceived complexity, trialability, and observability [32]. The relative advantage for future users is the reduction of paper work. Physicians will gain time at discharge; the paper forms require writing the same information three times. In addition, the information in the progress notes will be more accessible, because data are organised better. Nurses will benefit while writing their daily report and the care list. In the EPR, all information is entered once and can be shown wherever and whenever relevant. Illegibly scribbled notes are impossible in an EPR. A remaining problem might be the possible difference in interpretation of a certain comment or note. The use of standardised, predefined response categories might resolve this problem although it could result in a loss of nuance in information. To increase compatibility of the EPR with existing practices and values and to reduce the perceived complexity, we intended to maintain the familiar aspects of the existing forms regarding layout and structure of content and in a few cases even the colour of the form was maintained. In addition we wanted to embed familiar aspects of the source-oriented organisation in the paper records. This was achieved by holding on to the source oriented approach, and refining this organisation with subheadings. The fact that the EPR was designed specifically for stroke patients might increase trialability, but on the other hand it is a complicating matter since future users will need to apply two - paper and electronic - systems of record keeping simultaneously. Record keeping will be electronic for stroke patients and on paper for the other neurological patients. Observability will be high. Since computers will be in use at the ward and doctors will do their ward round with their laptops, the use of the EPR will not go unnoticed. 


\section{Lessons learnt}

Early in the project we assumed that the stroke patients were a well-defined patient group within a transparent organisation. While developing the EPR for stroke patients we were confronted with several difficulties, some of them unanticipated.

The analysis of the paper records revealed that organising the record could increase completeness only partly. Users themselves will always play a key role in completing documentation. An EPR will not improve record keeping, unless users correctly and completely fill in the information.

We were confronted with the fact that the ancillary departments that are frequently visited by stroke patients, radiology for example, check for certain medical data in the paper medical record. Similarly, paramedical personnel and consulting physicians might require information from the nursing or medical records. They visit the neurology ward and see the patient there and to be informed they will need access to the EPR. Initially, the consulting physicians were expected to use the EPR, but it is doubtful whether or not they will. In case they refuse to use the EPR, their handwritten reports will have to be entered into the EPR by others. This is a consequence of developing a smallscale EPR we did not expect initially. Generally speaking, many problems of an EPR designed for limited use (e.g. for a specific specialism or patient group) relate to the communication with other departments and individual health care workers. And in connection with this, highly specialised care requires many different health care workers involved in the treatment of one patient and they might desire different views on (part of) the collected data. This has consequences for the user interfaces of different, preferably connected systems. To increase ease of use and user friendliness, user interfaces should be uniform in their layout and use of functionality.

Nurses and physicians need access to each other's records. Formally, they have their own type of work and their own, separate record. In practice they use both records, although strictly speaking it is not allowed. Consequently, the existing access rights for paper records should not be simply implemented, but they need to be reconsidered thoroughly.

\section{Conclusion}

We acknowledge that part of the problems of paper records, described in the literature, exist in our research setting. An EPR may support record keeping by avoiding copying of data and by structuring data more than in paper records. 
However, adequate documentation depends on the users as well. In addition, we conclude that an EPR for a small-scale setting has advantages. On the other hand, an EPR for a limited use entails that communication with other departments and specialisms deserves special attention. Finally, our study suggests that a strict application of authorisation rules in the EPR may obstruct work practices. A reconsideration of access rights is recommended.

\section{References}

1 Dick RS, Steen EB, eds. The Computer-based patient record: an Essential Technology for Health Care. Washington DC: National Academy press 1991.

2 Strauss A, Fagerhaugh S, Suczek B, Wiener C. Social organization of medical work. 2nd ed. New Brunswick, New Yersey: Transaction Publishers 1997.

3 Wyatt JC. Clinical data systems, Part 1: Data and medical records. Lancet. 1994; 344 (8936): 1543-7.

4 Berg M. Practices of reading and writing: the constitutive role of the patient record in medical work. Soc Hea Illn. 1996; 18 (4): 499-524.

5 Berg M. Medical work and the computer based patient record: a sociological perspective. Meth Inform Med. 1998; 37: 294-301.

6 Hunter KM. Doctors' stories. The narrative structure of medical knowledge. first ed. Princeton: Princeton University Press 1991.

7 Rees C. Records and hospital routines. In: Atkinson P, Heath C, eds. Medical work. Realities and routines. Farnborough: Gower 1981: 55-70.

8 Nygren E, Henriksson P. Reading the medical record. I. Analysis of physicians' ways of reading the medical record. Comput Methods Programs Biomed. 1992; 39: 1-12.

9 Hogan WR, Wagner MM. Accuracy of data in computer-based patient records. JAMIA. 1997; 4: 342-55.

10 Bates DW, Teich JM, Lee J, Seger D, Kuperman GJ, Ma'Luf N, Boyle D, Leape L. The impact of computerized computer order entry on medication error prevention. JAMLA. 1999; 6 (4): 313-21.

11 DeLone WH, McLean ER. Information systems success: the quest for the dependent variable. Inf Sys Res. 1992; 3 (1): 60-95.

12 Rector AL, Nowlan WA, Kay S, Goble CA, Howkins TJ. A framework for modelling the electronic medical record. Meth Inform Med. 1993; 32: 109-19.

13 Adelhard K, Holzel D, Uberla K. Design elements for a computerized patient record. Meth Inform Med. 1999; 38: 187-93.

14 Gamm LD, Barsukiewicz CK, Dansky KH, Vasey JJ. Pre- and post-control model research on end-users' satisfaction with an electronic medical record: preliminary results. Proc AMLA Symp. 1998;: 225-9. 
15 Lee F, Teich JM, Spurr CD, Bates DW. Implementation of physician order entry: user satisfaction and self-reported usage patterns. JAMIA. 1996; 3: 42-55.

16 Lorenzi NM, Riley RT, Blyth AJC, Southon G, Dixon BJ. Antecedents of the people and organizational aspects of medical informatics: review of the literature. JAMIA. 1997; 4: 79-93.

17 Aydin CE, Rice RE. Social worlds, individual differences, and implementation. Predicting attitudes toward a medical information system. Information \& Management. 1991; 20: 119-36.

18 Egger $\mathrm{E}$, Wagner I. Negotiating temporal orders. The case of collaborative time management in a surgery clinic. CSCW. 1993; 1: 255-75.

19 Symon G, Long K, Ellis J. The coordination of work activities: cooperation and conflict in a hospital context. CSCW. 1996; 5: 1-31.

20 Berg M. Patient care information systems and health care work: a sociotechnical approach. Int J Med Inf. 1999; 55 (2): 87-101.

21 Atkinson CJ, Peel VJ. Transforming a hospital through growing, not building, an electronic patient record system. Meth Inform Med. 1998; 37: 285-93.

22 Kaplan B. The influence of medical values and practices on medical computer applications. In: Anderson JG, Jay SJ, eds. Use and impact of computers in clinical medicine. New York: Springer Verlag 1987: 39-50.

23 McBride SH, Nagle LM. Attitudes toward computers. A test of construct validity. Comput Nurs. 1996; 14: 164-70.

24 Nickell GS, Pinto JN. The computer attitude scale. Comput Human Behav. 1986; 2: 301-6.

25 Startsman TS, Robinson RE. The attitudes of medical and paramedical personnel toward computers. Comput Biomed Res. 1972; 5: 218-27.

26 Teach RL, Shortliffe EH. An analysis of physician attitudes regarding computerbased clinical consultation systems. Comput Biomed Res. 1981; 14: 542-58.

27 Brown $\mathrm{SH}$, Coney $\mathrm{RD}$. Changes in physicians' computer anxiety and attitudes related to clinical information system use. JAMIA. 1994; 1: 381-94.

28 Adaskin EJ, Hughes L, McMullan P, McLean M, McMorris D. The impact of computerization on nursing: an interview study of users and facilitators. Comput Nurs. 1994; 12: 141-8.

29 Bailey JE. Development of an instrument for the management of computer user attitudes in hospitals. Meth Inform Med. 1990; 29: 51-6.

30 Bürkle T, Passian A, Prokosch U, Dudeck J. The impact of computer implementation on nursing work patterns: study design and preliminary results. In: Greenes RA, Peterson HE, Protti DJ, editors. Medinfo; 1995; Vancouver, Canada: IMIA 1995; 1321-5. 
31 Cork RD, Detmer WM, Friedman CP. Development and initial validation of an instrument to measure physician's use of, knowledge about, and attitudes towards computers. JAMIA. 1998; 5: 164-76.

32 Rogers EM. Diffusion of innovations. 3rd ed. New York: The Free Press 1983.

33 Ash J. Organizational factors that influence information technology diffusion in academic health science centers. JAMIA. 1997; 4: 102-11.

34 Sicotte C, Denis J, Lehoux P. The computer based patient record: a strategic issue in process innovation. J Med Sys. 1998; 22 (6): 431-43.

35 Axford RL, Carter BEL. Impact of clinical information systems on nursing practice. Nurse' perspectives. Comput Nurs. 1996; 14: 156-63.

36 Hebert MA. Impact of IT on health care professionals: changes in work and the productivity paradox. Health Serv Manage Res. 1998; 11: 69-79.

37 Hendrickson G, Kovner CT. Effects of computers on nursing resource use. Do computers save time? Comput Nurs. 1990; 8 (1): 16-22.

38 Aydin CE. Occupational adaptation to computerized medical information systems. J Health Soc Behav. 1989; 30: 163-79.

39 Aydin CE, Rice RE. Bringing social worlds together: computers as catalysts for new interactions in health care organizations. J Health Soc Behav. 1992; 33: 168-85.

40 Weiner M, Gress T, Thiemann DR, Jenckes M, Reel SL, Mandell SF, Bass EB. Contrasting views of physicians and nurses about an inpatient computer based provider order-entry system. JAMLA. 1999; 6: 234-344.

41 Weir C, Johnsen V, Roscoe D, Cribbs A. The impact of physician order entry on nursing roles. Proc AMIA Annu Fall Symp. 1996;: 714-7.

42 Turley JP. The relationship between nursing and medical cultures: implications for the design and implementation of a clinicians' workstation. Proc Annu Symp Comput Appl Med Care. 1993; 17: 233-7.

43 Kaplan B. Combining qualitative and quantitative methods in information systems research: a case study. MIS Quarterly. 1988; (12): 571-86.

44 Hughes D. When nurse knows best: some aspects of nurse/doctor interaction in a casualty department. Soc Hea Illn. 1988; 10: 1-22.

45 Coiera E, Tombs V. Communication behaviours in a hospital setting: an observational study. British Medical Journal. 1998; 316: 673-7.

46 van Ginneken AM, Stam H, Moorman PH. A multi-strategy approach for medical records of specialists. Int J Biomed Comput. 1996; 42: 21-6.

47 Tange HJ, Dreessen VA, Hasman A, Donkers HH. An experimental electronic medical-record system with multiple views on medical narratives. Comput Methods Programs Biomed. 1997; 54 (3): 157-72. 

CHAPTER 3

\section{Development and implementation: how to encourage the user}

\section{PUBLISHED AS}

M.J. van der Meijden, H. Tange, J.Troost, A.Hasman. Development and Implementation of an EPR: How to encourage the user. International Journal of Medical Informatics (2001) 64 pp 173-185. 


\section{Introduction}

Information technology (IT) is believed to create many opportunities in health care. One is the computerised support of the primary process. In 1990, a study of the Institute of Medicine (IOM) identified the strengths and weaknesses of paper based records [1]. Poor availability, illegibility, poor organisation and incompleteness are such weaknesses. These shortcomings are often used to justify the call for widespread use of electronic record keeping [2]. Access to clinical information can be improved by well-organised, legible data, but also with availability of information at several places simultaneously. Nowadays, the process of care is still mainly supported by paper-based medical and nursing records. These records play an important role in accumulating information and coordinating medical work [3]. Patient records are not simple stores and sources of information that are filled and referred to whenever necessary, but they also influence medical work. Berg explained that paper records and health care workers interact with each other and mutually affect each other [3]. Hence, The information present in the records is not simply the basis of decision-making, it has an influence on the decisions made as well. In the process of computerisation of paper records this is an important aspect to consider, because it means that records are not just tools in the hands of a doctor or a nurse. It also explains why electronic records need to be tailored to the work practices in order not to obstruct the process of care. Tange analysed the satisfaction of physicians with paper based medical records in the Maastricht University Hospital [2]. They appeared to be rather satisfied with their paper records, although data retrieval could be improved. Opportunities of IT, then, lie in those features that reduce administrative tasks of health care workers, performing computations or generating reminders in case of specific events for example [3]. To increase the usability of systems the involvement of health care workers in design and development processes of electronic record systems is important [4]. Moreover, considering the attitude of future users in the process of development and implementation is important to increase final acceptance [5].

The department of Medical Informatics, Maastricht University, co-operates with the department of neurology, University Hospital Maastricht, to develop and implement an electronic patient record (EPR) for stroke patients. In this project we involved the future users in an early stage, which served three purposes: 1) to determine the required functionality of the EPR, 2) to create and increase social support and 3) to measure social support for the EPR. The purpose of this chapter is to describe in more detail the participation of our future users, realised as follows: 
- Two nurses and two residents were actively involved as key users in the development process to determine and test functionality and to create social support. They were expected to act as change agents.

- We measured the attitude, knowledge and expectations about the use of computers in health care of all potential users by means of a questionnaire. These results served to determine the training the users required, to measure the social support for our project and to trigger the interest and curiosity of potential users.

- We conducted in-depth interviews to clarify and supplement results, mentioned under the previous bullet. Additionally, we wanted to assess and increase social support with these interviews.

\section{Methods}

\section{Data collection}

Data were collected with two different questionnaires and two sets of indepth interviews. The aim of the interviews was to explain and supplement the results of the questionnaires. Figure 1 explains how questionnaires and interviews relate to each other in time and content.

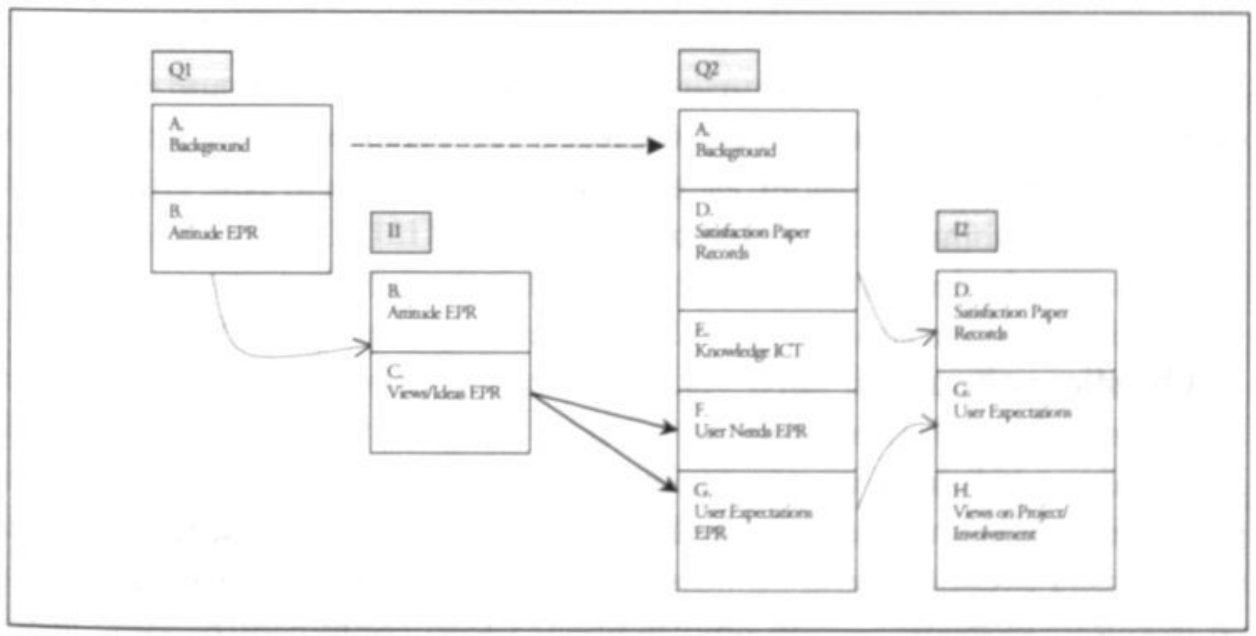

Figure 1

User involvement was partly established with questionnaires $\left(Q_{1}\right.$ and $\left.Q_{2}\right)$ and interviews ( 11 and 12). Background questions were similar in both questionnaires. The results of section $C$ of $Q_{1}$ were the basis of $I_{1}$ and a preparation for $Q_{2}$, sections $F$ and $G$. The results of sections $D$ and $G$ of $Q_{2}$ were elaborated in 12 . similar questions.$- \rightarrow$; question making $\rightarrow$;

elaboration $\rightarrow$ 


\section{Questionnaire 1}

In March 1998, all 63 future users ( 9 specialists, 12 residents and 42 nurses) of the neurology department received a questionnaire to measure their attitude towards computers. The questionnaire contained nine general questions, asking for age, sex, profession, years of working experience, respondents indicated their actual usage of the paper records (daily-weekly-irregularly-no usage at all), usage of the hospital information system (HIS) and other office- computer applications and how they judged their own computer experience (figure 1: Q1A). The questionnaire further contained 21 items to measure the users' attitude derived from several existing attitude scales (figure 1: Q1B) [6-12]. The questions focussed on whether the respondents expected that their work would become easier or better with an EPR, what their general feelings were about computerising the clinical records, how urgent the need was for computerising the records, whether they expected improvement of record keeping with an EPR, and whether they feared that with an EPR it would take longer to enter or retrieve data, or that it would limit them in different aspects of their work. All items were scored on a 5-point Likert scale.

\section{Interviews 1}

Supplementary to this questionnaire, two nurses, two residents and the nurses' team leader were interviewed to discuss the paper records and to elicit their ideas and feelings about an electronic patient record (fig 1: I1B, C). Therefore, these interviews were not structured.

\section{Questionnaire 2}

A second questionnaire was sent to 65 potential users in February 1999. The population of the department had slightly changed and consisted of nine specialists, 14 residents and 42 nurses. This second questionnaire was divided into four sections. Section one (figure 1: Q2A) contained the same general questions as the first questionnaire. The rest of the questionnaire was different from the first one. Section two (figure 1: Q2D) contained 24 items about the respondent's satisfaction with the paper medical and nursing records. These items were scored on a 5-point Likert scale. Users also marked the significance of each item. Items rated 'not important' by a respondent 
were excluded from the analysis for that specific respondent. The items were selected from a previously developed questionnaire [2]. Section three and four were based on the questionnaire developed by Cork et al [13]. Section three contained eighteen pairs of terms that are related to computers and computer usage, e.g. floppy - hard disk. Respondents indicated to what extent they thought they knew what the distinction between the two terms was. These items were categorised on a 3-point Likert scale. Section four was divided into two parts, I (figure 1: Q2F) and II (figure 1: Q2G). In part I the respondents were asked to score the need for certain features of computer applications in health care, e.g. 'I have access to the system where I need it'. The 14 items in part I were scored on a 4-point Likert scale, plus an 'unable to respond' - option. Part II consisted of 16 items to measure the expected influence of computer applications on health care, e.g. "how do you think computer applications will influence the costs of health care, or the quality of care'. These items were scored on a 5-point Likert scale. Since all items in this questionnaire were positively worded, higher scores mean that respondents are more satisfied, possess more knowledge, positive effects or features being more necessary.

\section{Interviews 2}

Three months prior to the implementation, nine semi-structured in-depth interviews were held with two residents, four nurses, the head of the department, the head nurse and the IT manager of the department. The interview for the end-users was divided into three clusters (figure 1 : I2D, G and $\mathrm{H}$ ). Cluster one (figure 1: I2D) contained six questions about the positive and negative aspects and the usage of the paper clinical records. In cluster two (figure 1: $\mathrm{I} 2 \mathrm{H}$ ) the respondents answered five questions about the development and implementation of the EPR, e.g. 'What do you know about the EPR?' In section three (figure 1: I2G) of these interviews the expected impact of computer applications on several aspects of daily practice, like communication with colleagues within the department and within the hospital, the quality of record keeping, expected changes in work procedures, were elaborated. In the interviews with the managers, the positive and negative aspects of paper records were only addressed indirectly. In stead, the interview concentrated on their opinion about the course of the whole project and their expectations of the implementation. Those results are presented in Chapter 5. 


\section{Data analysis}

Statistical analysis of the questionnaires was performed with SPSS version 8.0. The mean score of all attitude statements were combined to one mean score. Likewise, an overall score for satisfaction, knowledge and expectations of health care applications were calculated. We used the independent t-test to test for differences between experienced and inexperienced users and the paired sample t-test to test for differences in satisfaction between (aspects of) medical and nursing record. The first author held the first set of interviews, and an independent interviewer familiar with the situation at the department, did the second series of interviews. The second set of interviews was analysed with the aid of QSR NUD*ist, a software package to analyse qualitative data.

\section{Results}

\section{Background of the users}

In March 1998 the users received the questionnaire to measure their attitude towards computerising the paper clinical patient records. Forty-one of the 63 questionnaires were returned completely filled in $(65 \%)$. Nurses had the lowest response rate, $52 \%$ of them returned the questionnair e. The response rate of residents and specialists was $92 \%$ and $82 \%$ respectively. Twenty-eight respondents were younger than 40 and on average the respondents had 12.6 years of working experience (range 0-35). Twenty-seven (66\%) respondents classified themselves as inexperienced computer users. Five respondents hardly used the HIS, and 36 of them used it frequently. Moreover, about $75 \%$ of the respondents indicated to use a computer at work and/or at home - besides the HIS -.

The second questionnaire was distributed in February 1999. It dealt with the satisfaction of users with paper clinical medical and nursing records, their knowledge of computers and their expectations of applications in health care. The overall response rate was $66 \% ; 6$ specialists, 14 residents and 22 nurses returned the questionnaire. Twenty-two respondents were male, 32 were younger than 40 and on average the respondents had 11.5 years of working experience (range 0-24). Twenty-six (62\%) of the respondents classified themselves as illiterate or inexperienced computer users, whereas 16 $(38 \%)$ thought of themselves as experienced computer users. Only three in the latter group were nurses, eleven were residents. The HIS was used daily by 36 respondents, and weekly or monthly by 6 of them. Fourteen nurses, 
12 residents and five specialists actually used the medical record. All of the responding nurses, four residents and four specialists actually used the nursing record. Thus, not every respondent made use of both records.

\section{Attitudes towards an EPR}

The overall mean attitude score was 3.2 (s.d. 0.69; $\mathrm{n}=41$; Q1B). Inexperienced computer users had a less positive attitude towards an EPR than experienced users (mean 3.0 s.d. $0.73 n=27$ vs mean 3.6 s.d. $0.45 n=13$; $\mathrm{p}<0.05 \mathrm{t}$-test). Table 1 shows the results of those questions in this questionnaire that showed significant differences between experienced and inexperienced users. In comparison with experienced respondents, inexperienced respondents thought that an EPR would cost them more time to enter data into and to retrieve data from it, that it would take a long time to learn to work with an EPR. In addition, experienced users agreed more with the statement that an EPR can contribute to improving the quality of care.

\section{Table 1}

Mean scores of answers to individual questions of respondents who considered themselves experienced or inexperienced computer users.

\begin{tabular}{|c|c|c|c|c|c|c|}
\hline & $\begin{array}{l}\text { Experie } \\
\text { Mean }\end{array}$ & $\begin{array}{l}\text { nced } \\
\text { s.d. }\end{array}$ & $\mathbf{n}$ & $\begin{array}{l}\text { Inexper } \\
\text { Mean }\end{array}$ & $\begin{array}{l}\text { ienced } \\
\text { s.d. }\end{array}$ & $\mathbf{n}$ \\
\hline \multicolumn{7}{|l|}{ I am afraid that.... } \\
\hline ...data entry will cost more time in an EPR & 2.6 & 1.6 & 13 & 3.7 & 1.2 & 26 \\
\hline ...data retrieval will cost more time in an EPR* & 2.2 & 1.5 & 13 & 3.3 & 1.3 & 27 \\
\hline $\begin{array}{l}\text {...it will take a long time to learn to work with an } \\
\text { EPR. }\end{array}$ & 2.5 & 1.4 & 13 & 3.4 & 1.0 & 27 \\
\hline \multicolumn{7}{|l|}{ I think that.... } \\
\hline ....an EPR can help to improve the quality of care & 4.0 & 0.8 & 13 & 3.0 & 1.5 & 27 \\
\hline \multicolumn{6}{|l|}{ "peo.os } & \\
\hline
\end{tabular}

In the first set of interviews, the respondents were not negative about electronic record keeping which supports the results of the questionnaire. However, they had a critical attitude: what do we gain when we invest in electronic record keeping? Most respondents stressed that verbal communi- 
cation should complement electronic record keeping and should not replace it. The dialogue about patients was said to be vital for good care. Moreover, concern was expressed about electronic records making life too easy so nurses would not (need to) think anymore before acting. Nevertheless, one rather sceptical - resident came to the conclusion that an EPR could have some positive aspects. Furthermore, nurses commented that at first all new work routines invoked resistance and difficulties, but in the end all got used.

\section{Satisfaction with paper records}

In general, the users were relatively satisfied with their paper clinical records. In one of the first interviews a resident made the following remark about paper records

...I cannot name the disadvantages of the current [paper] record system. There are no aspects that I would say about: that needs to be improved.

During the interview this resident came to the conclusion that some aspects of paper records could be improved by an EPR. The following example was mentioned: dividing the medical progress notes into chapters e.g. assessment notes, medication, diagnostic tests, could overcome the problems with just chronologically adding information to these notes. To the question in the questionnaire if in general their paper record was user friendly, the residents and specialists answered on average 3.6 (s.d. 0.9; $n=19$ ), whereas the nurses answered on average 4.0 (s.d.0.6; $n=21$ ). Thus, the residents were slightly positive about their paper records, nurses were more positive. Overall, the users of the medical and the nursing record were more satisfied about data entry than about data retrieval of the paper records (table 2).

\section{Table 2}

Satisfaction with data entry and data retrieval aspects of medical and nursing paper record (paired t-test).

\begin{tabular}{|c|c|c|c|c|c|}
\hline Satisfaction & $\begin{array}{l}\text { Data en } \\
\text { Mean }\end{array}$ & $\begin{array}{l}\text { try } \\
\text { s.d. }\end{array}$ & $\begin{array}{l}\text { Data re } \\
\text { Mean }\end{array}$ & $\begin{array}{l}\text { trieval } \\
\text { s.d. }\end{array}$ & $n$ \\
\hline 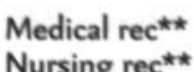 & $\begin{array}{l}3.6 \\
3.8\end{array}$ & $\begin{array}{l}0.9 \\
0.9\end{array}$ & $\begin{array}{l}3.0 \\
3.4\end{array}$ & $\begin{array}{l}0.5 \\
0.9\end{array}$ & $\begin{array}{l}28 \\
27\end{array}$ \\
\hline \multicolumn{6}{|l|}{$\begin{array}{l}* \text { pea.oo1 } \\
\text { Items were rated }\end{array}$} \\
\hline
\end{tabular}


Having the possibility to browse for information by flipping through pages was clearly regarded as a positive aspect of paper records, as became clear in the second set of interviews with nurses and residents. However, this was also mentioned to be a negative feature of paper records, because data are lost in thick piles of paper, overview is lacking due to scattered information throughout the record, relevant data are documented only in the medical record, or only in the nursing record. Moreover, data are often not found where expected, especially if data should be documented at multiple places in the records. An interviewed (inexperienced) resident commented on the overview of data. She had overview

if I write it [patient data] myself, yes...If I take over a patient, it usually requires an intensive search to collect all necessary information...

In addition, the portability of the paper records was valued highly, because data could be documented where assessed.

The nursing record was more structured than the medical record and the nurses thought their record to be more clear and legible than the medical record. On the other hand, they said that their written reports were too extensive in many cases, which reduced the legibility. Furthermore it was said that, if a page is turned, the information on that page had been 'forgotten'. That is, usually no one turns that page back again to view what was written down before; people only read the page they are working on. All respondents expected that the positive aspects of the paper records could be maintained and that the negative aspects could be improved by an EPR.

Inexperienced and the experienced users were not equally satisfied with the paper nursing records (table 3 ). The inexperienced users were significantly more positive about the nursing record than experienced users. When we considered only those items related to data retrieval aspects of the paper record, the results showed that experienced respondents tended to judge the data retrieval aspects of the nursing record more negative, but the differences were not significant $(\mathrm{p}=0.069)$. No differences existed for the medical record. A comparison between the satisfaction with data entry aspects of the medical record and those of the nursing record the data showed no significant difference between experienced and inexperienced respondents. Similar results were found for the data retrieval aspects. 


\section{Table 3}

Mean satisfaction scores of inexperienced and experienced users for the medical and nursing records.

\section{Satisfaction}

\section{General}

Medical rec

Nursing rec*

Data entry

Medical rec

Nursing rec

\section{Data retrieval}

Medical rec

Nursing rec

* p<o.os

Items were rated on a s-point Likert scale, where 1 = fully disagree and s = fully agree

\section{Experienced \\ Mean s.d.}

$\begin{array}{lll}3.4 & 0.67 & 14 \\ 3.1 & 0.67 & 7\end{array}$

$3.4 \quad 1.07$

$3.3 \quad 0.89$

$\begin{array}{lll}3.1 & 0.73 & 14\end{array}$

$\begin{array}{lll}2.8 & 0.81 & 7\end{array}$

13

6

4

3.0

0.57

0.79

3.5

3.7

0.72

0.83

15

21

\section{Mean s.d. $\mathbf{n}$}

$\begin{array}{lll}3.3 & 0.72 & 16 \\ 3.7 & 0.72 & 21\end{array}$

\section{Knowledge of computers}

Section three of the second questionnaire dealt with self-reported knowledge of computers. Inexperienced users appeared to possess less knowledge of computers than those who considered themselves experienced computer users (mean: 1.5 , s.d. $0.45, \mathrm{n}=25$ vs. mean: 2.0 , s.d. $0.40, \mathrm{n}=16$; $\mathrm{p}<0.05$ ). Many of the inexperienced computer users were female nurses and also in the interviews mostly that group indicated that they expected the residents and the male nurses to be more experienced computer users than their female colleagues. Moreover, they were critical of the forthcoming changes in record keeping. Elder respondents did not know less or more about computers than younger respondents.

\section{User needs and user expectations}

Table 4 shows that ease of use, availability, speed and reliability were marked as important features. Overall, respondents did not expect health care to be negatively affected by computer applications. No significant difference existed between experienced and inexperienced respondents. Respondents 
expected that access to up-to-date knowledge in computer applications would positively influence health care (table 4).

\section{Table 4}

Overall results and results of several individual items concerning applications of computers in health care.

\section{Computers in health care}

\section{Desired functionality}

not necessary to learn special codes accessibility

speed of data retrieval

reliability

\section{Influence on health care}

quality of care

interactions between care providers

access to continuous education

access to up-to-date knowledge
Experienced
Mean s.d.

2.0

1.3

1.9

1.3

3.2

3.9

3.4

3.6

4.0

\subsection{6}

0.49

0.52

0.62

0.43

0.50

0.73

0.73

0.52

Inexperienced
n Mean s.d.

$\begin{array}{ll}15 & 1.7\end{array}$

0.69

0.71

0.82

0.71

$\begin{array}{ll}15 & 1.3\end{array}$

0.41

0.57

0.86

0.74

$0.71 \quad 26$

The scores of the desired functionality scale are a'vitally necessary', 2 = 'generally necessary', 3 = 'somewhat necessary', 4='not necessary. The scores to measure the expected influence on health care $1=$ 'absolutely negative' to $5=$ 'absolutely positive'

The second set of interviews zoomed in on several issues, directly related to consequences of an EPR on the daily work of the respondents. Respondents defined several improvements of an EPR in comparison to paper records: better legibility, more concise reporting, more overview and data entry required only once. Single data entry was thought to have two advantages:no more copying of data and the patient does not need to provide data over and over again.

None of the respondents expected the EPR to be a better means of communication than the paper records, nor did they expect different usage of the EPR. Only one - experienced - nurse expected the EPR in the end to result in a reduction of time spent on administrative tasks. One of the residents expected more search work, since a computer file does not show the number of pages already filled in. In a paper record, the number of pages was an indication of how many data were collected of that patient.

Neither managers, nor the users expected an EPR to greatly influence verbal and written reporting, either negatively or positively. They did only expect that the written report would become more concise and relevant. One of the 
nurses thought that maybe she would become more conscious of what needed to be reported and what not. The example she gave was the fact that a patient slept well need not be reported. If, however, a patient slept badly, this should be reported. Now, often either case is reported. Additionally, managers expected a practical problem in verbally reporting from a computer screen.

Most users did not expect their work routines to change drastically after changing to electronic record keeping. In their opinion, writing or typing does not make a difference; it will take more time initially. One nurse, however, mentioned that the reporting might change a lot, since she expected reading on a computer screen to be difficult. Furthermore, until now the nurses have had the routine to sit down together and write their reports at the same time and this may become difficult with a limited number of computers. Managers hoped for more efficient handling of information, although they were not sure of it. And, due to a more organised and structured record, reporting might become more uniform and clear.

The impact on patient care was expected to be limited. One of the managers thought that decision-making could improve, because the overview of data would improve with the EPR. Another one said to hope that an EPR could prevent that patients have to respond to the same questions over and over again with each new nurse or physician appearing. In addition, it was expected that only an EPR interacting with a reminder or protocol system would make a real difference in patient care.

Problems that were expected mainly related to communication aspects. The paper record for example, goes with the patient if (s)he has to go for an examination. In our project only one department was involved in the project and respondents expected difficulties to arise when no record could be sent with the patient and the examining doctor would not have access to the EPR.

In many cases the respondents appeared to have no idea of what to expect or they were very awaiting; "I will wait and see what happens..." was heard often in the interviews.

\section{Discussion}

The participation of health care workers in the development and implementation process of a system is said to be crucial for its success [14-17]. In addition, to prevent one single viewpoint on a system's requirements it is important to involve all user groups in the development phase [18]. Furthermore, the organisational aspects of health care work should be considered [15]. The 
choices we made during the development and implementation process were aimed at enhancing participation and social support of all groups. We measured the attitude of all potential users and their expectations of computer applications in daily work. We also assessed their opinions about advantages and disadvantages of the paper records in use at the department to be able to develop a tailor-made EPR. In addition, several users were closely involved in the actual development process of the EPR.

\section{Background of the respondents}

Many users considered themselves as inexperienced computer users. Therefore, emphasis on training was important. In addition, the EPR should be simple and easy to learn. Most of the inexperienced users appeared to be nurses, which has led to the decision to train all nurses individually.

\section{Attitudes towards an EPR}

Previous research indicates that years of professional experience, the profession of respondents and self-reported previous computer experience are predominant factors in accepting or rejecting information systems [7, 9-12, 19, 20]. In our case we could only demonstrate that self-reported computer experience was related to the users' attitudes. Overall, the attitude of experienced computer users was more positive, but in general both experienced and inexperienced users appeared to be neither positive nor negative. The interviews following questionnaire 1 confirmed the earlier obtained results about the attitude of future users. At the same time the users were critical and curious. This critical attitude was an indication that we needed to involve our future users in the whole development process and to prepare them for the change. Only then they would gain insight in the possibilities of electronic record keeping and develop a sense of ownership of their EPR.

\section{Satisfaction with paper records}

The study of the IOM identified strengths, but many more shortcomings of paper records [1]. In a previous study by one of us, physicians assessed the data entry aspects of paper records positively, whereas data retrieval could be improved [2]. Also in our study, the users were more positive about the data 
entry aspects of both the paper medical and the paper nursing record than about the data retrieval aspects. Long before the EPR project started, the department itself started structuring the paper records and these paper records are still under continuous development. Thus, the paper records in the neurology department are more structured than usual. We expected this to facilitate the transition to electronic record keeping and to increase the user acceptance of an EPR, since applications that deviate too much from the intended users' daily practice are more likely to be rejected [21]. In the interviews, the respondents indicated that the ease of data entry made paperbased reports often more extensive than necessary. Consequently, tracing relevant information often became difficult. The respondents indicated that an EPR should give them more overview than the paper records and should release them from copying data from one sheet to the other. Therefore, in our EPR, we tried to incorporate the positive aspects of the paper records, defined by our future users. In fact, most of the respondents' wishes could be realised in the EPR (chapters 2 and 4).

\section{User needs and expectations}

Since experienced users had more knowledge of computers, one might expect that they may be more capable of judging possible consequences and potential effects of computer applications on daily routines. However, our results showed that both experienced and inexperienced users had little definite expectations regarding the effects of computer applications on health care. Accessibility and reliability were the only important aspects for our future users. These results lead to the conclusion that the future users had no clear view of what could be expected after introducing computers into their daily work. Hence, we needed to increase the efforts to involve and inform the potential users. Rogers assigns change agents an important role in this process [22]. Change agents promote an innovation and can influence the opinion of others about a certain innovation, an EPR in this case. Our wish was that the key users would act as change agents in the group of users. However, we noticed that the key users did not sufficiently communicate the knowledge and information they obtained to their colleagues. In the project team we repeatedly stressed the importance of informing and consulting the future users. The developer also visited the department and frequently talked to different future users. The second set of interviews (three months prior to the implementation) was an opportunity to evaluate our efforts. It appeared that the attitude and expectations had not been changed, since neither users 
nor managers had a clear view of the changes ahead. Both users and managers said to expect no major positive impact of electronic record keeping on daily practice, not in patient care and not in administrative tasks. Instead, they feared more time consuming reporting, and difficulties in communications with other departments. Yet, they expected more from an EPR with decision support, for example critical pathways

\section{First impressions of the EPR in daily practice}

Currently, the implementation of the EPR is ongoing and so far no major problems have been reported. Users are reporting both in the EPR and in their paper records, but the number of nurses and physicians actually using the EPR is still limited. So far, the users have encountered several difficulties. The first is the number of stroke patients. We started off with the main population of the department being the stroke patients. For unknown reasons, the number of stroke patients admitted to the neurology ward declined drastically in our research period, which means that users have much less opportunities to use the EPR than anticipated. A second issue is the decision to offer only an EPR, without decision support. Reason for this was the higher rate of complexity of such a system. In the interviews, however, managers said to expect much more from an EPR with decision support than the EPR alone. Nevertheless, they were very enthusiastic about the EPR itself. The impact on daily routines with only an EPR is less, but the direct advantage for the user is limited as well. This is exactly what we sense in the group of users. A third problem is the lack of links with other systems. These links could provide immediate advantages for the users if we think about electronic ordering of lab tests or medication. Adoption of an innovation depends on, among others, relative advantage, compatibility with existing values and experiences, complexity, ability to test the innovation, and the visibility of results [22]. For our key users the relative advantage and the visibility of results might have been too low to actively participate and communicate with colleagues. They themselves said to expect no clear advantages, but were assigned to a task. Yet, the key users' functioning is a key issue in a system's success [23]. On the one hand, our key users could have invested more time, while on the other hand they could have been encouraged more. Introducing IT into an organisation means invoking changes and the extent to which the organisation, management and employees, are apt to change influences the rates of success [23]. While we expected that during the development phase users with a neutral attitude would become interested in the 
EPR and its possibilities, this did not occur. Probably, we should have assessed readiness for change, before starting the development.

\section{Conclusions}

Involving the users is said to be important in the development process of an EPR. Initially, we considered the way we consulted the users, besides the project team, as sufficient. The users received two questionnaires about subjects that related to electronic record keeping and the subsequent changes in their daily work. We expected them to start thinking about the consequences of an EPR and maybe to become interested. However, after the development phase their opinions had not significantly been changed. Both at the start and at the end of the design process users seemed rather indifferent about the EPR. Whether or not we will succeed in successfully introducing and maintaining our innovation, we will discover in the formal evaluation study of the EPR for stroke patients.

\section{References}

1 Dick RS, Steen EB, eds. The Computer-based patient record: an Essential Technology for Health Care. Washington DC: National Academy press 1991.

2 Tange HJ. The paper-based medical record - Is it really obsolete? Comput Methods Programs Biomed. 1995; 48: 127-31.

3 Berg M. Accumulating and coordinating: occasions for information technologies in medical work. CSCW. 1999; 8: 373-401.

4 Brooke C, Maguire S. Systems Development: A Restrictive Practice? Int J Inform Manag. 1998; 18 (3): 165-80.

5 Aydin CE, Rice RE. Social worlds, individual differences, and implementation. Predicting attitudes toward a medical information system. Information \& Management. 1991; 20: 119-36.

6 Bailey JE. Development of an instrument for the management of computer user attitudes in hospitals. Meth Inform Med. 1990; 29: 51-6.

7 Brown $\mathrm{SH}$, Coney RD. Changes in physicians' computer anxiety and attitudes related to clinical information system use. JAMIA. 1994; 1: 381-94.

8 Cohen BA, Waugh GW. Assessing computer anxiety. Psychol Rep. 1989; 65: 735-8.

9 Nickell GS, Pinto JN. The computer attitude scale. Comput Human Behav. 1986; 2: 301-6. 
10 McBride SH, Nagle LM. Attitudes toward computers. A test of construct validity. Comput Nurs. 1996; 14: 164-70.

11 Startsman TS, Robinson RE. The attitudes of medical and paramedical personnel toward computers. Comput Biomed Res. 1972; 5: 218-27.

12 Teach RL, Shortliffe EH. An analysis of physician attitudes regarding computerbased clinical consultation systems. Comput Biomed Res. 1981; 14: 542-58.

13 Cork RD, Detmer WM, Friedman CP. Development and initial validation of an instrument to measure physician's use of, knowledge about, and attitudes towards computers. JAMIA. 1998; 5: 164-76.

14 Berg M. Considerations for sociotechnical design: experiences with an electronic patient record in a clinical context. Int J Med Inf. 1998; 52: 243-51.

15 Lorenzi NM, Riley RT. Managing change: an overview. JAMIA. 2000; 7: 116-24.

16 Berg M. Patient care information systems and health care work: a sociotechnical approach. Int J Med Inf. 1999; 55 (2): 87-101.

17 Wyatt JC. Clinical data systems, Part 3: Development and evaluation. Lancet. 1994; 344 (8938): 1682-8.

18 Forsythe DE. New bottles, old wine: Hidden cultural assumptions in a computerized explanation system for migraine suffers. Med Anthropol Q. 1996; 10: 551-74.

19 Scarpa R, Smeltzer S, Jasion B. Attitudes of nurses toward computerization: a replication. Comput Nurs. 1992; 10: 72-80.

20 Lee F, Teich JM, Spurr CD, Bates DW. Implementation of physician order entry: user satisfaction and self-reported usage patterns. JAMIA. 1996; 3: 42-55.

21 Kaplan B. The influence of medical values and practices on medical computer applications. In: Anderson JG, Jay SJ, eds. Use and impact of computers in clinical medicine. New York: Springer Verlag 1987: 39-50.

22 Rogers EM. Diffusion of innovations. 4th ed. New York: The Free Press 1995.

23 Lorenzi NM, Riley RT. Organizational aspects of health informatics. Managing technological change. 1st ed. New York: Springer-Verlag 1994. 



\section{CHAPTER 4}

\section{System description}

\section{PUBLISHED AS}

M.J. van der Meijden, H.J. Tange, J.Boiten, J.Troost, A.Hasman. An experimental electronic patient record for stroke patients. Part 2. System description International Journal of Medical Informatics (2000) 58/59 pp 127-140. 


\section{Introduction}

Computers entered the health care environment decades ago. Since then many administrative and clerical tasks were automated. Additionally, laboratories, pharmacies and radiology departments were automated to a great extent. The nurses and physicians, however, still report their findings mainly on paper. Nowadays, introducing information technology (IT) into the care process is believed to resolve many problems faced by health care institutions. Shared care, accountability, rising costs of health care, these issues would be facilitated or in the case of costs, reduced by the use of IT. That also the quality of care, eventually, will improve due to the introduction of IT is widely believed. Shared care requires coordination of the work of different disciplines that in turn requires more communication about patients. An electronic patient record (EPR) can serve as a means of communication, provided a good quality of the data. Accuracy is one aspect of the quality of data. Hogan and Wagner recognised two distinct features of data accuracy in their review on the subject, completeness and correctness [1]. More accurate data can be collected for example by proceduralising processes or structuring data capture [2]. This can be achieved with standard operating procedures (SOPs), for instance guidelines, protocols or critical pathways. SOPs can cover diverse activities in the patient trajectory, from medical and nursing tasks to administrative tasks [3]. Electronically stored patient data are better accessible for other than care purposes, than data registered on paper [4]. Management reports, for example, can be made available more quickly and accountability will be easier to realise.

Aspects of coordination and communication in relation to shared care, as well as the ongoing proceduralisation of work processes provide a point of departure to automate the information exchange in the care process. Easy generation of management reports, data readily available for scientific research and possibilities for accountability are welcome side effects that will ensue from automating information exchange in the care process.

Nowadays, many hospitals have a hospital information system (HIS). The research site of the current study, an academic hospital, has a HIS that contains demographic data, laboratory results, discharge letters of several specialisms, the reports of radiologists, a billing function, and a function to keep track of admitted patients. Currently, the University Hospital Maastricht is adapting its HIS to a more up-to-date system. A new user interface in a Windows 95 environment, Mirador ${ }^{1}$ presents all patient data stored in the HIS in one view. In all outpatient clinics, physicians can view data stored in the HIS via Mirador. Recently, the hospital started installing computers in 
the inpatient clinics so doctors there can also use Mirador. Linking to the HIS an EPR, in which information can be captured, that is currently stored in the paper charts, will thus provide the professionals with useful additional information.

\section{Objectives}

This chapter describes an EPR that was developed to support the treatment of stroke patients at the University Hospital Maastricht. Time is critically important in case of a stroke. After a stroke event a patient should be transferred to the hospital as soon as possible. Preferably to a hospital with a special unit, a so-called stroke unit, where patients can receive intensive care and can be monitored carefully [5]. The research site participates in a special project (concerning transmural care for stroke patients) to improve the treatment of stroke patients. In this project also GPs in the region participate. They refer every patient they suspect of having had a stroke to the hospital. Before the patient arrives at the hospital, the GP warns the neurologist. At the emergency department a neurologist examines every potential stroke patient. Upon admission, patients are transferred immediately to the stroke unit of the department. At this unit, a multidisciplinary team takes responsibility for the treatment of the admitted stroke patient. In this team neurologists and nurses collaborate with physical therapists, social workers, occupational therapists and speech therapists to optimise (diagnostic) treatment and care for each patient. Adequate and timely information exchange is of high importance here. Currently, nurses and physicians document their findings in separate records. Also other care providers report in the nursing or the medical record on separate forms. Besides that, they maintain their own paper records. An analysis of work practices at the research site is described in detail in Chapter 2.

In the current project an EPR was developed in close cooperation with members of the department to support daily routines at the ward. The decision to develop this system was based on the belief that the multidisciplinary team can function better when using electronic record keeping and that a combined medical and nursing EPR is better equipped to serve as a means of communication than the separate paper records. Main goal was to examine what consequences the introduction of the EPR would have on daily practice. A thorough evaluation of this EPR is planned to explore the kind of organisational changes that will be invoked, the effects on individual professionals, the consequences for communication patterns and the quality of care. 


\section{Design considerations}

The design and development of a valuable and practical electronic record require considerable attention and efforts from both developers and future users. A valuable and practical electronic record is one that fits neatly into daily practice and offers a substantial gain in comparison with a paper record. Our reasons for introducing an EPR in the research setting were twofold: to support daily practice on the one hand and to serve scientific research in the field of neurology on the other. However, it is more critical to tailor an EPR to daily routines and practices then to scientific research. Therefore, our main concern was to develop a system that would truly support daily practice at the ward of the neurology department of the University Hospital Maastricht. Whether a system supports or hinders daily practice, depends on several factors. Important issues that need to be addressed are what information needs to be available in an electronic record and how this information should be offered. In our case, the issue of what information to incorporate in the records was determined by the physicians involved. Prior to the current project, both the medical record and the nursing record were already partly structured.

The second question, how to present information, is a more difficult one. Research purposes, accuracy of data and automated generation of overviews and summaries are best served by completely structured records with only predefined choices. The care provider, on the other hand, may insist on free text entries to be able to enter the exact words he wants. Since entering data is different from browsing data, a distinction should be made between presentation of data for data entry and presentation of data for data retrieval. Actually, the presentation of collected patient data is a very important element of the EPR user interface. We based our system on an experimental electronic medical record, developed in a previous research project conducted at our department. In that project the ease of consultation of medical narratives was subject of study. The contents of medical narratives were ordered according to source and type of data, and were presented in a flow sheet. Physicians were asked to answer a series of questions concerning three patients. They used the medical narratives that were offered in more or less detailed paragraphs, also described as differences in granularity of data. The results lead to the conclusion that both too large and too small paragraphs slowed the retrieval of relevant information [6]. 


\section{From user needs to user requirements}

In the design phase of the system we communicated intensively with the future users to obtain their information needs and wishes. In close cooperation with them, we formulated several criteria for the system and its user interface. These criteria can be divided into two main categories: the ease of use and integration. Criteria concerning the ease of use were: a) the EPR simultaneously available at multiple sites, b) simple data entry forms with predefined (multiple) choices and only limited free text entries, c) data entry forms based on the available, familiar structured paper record forms, d) a clear overview of patient data and e) discharge summaries should be easy to compose and to print. Integration of records and systems is highly desirable. Patient data are oftentimes registered more than once. Furthermore, health care workers often collect the necessary information in different records and the HIS. Integration of the nursing and medical records and coupling of the HIS and the EPR resolves those disadvantages and eliminates potential sources of errors.

We translated those criteria into the following functional requirements. In the first place several requirements that relate to the ease of use. The EPR should provide a multi-user environment, since all care providers need access to the same records, probably simultaneously. As a consequence, access rights needed to be defined for different disciplines and information must be presented from different user perspectives. Furthermore, in an academic setting residents often change and student-nurses come and go. Therefore, the EPR must be easy to learn for novice (computer) users. The fluid nature of medical work requires also that users can log on and off the system very quickly and that switching between patients is easy and fast. Additionally, on-line help, providing support and feedback on the usage of the system, and a clear presentation of data are indispensable to guide users through the system. Offering structured data entry where possible is required to increase the learnability, reduce typing efforts and lead to more consistent records. A second aspect that deserved attention is the intended integration of our EPR with the HIS. Ideal would be a complete integration of the two systems.

\section{The structure of the records}

A flexible structure of the record is necessary to offer a combined medical and nursing record without introducing redundancy in the database. Moreover, transparency of the structure of the records will increase ease of 
use and thus enhance user acceptance. Therefore, both the medical and the nursing record were structured according to the current, familiar categories applied in paper records.

Shared data are data that are necessary to both physicians and nurses. Currently, in the paper records this information is copied from one record to the other. This copying is a potential source of errors. Moreover, copying data introduces data redundancy. Therefore, the EPR was constructed in such a way that data can be shown in different contexts. Figure 1 shows the basic structure of the records. The grey boxes indicate the presence of (partly) shared information.

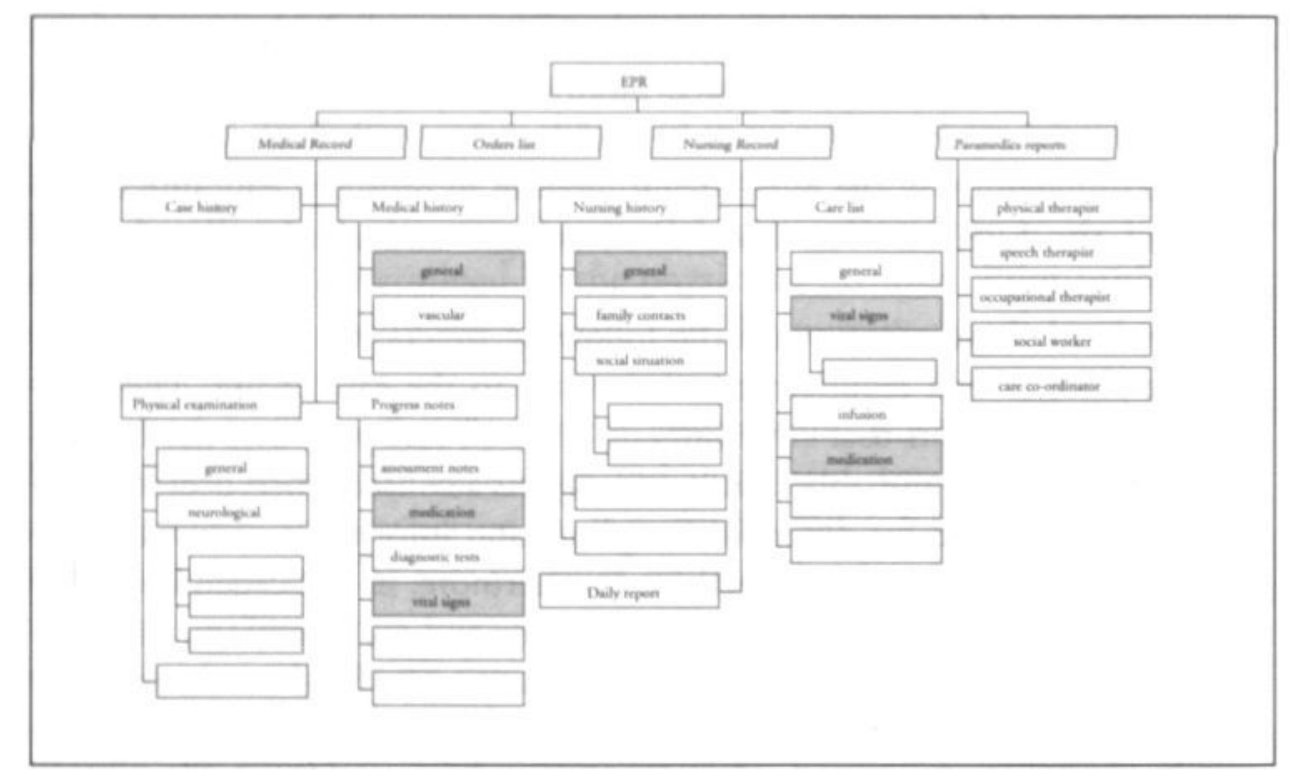

Figure 1

The overview of the EPR structure.

\section{The user interface}

A crucial element of an EPR is the user interface, for the interface represents the system for its users $[7,8]$. To accomplish an EPR that is readily accepted, emphasis should be placed on the design of the system's interface. The ease of use can be enhanced by increasing the extent to which the system's behaviour corresponds with the user's knowledge [8-10]. Thus users should be involved in the design process at an early stage.

Since the users are not yet familiar with EPRs, the layout of the screens should 
approximate the current paper based records. For instance, care providers are accustomed to processing a lot of information and consequently, the interface should show relatively large volumes of data on a screen. Additionally, the relevance of medical information is highly related to the context in which the data is generated or presented. Thus, in the interface the context of information needs to be obvious. Apart from that, the layout of the data entry and the data presentation forms reflect the design delineated in the preceding paragraph to increase the transparency of the EPR for the care providers. Furthermore, predefined response categories were built in wherever possible. Often, time is critically important in medical practice. Speed of information processing is therefore of the utmost importance $[7,11,12]$.

\section{System description}

We developed an EPR, consisting of a database containing information about both the structure and the content of de patient record, a user interface, several programming modules, and a research module with a logging function. The system was implemented in a Windows 95 environment. We used an MS Access 97 database and MS Visual Basic 5.0 for developing the system. On-line help was created with RoboHelp ${ }_{\circledR}$ Office, version 7.

\section{Data entry}

Most data entry forms approximate the paper forms already in use at the ward. For the medical and the nursing record, and the reports of paramedical personnel, separate electronic data entry forms were designed. The medical record captures most intake data in a structured format (figure 2). At admission, results of medical history and physical examination are registered on one data entry form. Tabs are used to distinguish three different sections of this form. Many questions are formulated as multiple-choice items, with an option to add comments in free text. Figure 2 shows one section of that form. While the admission form resembles the paper form, the electronically reported medical progress notes are structured to a much greater extent than their paper counterparts. Medical progress notes are subdivided into eight sections: medication, complications and diagnostic tests, assessment notes, reports of talks with the patient and his/her family, a progress summary, the notes of consulting physicians and a list of vital signs. Three sections (medication, complications and diagnostic tests) support structured 
data entry. Four sections are composed of free text entries. In each section previous entries are presented chronologically, the most recent entry first. In addition, the list of vital signs filled in by the nurses is presented in a separate section.

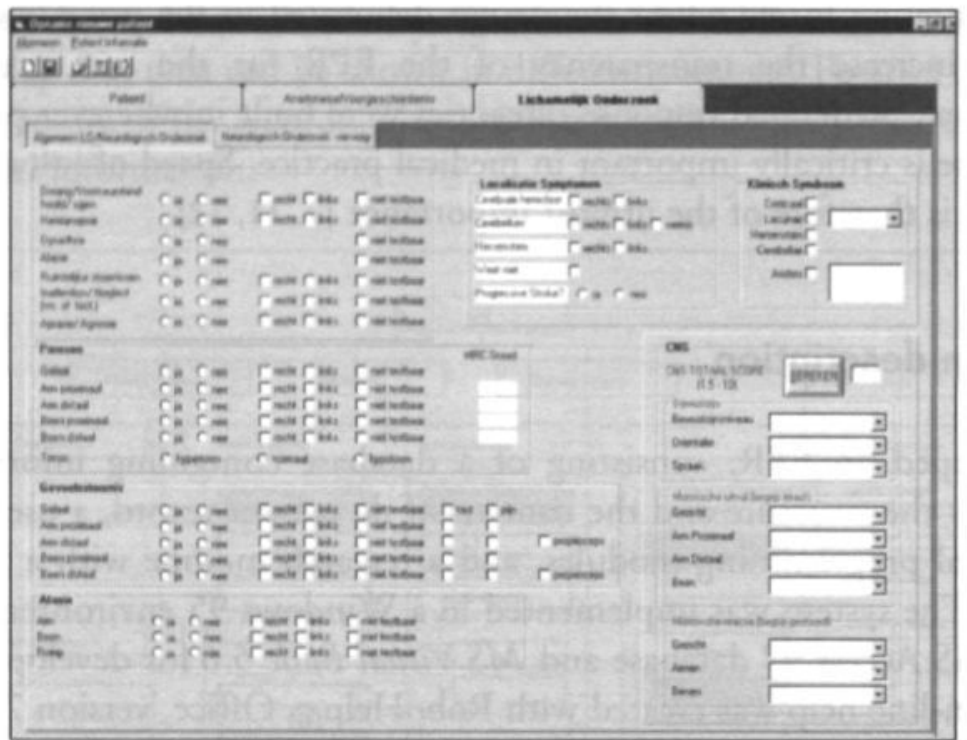

\section{Figure 2}

Example of a structured data entry form of the EPR. The physical examination (motor and sensibility dysfunctions) is reported in a structured format.

The nursing part of the EPR contains four data entry forms: the nursing history, the daily report, the care list, and the week list. Nursing history is registered on a data entry form, with some of the topics already filled in by the neurologist on medical data entry forms. Most of the remaining, empty topics can be entered by choosing from predefined lists. The daily report of both the stroke unit and the ordinary ward consists of a free text entry form. On the care list, the stroke unit of the ward reports vital signs, motor and sensory functions, consciousness etc. on a 24-hour flow sheet. Other information registered on the care list consists of infusions, medication, monitoring of the patient, appointments etc. The week list is a structured form, approximating the already structured paper form in use at the normal ward. Several aspects 
of the patient's health status are scored on a predefined list and presented in a one-week view. In one glimpse a patient's health status can be assessed.

Orders communication between nurses and physicians is registered on a special form. Nurses or the ward's secretary register and process the orders, while physicians just register orders. Processing an order can vary from requesting a test to making an appointment with the patient's family. Nurses enter questions for the physicians to answer. These questions cover practical problems they encounter or questions from the patient, for example 'Patient asks a higher dose of analgesics. What do we do?' The orders list is part of the EPR instead of only part of the nursing record.

New orders are added on top of the list. An order can be either processed or cancelled and the name of the professional who processed or cancelled the order is registered. The orders list can be sorted on date of entry, on date of processing or on order description. Unanswered questions are marked blue and not (yet) completed orders are marked yellow.

We implemented this list in such a way that when opening the medical progress notes, the care list, the week list or the daily report of a patient, the orders list always pops up on top. In this way, the orders list can easily be scanned for newly added orders or questions.

Not only nurses and physicians need access to patient data. Also the physical therapist, the social worker, the speech therapist, the care co-ordinator and the occupational therapist do. In the current - paper - records they report on a special paper form attached to the nursing record. In the EPR each discipline has a separate section of the paramedics report form to type its findings in free text.

\section{Presentation of patient data}

Although data are entered in a specific context, the same information can have additional value in other contexts. Creating different views on the same data by rearranging clinical items may therefore be advantageous. In the case of the currently described EPR the items in the database can be arranged and rearranged in a desired view, presenting related items on the vertical axis and the time on the horizontal axis. This view is then presented in the data retrieval form that gives an overview of all patient data (figure 3). In this experimental version of the EPR, users cannot manipulate the structure to their preferences without help of the developer.

The data retrieval form contains three sections (figure 3), a left pane, an upper and a lower right pane. The left pane shows the structure of the EPR as a hier- 
archically ordered list of the clinical items, comparable with the folders pane of the Windows Explorer. This list can be described as a tree with branches and leaves. By clicking, branches can be expanded to show sub branches or to show the leaves, called end nodes. By clicking the end nodes, the patient data are presented in the upper right pane. This section of the right pane shows an aggregated overview of the selected data in a day-by-day or week-by-week view. Data can be further selected column-wise and row-wise. Upon such selection all requested data are presented in the lower right pane.

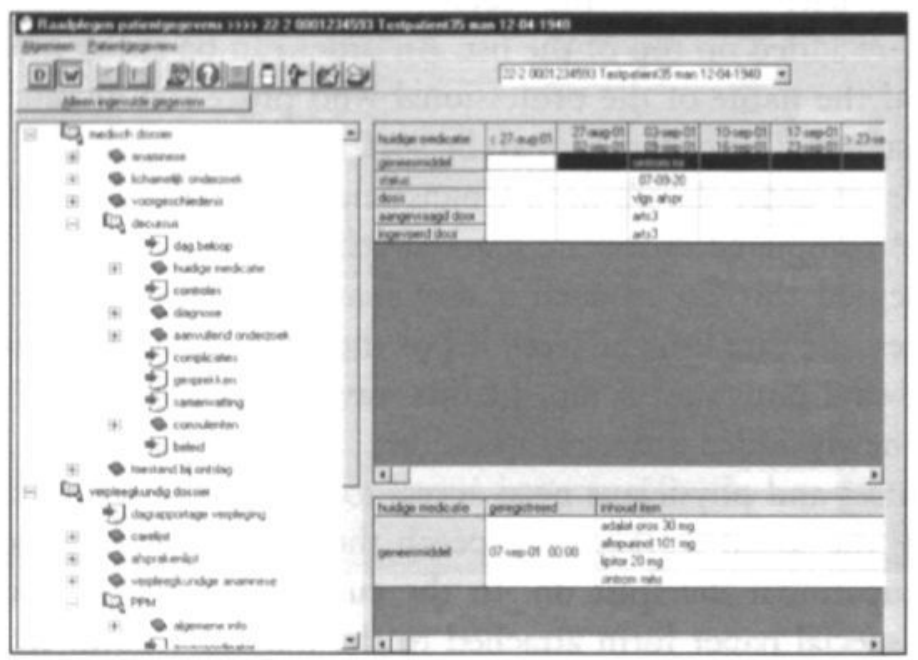

\section{Figure 3}

The data retrieval form. View of both the medical (=medisch dossier) and the nursing records (=verpleegkundig dossier) in the left pane. The upper right section presents an overview of this patient's medical, vascular history. The lower right section presents the complete content of selected items.

\section{Database}

Like in the experimental electronic medical record, developed in previous research, the structure of the patient record was stored in the database [13]. Three tables contain the relevant information. Patient data are stored the a separate table. Another table lists clinical items and their hierarchical relationship (see left pane figure 3) is stored in the third table. The items' position can vary depending on user requirements. Furthermore, one clinical item can show up in different parts and levels of the EPR. These two features 
result in a flexible structure of the record, that can easily be adapted to changing insights or needs.

\section{Linkage to other systems}

A coupling with part of the HIS was realised. Demographic data and location data are retrieved directly from the HIS database any time a patient is loaded into the EPR. Linkage with other systems, such as the pharmacy system or the laboratory system, fell outside of the scope of this project.

\section{Additional features}

\section{ON-LINE HELP}

On-line help is provided to guide (new) users in using the EPR.

\section{PAper output}

A preliminary discharge summary and the nursing transfer notes are overviews of relevant information partly generated by the EPR. If necessary, their content can be easily adjusted and subsequently, the overview can be printed.

\section{SeCURITY}

All professionals involved in the multidisciplinary treatment team have readaccess to the EPR. Each profession has forms to register the data relevant to its members. Differences exist in the writing rights of the professionals; these rights are based on their professional group.

\section{LOGgING DATABASE}

The users' navigation through the system can be recorded in a research, logging database. This information will provide insight in the usage of the EPR. We are interested in analysing the forms and features that are used. Insight 
in the navigation through the system must result in recommendations to improve this EPR.

\section{First experiences}

At present the EPR contains all desired functionality. Users expressed their satisfaction with the EPR and are actively participating to improve it. However, during the process of developing the EPR some difficulties had to be overcome.

\section{Challenges encountered during development}

First, we had a problem with translating specific information needs into more generally applicable statements. Initially, we planned to design the EPR with help of the users from scratch. Gradually, it appeared that physicians gave examples instead of generally applicable information for a computer program. In the end, we computerised the existing forms and used them as a starting point. In an interactive process of prototyping we managed to develop a truly electronic record.

Second, in the development process we were confronted with conflicting views related to 'relevant' data to collect. One view concentrated on scientific research, whereas the other was directed only to patient care. The paper based admission form was structured, mainly to facilitate scientific research. This resulted in more specific and more extensive data capture than strictly necessary from a purely clinical point of view. An open discussion solved the topic.

Third, we encountered some difficulties related to security aspects. A strict description of the responsibilities of each professional group was required to implement the read/write access rights. In the paper record situation, a health care provider can complete information of a day in the past. This may occur for instance because time was lacking to write down the information or because the record was not available at the time and location the data were collected. In the EPR, that will be impossible. All information is added at the time it is produced and no information can be changed or erased at a later moment. 


\section{User acceptance}

Having overcome all these, some unanticipated, challenges, it was encouraging to detect a sense of excitement when talking to actively participating users. And also the future users not directly involved in the design process expressed their curiosity.

\section{Planned evaluation}

After testing the EPR exhaustively, an evaluation study will be conducted to answer our research questions. Our principal research question is how the use of an EPR will affect record keeping and the process of care and what effects the addition of decision support will have. In a before/after designed study we will investigate several aspects of the patient record itself as well as the process of care. First of all, completeness of the record will be evaluated. Secondly, the communication at the ward as a part of the process of care will be evaluated in a qualitative way using in-depth interviews and observations [14]. Finally, because the success of the system will depend heavily on the acceptance by its users, user satisfaction and user attitudes will be measured in every phase of the implementation. For this reason, we developed a questionnaire, based on existing ones [15-21]. The users' navigation through patient data will be recorded in a research database that will be analysed to check how the record is used and what functionality users prefer.

\section{Discussion}

This chapter describes an EPR developed to support daily practice at the neurology ward of an academic hospital. We aimed at an EPR that would facilitate the process of care in which many care providers participate. The relevance of timely information exchange in this environment served as a basis for the design of the EPR. But what could actually be gained with an EPR?

\section{Electronic versus paper-based record keeping}

Generally, it is recognised that paper record keeping does not suffice in the complex environment of modern medicine. In the study of 1991, the IOM 
subdivided the weaknesses of the paper patient record into four main headings (1) content, (2) format, (3) access, availability, and retrieval and (4) linkages and integration. It was believed that many of the objections of paper record keeping could be overcome by electronic record keeping [4].

Clearly, simply exchanging the paper record for an electronic one will not offer many advantages. Rather, the registration of data will probably become more time consuming. And it can be questioned whether or not the data will become more accessible.

What then are the drives to introduce electronic record keeping? Advantages of an EPR over a paper based medical record cover multiple aspects. If we return to the four main categories of weaknesses of paper records as defined by the IOM, the currently described EPR provides an advance in all aspects. As a first aspect, the IOM mentioned that the content of records requires improvement. Previous research indicated that computerizing (part of) the medical record actually resulted in more complete records [22, 23]. In addition, legibility of data, coding of data, more uniform data collection are believed to improve record keeping $[2,22,23]$. Since good data entry is the start of good record keeping, we attempted to enhance the ease of data entry. In our EPR we offer the user an overview of all possible responses, limited typing and data that are standardised to a large extent. A second weakness, as defined by the IOM, is the format of records. Already in the early seventies alternatives for the traditional source-oriented medical records were described: the problem-oriented record and the time-oriented record [24, 25]. The currently described EPR combines the source- and the time-oriented record. The latter is mainly expressed in the principal data retrieval form. A third aspect of attention was defined by the IOM as access, availability and retrieval. Access, availability and retrieval are related to each other in the case of paper records. Often, paper records are not available where needed and when needed. If they are available data retrieval requires an effort, depending on the size of the record. In an EPR access depends on the rights a professional has. In our case we based access rights on membership of a professional group. Moreover, ease of use determines if users can actually access the records. In previous research it appeared that multiple views of the same data, integrated systems, multi-user environments and a record that can serve as a means of communication could truly support the process of care [26-28]. Our windows based system provides a flexible and user-friendly environment. Multiple screens can be opened simultaneously to view and enter data. Users can log on and off quickly, switching between patients is easy and fast. These features are prerequisites for the hectic, unpredictable daily work at the stroke unit. The availability of an EPR depends on the number and loca- 
tion of computers with access to the EPR. At our research site, all three physicians have a laptop to guarantee access at any location they require it. Besides, several desktop computers are available at strategic locations at the ward. Since the EPR is provided at several locations it will be readily available in a multi-user environment. The multi-user environment of our EPR is designed to facilitate coordination and communication. An explicit example is the electronic orders list. Additionally, all data concerning one patient are presented in a special data retrieval form to give a complete overview. This means that members of the treatment team can easily survey the patient data, without having to browse two separate records that are not familiar to them. In our view, retrieval of electronic data is more related to the structure and format of the EPR than to access or availability.

The fourth aspect addressed was linkage and integration. Since the EPR is partly integrated with the HIS, users do not need to retype demographic and location data already available in the HIS. Unfortunately, complete coupling is not yet within reach, but laboratory results can be checked at the same computer simply by toggling between two applications.

\section{Electronic record keeping in health care}

The use of IT may have unanticipated, unwanted effects, like a higher workload or less time for patient care [29]. Health care is presumed to become more efficient with electronic record keeping. However, research does not unambiguously support this assumption [29, 30]. Moreover, organisational aspects or the characteristics of medical work may limit the anticipated advantages of electronic record keeping. If, for example, an application results in changes in work patterns or is thought to affect professional status and autonomy, it is likely to be rejected [31]. It is important to determine who will use a system and for what purposes, and also in what context a system needs to function $[32,33]$. Thus, health care providers and the organisation they are functioning in are very important to consider. Introducing IT in a health care environment induces changes in coordination and communication between individual care providers and occupational groups, productivity and efficiency, roles and responsibilities, working routines and job satisfaction $[27,29,34-39]$. Thus, the users play a key role in accepting an EPR. Users in our project indicated that they were sufficiently involved in the process of development and implementation. From the beginning some key users participated in the project. Furthermore, we expect our EPR to fit in with daily routines, because we attempted to stay close to the organisation 
of daily work. The introduction of the EPR was not used to redesign work routines. Rather, we benefited from the fact that data capture had already been proceduralised and structured prior to the current study. Not only if the system fits into the users' daily practice is of importance, but also their attitude toward IT in general has great influence on the degree of acceptance $[15,16,37,40-42]$. In an early phase of the project we questioned the future users about their attitudes towards computerising by means of a questionnaire. The results gave us no reasons for concern and we continued the project as planned. Several months after starting the development, the users received a second questionnaire to measure their knowledge of computers. These results were utilised to develop the training program and the on-line help function.

\section{Lessons learnt}

During the process of design and development some important issues for future developments emerged. The intensive user participation from the start was advantageous for the project. On one hand, we were constantly aware of the practice our EPR should support and on the other hand the users had an opportunity to adopt the EPR and influence its development. Gradually users developed initiatives and ideas to improve the EPR. As the users became aware of the possibilities of computers, however, it proved necessary to define the scope of the study very strictly. The availability of the EPR was limited to the neurology ward. Moreover, no connection was made with ancillary departments. From the users' perspective such connections could provide advantages in reducing double work and errors, in improving the communication between departments etc. In addition, the current HIS was not yet fully equipped to couple the EPR and the HIS, but that should be strived for in future. Facilities to print discharge summaries and other paper output were an incentive to the users, since the written versions of their electronic counterparts required filling in exactly the same information several times.

Very important in the whole process was the fact that we had the structured paper records as a starting point, so we did not need to interfere with the content of the records and the organisation of the data in them. The inevitable changes in daily practice will therefore be limited to the organisation and not the content of work.

In conclusion, the approach we applied in this project resulted in an EPR that we believe to have potential to succeed in daily practice. 


\section{References}

1 Hogan WR, Wagner MM. Accuracy of data in computer-based patient records. JAMIA. 1997; 4: 342-55.

2 Moorman PW, van Ginneken AM, Siersema PD, van der Lei J, van Bemmel JH. Evaluation of reporting based on descriptional knowledge. JAMIA. 1995; 2: 365-73.

3 Strauss A, Fagerhaugh S, Suczek B, Wiener C. Social organization of medical work. 2nd ed. New Brunswick, New Yersey: Transaction Publishers 1997.

4 Dick RS, Steen EB, eds. The Computer-based patient record: an Essential Technology for Health Care. Washington DC: National Academy press 1991.

5 Langhorne P, Williams BO, Gilchrist W, Howie K. Do stroke units save lives? Lancet. 1993; 342: 395-8.

6 Tange HJ, Schouten HC, Kester ADM, Hasman A. The granularity of medical narratives and its effect on the speed and completeness of information retrieval. JAMIA. 1998; 5 (6): 571-82.

7 Tang PC, Patel VL. Major issues in user interface design for health professional workstations: summary and recommendations. Int J Biomed Comput. 1994; 34: 139-48.

8 Thomas PJ, editor. The social and interactional dimensions of human-computer interfaces. first ed. Cambridge: Cambridge University Press 1995.

9 Shneiderman B. Designing the user interface. second ed: Addison-Wesley publishing company 1992.

10 Norman DA, Draper SW, eds. User centered system design. Hilsdale, New Jersey: Lawrence Erlbaum Associates 1986.

11 Nygren E, Johnson M, Henriksson P. Reading the medical record. II. Design of a human-computer interface for basic reading of computerized medical records. Comput Methods Programs Biomed. 1992; 39 (1-2): 13-25.

12 Nygren E, Henriksson P. Reading the medical record. I. Analysis of physicians' ways of reading the medical record. Comput Methods Programs Biomed. 1992; 39: 1-12.

13 Tange HJ, Dreessen VA, Hasman A, Donkers HH. An experimental electronic medical-record system with multiple views on medical narratives. Comput Methods Programs Biomed. 1997; 54 (3): 157-72.

14 Friedman CP, Wyatt JG. Evaluation methods in medical informatics. New York: Springer-Verlag 1997.

15 Startsman TS, Robinson RE. The attitudes of medical and paramedical personnel toward computers. Comput Biomed Res. 1972; 5: 218-27.

16 Teach RL, Shortliffe EH. An analysis of physician attitudes regarding computerbased clinical consultation systems. Comput Biomed Res. 1981; 14: 542-58.

17 Bailey JE, Pearson SW. Development of a tool for measuring and analyzing computer user satisfaction. Manag Sci. 1983; 29 (5): 530-45. 
18 Brown SH, Coney RD. Changes in physicians' computer anxiety and attitudes related to clinical information system use. JAMIA. 1994; 1: 381-94.

19 Lewis JR. IBM computer usability satisfaction questionnaires: psychometric evaluation and instructions for use. Int J Human-Comput Interact. 1995; 7: 57-78.

20 Tange HJ. The paper-based medical record - Is it really obsolete? Comput Methods Programs Biomed. 1995; 48: 127-31.

21 Cork RD, Detmer WM, Friedman CP. Development and initial validation of an instrument to measure physician's use of, knowledge about, and attitudes towards computers. JAMIA. 1998; 5: 164-76.

22 Tang PC, LaRosa MP, Gorden SM. Use of computer-based records, completeness of documentation, and appropriateness of documented clinical decisions. JAMLA. 1999; 6 (3): 245-51.

23 Whiting O'Keefe QE, Simborg DW, Epstein WV, Warger A. A computerized summary medical record system can provide more information than the standard medical record. JAMA. 1985; 254 (9): 1185-92.

24 Weed LL. Medical records, medical education, and patient care. 6 ed. Chicago: Year book medical publishers 1971.

25 Fries JF. Alternatives in medical record formats. Med Care. 1974; 12 (10): 871-81.

26 Rigby M, Roberts R, Williams J, Clark J, Savill A, Lervy B, Mooney G. Integrated record keeping as an essential aspect of a primary care led health service. BMJ. 1998; 317: 579-82.

27 Sicotte C, Denis J, Lehoux P. The computer based patient record: a strategic issue in process innovation. J Med Sys. 1998; 22 (6): 431-43.

28 Schneider K, Wagner I. Constructing the 'Dossier Représentatif'. Computer-Based Information-Sharing in French Hospitals. CSCW. 1993; 1: 229-53.

29 Hebert MA. Impact of IT on health care professionals: changes in work and the productivity paradox. Health Serv Manage Res. 1998; 11: 69-79.

30 Bürkle T, Kuch R, Prokosch H-U, Dudeck J. Stepwise evaluation of information systems in an university hospital. Meth Inform Med. 1999; 38: 9-15.

31 Kaplan B. The influence of medical values and practices on medical computer applications. In: Anderson JG, Jay SJ, eds. Use and impact of computers in clinical medicine. New York: Springer Verlag 1987: 39-50.

32 Berg M. Considerations for sociotechnical design: experiences with an electronic patient record in a clinical context. Int J Med Inf. 1998; 52: 243-51.

33 Forsythe DE. New bottles, old wine: Hidden cultural assumptions in a computerized explanation system for migraine suffers. Med Anthropol Q. 1996; 10: 551-74.

34 Papa MJ. Communication network patterns and employee performance with new technology. Communication Research. 1990; 17: 344-68.

35 Kaplan B. An evalutation model for clinical information systems: clinical imaging systems. In: Greenes RA, Peterson HE, Protti DJ, editors. Medinfo; 1995; Vancouver, Canada: IMLA 1995; 1087. 
36 Kaplan B. Addressing organizational issues to the evaluation of medical systems. JAMIA. 1997; 4: 94-101.

37 Aydin CE. Occupational adaptation to computerized medical information systems. J Health Soc Behav. 1989; 30: 163-79.

38 Aydin CE, Rice RE. Bringing social worlds together: computers as catalysts for new interactions in health care organizations. J Health Soc Behav. 1992; 33: 168-85.

39 Symon G, Long K, Ellis J. The coordination of work activities: cooperation and conflict in a hospital context. CSCW. 1996; 5: 1-31.

40 Barry CT, Gibbons LK. Information systems technology: Barriers and challenges to implementation. J Nurs Adm. 1990; 20: 40-2.

41 Aydin CE, Rice RE. Social worlds, individual differences, and implementation. Predicting attitudes toward a medical information system. Information \& Management. 1991; 20: 119-36.

42 Davis FD. Perceived usefulness, perceived ease of use and user acceptance of information technology. MIS Quarterly. 1989; 13: 319-39. 


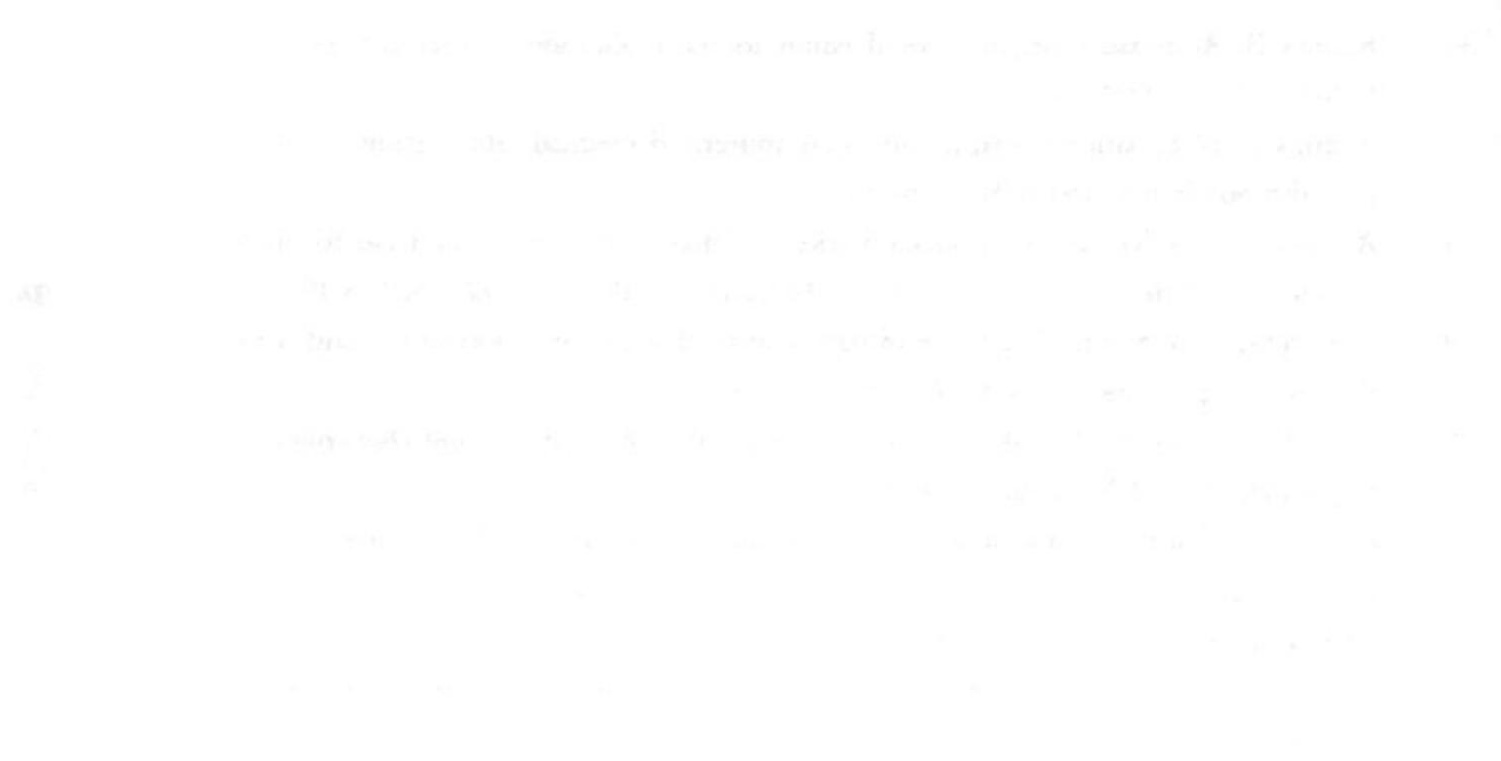


CHAPTER 5

\section{Evaluation in daily practice}




\section{Introduction}

Documenting intake data, progress notes and test results is an important aspect of the health care process. It is disliked by many health care professionals who regard it to be a burden. Collection and documentation of data starts the moment a patient enters the hospital, often the same data are documented on a number of different forms and for different reasons. Financial purposes, managerial purposes, and most and for all, delivery of care require adequate and timely data about individual patients or patient populations. Particularly developments like shared care require that collected data are easily available to all health care professionals involved. Paper patient records, although having many advantages, do not suffice then. Electronic records can provide the essential functionality of (multi-site) availability, of timeliness, etc., and can be of additional value provided they fit their users' practice [1]. In addition, electronic records can be beneficial for the quality of care [2].

Subject of this chapter is the evaluation of an electronic patient record for stroke (stroke EPR), which was tested in daily practice. The objective of the project was to define the requirements of an EPR, and to explore the possibilities of an EPR to improve the quality of record keeping and to support the communication in multidisciplinary care. In the present evaluation study we tried to answer the following research questions. What consequences does an EPR have on the completeness of record keeping? What consequences does an EPR have on the daily work of nurses and physicians? What consequences does an EPR have on their opinions about electronic record keeping? How is their usage behaviour? Finally, what are management's experiences?

\section{Research setting}

\section{Context}

Research took place at the stroke unit of the neurology department of an academic hospital in the Netherlands, where in 1996 a project started to coordinate the care for stroke patients. This project aimed at improving the information exchange between all health care providers involved in treatment and care for stroke patients. The first two weeks after the event, the acute phase of stroke, are considered to be crucial for further prognosis. Therefore, time is critically important and an immediate admission in the hospital after the 
event is considered essential. The neurology department has a fully equipped stroke unit, existing of a medium care unit and two normal care wards. Upon admission, patients are transferred to the stroke unit of the neurology department, where a multidisciplinary team takes responsibility for the stroke patient. In this team neurologists and nurses collaborate with physical therapists, social workers, occupational therapists and speech therapists to optimise diagnosis, treatment and care for each patient. Approximately 300 stroke patients are admitted yearly to the stroke unit, being about $70 \%$ of all patients admitted at the ward. The stroke patients are cared for by 20 experienced nurses and 12-14 residents with their supervisors. One resident is responsible for the emergency care and together with two nurses also for the medium care unit. At each normal care ward one resident and teams of four to five nurses are responsible for the patients.

Adequate and timely information exchange is of high importance. Before the present study, nurses and physicians documented their findings in separate records, structured to a certain extent. Additionally, the other care providers reported in the nursing or the medical record, while maintaining their own paper records as well. In this setting an EPR for stroke was developed in close cooperation with staff - nurses and physicians. The decision to develop an EPR was based on the belief that the multidisciplinary team can be effectively supported by electronic record keeping and that a combined medical and nursing EPR is better equipped to serve as a means of communication than the separate paper records. Moreover, a hospital-wide electronic record proceeded slowly and therefore, anticipating on hospital-wide developments, it was decided to develop a stroke EPR in a research project.

\section{Intervention}

The stroke EPR was based on an experimental electronic medical record, developed in a previous research project conducted at our department [3-5]. That experimental electronic medical record had only a viewer function. Based on existing, structured paper forms the medical intake and discharge forms and all nursing forms were designed. Medical progress notes were subdivided into main headings: medication, diagnostic tests, complications, assessment notes, reports of family talks, and the summary. The medication, diagnostic tests and complications were structured, whereas assessment notes, reports of family talks, and the summary remained free text. Nursing progress notes were free text as well. The medical and nursing record were integrated into the EPR that was meant for documenting data of inpatient 
stroke patients only. To minimise double data entry, demographic data (admission data, date of birth, address, GP, etc) of patients were downloaded from the HIS. Other data, like lab results, radiology reports were available in the hospital information system (HIS) and could be consulted using ALTTAB. This stroke EPR was described in detail in Chapter 4.

The implementation of the stroke EPR started at the medium care unit in July 2000. The residents of the normal care wards started using it shortly afterwards. For practical reasons, only the stroke patients that were admitted via the emergency department to the medium care unit were included in the EPR (no transfers and no admissions directly to the normal care ward). During the trial period every user could telephone the developer with questions or problems to be solved. Moreover, at a certain point in the implementation phase a booklet for comments, questions and trouble reporting was "installed". In July 2001, the trial period ended.

As became apparent during the implementation, the EDP department could not realise back-up facilities. This unanticipated inconvenience influenced the course of the EPR project, because users felt the need to document all data both in the EPR and in their paper records to create some sort of back up. However, this situation offered us the opportunity to compare patient data that were documented electronically as well as on paper.

\section{Methods}

In our evaluation study we included several aspects of electronic record keeping. We studied system quality, data quality, usage, user satisfaction, individual impact and organisational impact. In addition, we evaluated the process of development and implementation. We collected data with qualitative and quantitative methods and combined the results through triangulation.

\section{Study design}

The evaluation was originally designed as a before/after study with a series of baseline measurements before the implementation and a similar series of measurements post implementation. 


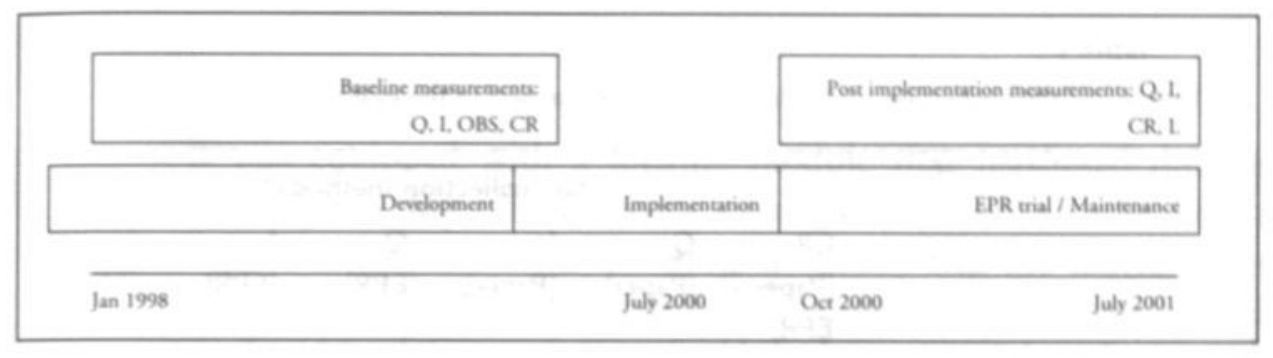

\section{Figure 1}

The schedule of research measurements and development, implementation and maintenance in the stroke EPR project. Q: questionnaire, I: interviews, OBS: observations, CR: chart review, L: logging module.

As shown in figure 1 the baseline measurements commenced during development. These measurements started with a questionnaire assessing the user attitude toward computers, followed by a questionnaire assessing user satisfaction with the clinical paper records, user expectations and user requirements of IT applications in health care. The questionnaires were complemented with face-to-face interviews, observations and reviews of paper records. These results were presented in chapters 2 and 3. Post implementation measurements started in October 2000. Usage behaviour was logged in a special logging module. In addition, chart reviews of paper and corresponding electronic records were conducted during the trial. Completeness of data in these records was compared in a non-controlled trial. Towards the end of the trial period questionnaires were sent to all eligible users. Shortly after the end of the trial six nurses, six residents and four departmental managers were interviewed. The data collection methods are described in the next paragraph.

\section{Data collection}

Data were collected through reviews of paper charts, questionnaires, interviews and logging of users' actions. Table 1 shows which aspects were evaluated and which type of data was collected in the baseline study, in the EPR trial or in both. Through triangulation data collected at different times and with different methods were combined to present a more complete picture. 


\section{Table 1}

Timing and data collection methods for the different aspect of the evaluation.

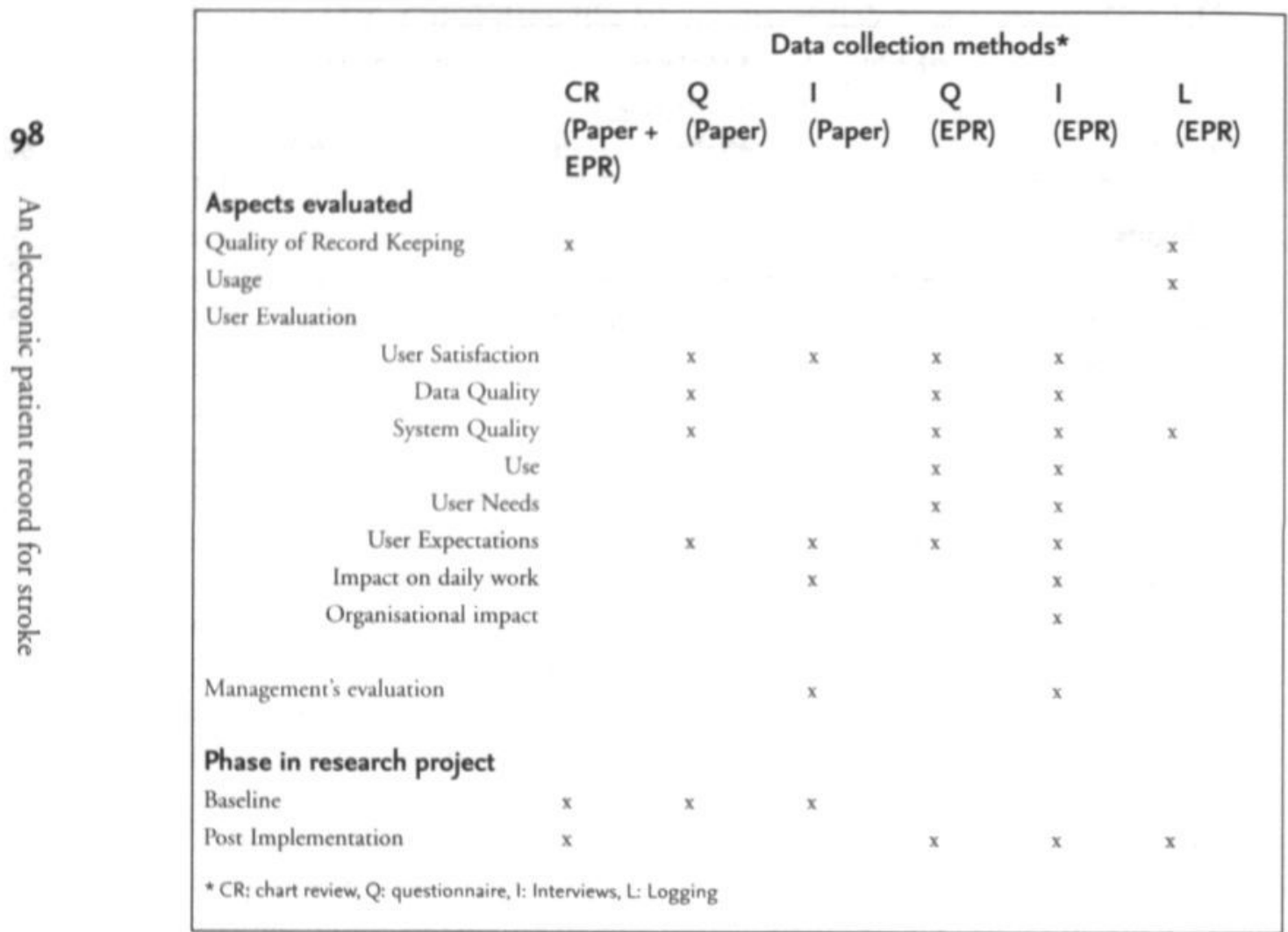

\section{QUALITY OF RECORD KEEPING}

To investigate the quality of record keeping during the EPR trial we analysed the paper and corresponding electronic patient records of all stroke patients admitted and discharged or deceased between October $1^{\text {st }} 2000$ and June $1^{\text {st }} 2001$. We compared these results with the baseline completeness analysis. The attributes rated were completeness of the medical intake form and discrepancies in information between paper records and electronic records. The completeness analysis concentrated on a set of medical intake items that had been selected in close consultation with a senior neurologist (Chapter 2). This set of clinical items was the minimum necessary for diagnosing stroke. 


\section{USAGE}

The EPR was equipped with a logging module that registered different actions, like log on/ log off, the name of the current screen, the type of information, like admission data or progress notes, and the userid. These data were stored in a database, separate from the actual patient data. In addition, entered patient data were categorised based on type of data, for instance intake data or vital signs.

\section{USER EVALUATION}

User satisfaction, user needs, expectations and other opinions were assessed by means of questionnaires and in-depth interviews. The aim of the interviews was to explain and supplement the results of the questionnaires. In addition, in the interviews the impact on daily work and the organisational impact were investigated.

\section{Questionnaire}

Immediately after the end of the trial period, EPR users received a questionnaire to assess their satisfaction with the EPR, to assess their knowledge of computers, their expectations of computer applications in health care, and required functionality. Two weeks after the initial questionnaire a reminder was sent. The questionnaire was divided into four sections. Section one, three and four were identical to the questionnaire used to collect baseline data (Chapter 3). Section two contained items concerning the respondent's satisfaction with the EPR. Eleven items concerning screen messages and the organisation of data on screens were added, as well as three statements concerning training and support. These items were scored on a 5-point Likert scale. Except for the last three, items were selected from previously developed questionnaires [6,7]. All items in this questionnaire were positively worded. Higher scores indicated that respondents were more satisfied, possessed more knowledge of computers, expected more positive effects or considered features to be more necessary. 
After the trial period in-depth interviews were held with twelve users. Six residents and six nurses were selected on frequent or infrequent usage. An independent interviewer did the interviews. This interview was divided into three clusters. Cluster one contained questions about the experienced positive and negative aspects of the EPR and the actual usage of the EPR in daily practice. In cluster two the respondents spoke about the development and implementation of the EPR, e.g. 'What did you expect from the EPR?' In cluster three of these interviews the expected impact of computer applications on several aspects of daily practice, like communication with colleagues within the department and within the hospital, the quality of record keeping, and expected changes in work procedures, were elaborated.

\section{MANAGEMENT'S POINT OF VIEW}

In addition to the users, the head of the department, a senior who was involved in the project, the head nurse and the informatician of the neurology department were interviewed by the same interviewer. The interview concentrated on their opinions about the course of the whole project, a reflection on their own role in the project, and what requirements an EPR and its implementation should meet in the future. In these interviews the positive and negative aspects of electronic records were only addressed indirectly. The results of these interviews were compared with the baseline interviews in which management reflected on the problems they had encountered until then, and positive as well as negative impacts they expected to occur after implementation.

\section{Data analysis}

Completeness was analysed in all electronic patient records containing a medical intake, and in their corresponding paper records. Missing items were counted per patient and the counts for paper and for electronic records were compared with a paired T-test, showing the effect of the computer. To compare the completeness of paper records before and after the implementation (reflecting changes over time), as well as to compare the medical paper records before and the electronic records after the implementation, the independent $\mathrm{t}$-test was used. The overall average scores for satisfaction, knowl- 
edge and expectations of health care applications were calculated. Statistical analysis was performed with SPSS version 10.0. All interviews were audio taped and transcribed. The transcripts of the interviews were analysed with the aid of QSR NUD*ist, a software package to structure qualitative data. Usage behaviour was analysed by combining the logging file that registered all login and log-out actions, save actions, switches between screens, and the data entered in the EPR. We concentrated on data entry actions, the type of data entered, intake data and daily-entered data, and the number of log-ins during the trial period. Usage was assessed with two attributes: the login frequency and the number of entries per patient record.

\section{Results}

Results of the different sources of information are combined when possible and necessary. Furthermore, baseline measurements are shown along with the trial measurements where relevant.

\section{Quality of record keeping}

The analysis of quality was limited to completeness. Discrepancies in information were hard to detect, because the number of completely filled in EPRs was too limited.

In the baseline measurement the completeness of medical intake data were analysed in 42 paper records. After the implementation, data of 100 patients were entered in the EPR. Residents entered the intake data of 54 patients. Of the corresponding 54 paper records sixteen were excluded from the analysis, because no proper stroke intake form was used (8), a print-out from the EPR served as paper intake form (identical to the EPR data and therefore excluded) (3), the intake form was missing (1), the clinical neurological paper record was unavailable in the medical archive (2) or there were no intake data available in the EPR (2). Thirty-eight usable combinations of paper and electronic patient records remained. One item was excluded in the comparison with the electronic records, because it had not been recorded due to a software error.

Paper records in the baseline had a mean of 2.38 (sd: $2.24 ; n=40)$ missing data, paper records post implementation 2.58 (sd: 2.31 ; $n=38$ ) and electronic records 0.89 ( $\mathrm{dd}: 1.29 ; \mathrm{n}=38$ ). A comparison of completeness of paper records before implementation and paper records after implementation 
showed no significant difference. However, a significant difference was found when the completeness of the electronic patient records was compared with the completeness of paper records before implementation (paper: mean: 2.25; sd: 2.05 ; $\mathrm{n}=40 \mathrm{vs}$. electronic: mean: 0.89 ; $\mathrm{sd}: 1.89 ; \mathrm{n}=38 . \mathrm{t}=3.476$, $\mathrm{p}=0.001$ ). Electronic patient records were also more complete than their corresponding paper records $(\mathrm{t}=4.58 ; \mathrm{p}=0.000)$.

\section{TIME TRENDS}

At three points in time the completeness of data in the EPR was analysed. After 4 months 19 patient records were included, between 4 and 6 months 8 were and between 6 and 8 months 29 were. As shown in table 2 the completeness of data tended to decrease during the trial period. The number of residents entering data increased from four to ten, the average number of missed items per patient increased from 0.90 at 4 months to 1.54 between 6 to 8 months. During the 8 months of regular use of the EPR the recording of the items did not significantly deteriorate. In several patient records, nurses entered blood pressure and pulse in their intake form if the resident, who filled in the medical intake form, did not enter any values. After distracting the nurses input from the data the average number of missed items per patient increased to 1.37 at 4 months and to 2.0 between 6 to 8 months. These changes were not significant.

\section{Table 2}

Data completeness in EPRs.

\begin{tabular}{|c|c|c|c|}
\hline & $4 \mathrm{mo}$ & 4-6 mo & 6-8 mo \\
\hline No of residents using the EPR & 5 & 4 & 10 \\
\hline No Records analysed & 19 & 8 & 29 \\
\hline Average number of missing items* & 0.90 & 0.88 & 1.54 \\
\hline $\begin{array}{l}\text { Average number of missing items without } \\
\text { nurses' input* }\end{array}$ & 1.37 & 1.38 & 2.00 \\
\hline - average number per patient record & & & \\
\hline
\end{tabular}




\section{Usage}

Figure 2 shows that the number of newly created electronic patient records gradually declined till February. Afterwards it rose until May. In correspondence with this trend, usage showed a gradual decline until February. In the first six months of the trial period few residents used the EPR. Nurses used the EPR much more frequently. After February, usage by nurses as well as physicians increased. Nurses entered more patient records than residents and they did more entries per patient record than residents. Although the number of logins showed a dip in February, the number of entries was rather high.

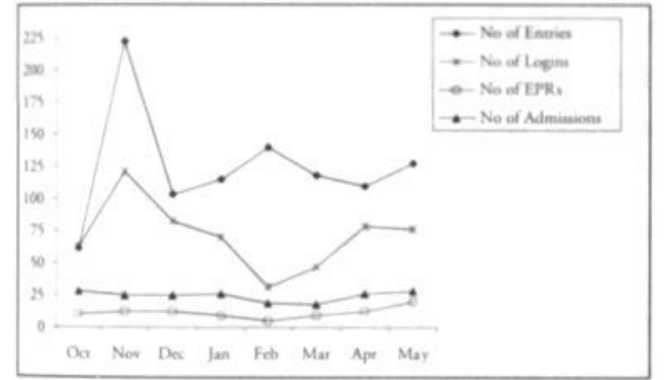

a

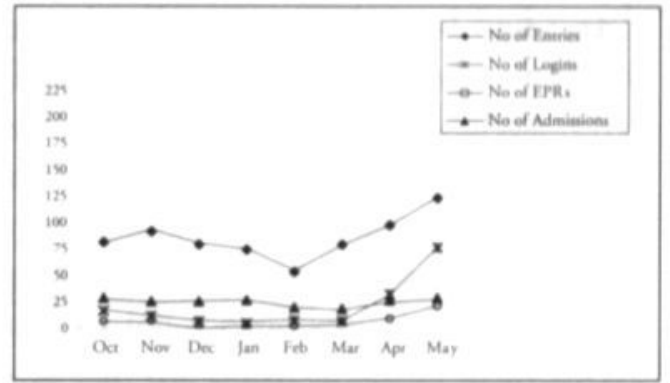

b

Figure 2

The number of electronic patient records, the number of logins, the number of entries per patient record, and the number of admissions in each month of the trial. a: Nurses; $b$ : Residents. No of admission of stroke patients of the whole ward. The exact number of stroke patients admitted directly to the medium care unit is unknown.

Table 3 shows the number of patient records in three categories. Patient records with less than 10 entries were excluded from the analysis. Category 1 comprised basic admission parameters, the nursing intake, vital signs and in some cases a few orders. The second category included medical and nursing intake data, progress notes, vital signs, and orders. The majority of the patient records contained all types of data (in addition to category 2: infusions, reports of meetings with patient and family, test results, summaries, etc.). 


\section{Table 3}

The number of patient records in three different data type categories. The categories are based on the number of entries.

Category 1
Nursing Intake
Vital Signs
Orders

Oct 2000

Nov 2000

Dec 2000

Jan 2001

Feb 2001

Mar 2001

Apr 2001

May 2001

total

2
2
6
1
1
1
1
11

11

\section{Category 2}

Category 1+ Medical Intake

Progress Notes

\section{Category 3}

\section{Category 2+}

All other data

An analysis of data collected after a considerable learning period ( 3 months) showed that at admission, nurses entered intake data plus orders and vital signs. During the course of an admission vital signs and daily progress notes were added to the patient record. The medical part of the patient record was filled only with intake data, and occasionally with progress notes and orders. The analysis of daily nursing data showed a data entry peak at the times of changes of shifts: shortly before 7:30 am, 14:30 pm and 22:30 pm, and in the afternoon data were entered at other times as well (figure 3).

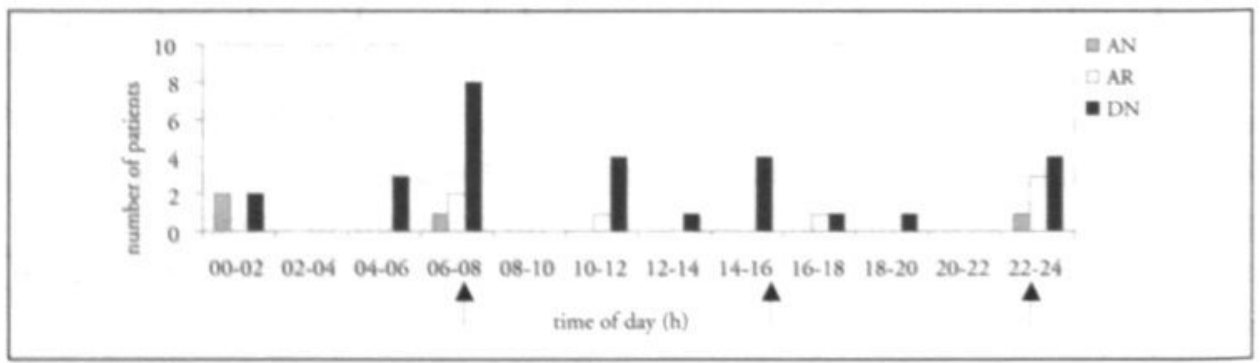

\section{Figure 3}

The number of patients whose data were collected: at admission by nurses (AN) and by residents (AR) or daily by nurses (DN) at different times of day in the first two weeks of Mayzoo1. Arrows indicate changes of shifts. 


\section{Users' evaluation}

The users' evaluation of the EPR consisted of a questionnaire, and in-depth interviews. In the interviews aspects of the EPR itself, data quality and system quality, as well as aspects of the project as a whole were addressed. The main themes emphasised by the interviewees were: (1) process of development and implementation, (2) user satisfaction, (3) impact on daily work, (4) users' expectations of electronic record keeping, and (5) requirements for future systems.

Thirty-four users received the post implementation questionnaire. The total response rate was $59 \%$; ten nurses and ten residents returned the questionnaire. One respondent returned the questionnaire empty with the remark that $s /$ he had worked at another department for 12 months and had never used the EPR. Two other respondents had never used the EPR and only filled in the general section. Their responses were excluded from the analysis. Five respondents were male, nine were female and the gender of three was not filled in. Thirteen respondents were younger than 40 years old, two were older and two did not fill in their age. Eleven respondents regarded themselves as experienced computer users and six felt inexperienced. The number of respondents after implementation was half the number before implementation and the number of respondents that answered both questionnaires was six. Therefore, data were descriptively analysed.

\section{Contact with developers}

Users who had been involved in the development of the EPR were satisfied with their role. Questionnaire respondents were satisfied with the training they received prior to the implementation. All interviewees remembered their initial training session and stated that it had been sufficient. The questionnaire results showed that 14 of the 16 respondents, who had used the EPR, knew whom to contact in case of problems with the EPR. This was confirmed by interviewees who could mention names and phone numbers of contact persons.

According to the interviewees the booklet served as an effective means of communication. Users jotted down remarks, questions and problems, the developer in turn wrote down answers to questions and tried to solve problems. Most users consulted the on-line help and the EPR's manual rarely; they preferred to consult colleagues or to contact the developers directly. 


\section{USER SATISFACTION}

User satisfaction with the EPR was assessed by means of a questionnaire and it was also an important aspect of the interviews. The mean overall satisfaction score was 3.23 (sd: $0.53 ; n=18$ ) out of 5 . Data entry and data retrieval had an overall score of 3.29 (sd: $0.48 ; n=18$ ) and 3.20 (sd: $0.84 ; n=17$ ) respectively. A complete overview of the questionnaire results is shown in appendix I. In the interviews many of these results were confirmed. While the questionnaire concentrated on specific functionality of the EPR and ease of use, the interviews addressed also other aspects relating to the EPR and electronic record keeping, like system quality, data quality and usage. They also showed that users were rather satisfied with the EPR as such.

\section{Perceived system quality}

According to interviewees, the EPR was easy to learn to use and, once learned, it was easy to use. This is not supported by the questionnaire results where six respondents were neutral, three respondents thought the EPR easy to learn, while eight disagreed with that statement. A similar discrepancy was observed for general user friendliness. Thirteen respondents were - generally speaking - dissatisfied with the user friendliness of the system, while one respondent was satisfied.

An aspect of ease of use that interviewees mentioned was the organisation of data on the screen. Some identified the tabbed structure of many forms as a shortcoming compared to the paper record, others expected that once they got used to the EPR, they could locate the data easily. These results agree with the questionnaire results that show that respondents are relatively satisfied with the user friendliness of the screens. The next quote illustrates the opinion of several interviewees:

\section{.... when you use it regularly, you'll find your way [in the EPR] easily}

In addition, interviewees had critical remarks regarding the quality of the system. Real software problems were identified and solved. These were for example a dysfunctional link with the database of the HIS and the inability to save data of the discharge form. Many perceived problems, however, could not be reproduced nor explained. Part of the criticism seemed due to lack of understanding of how the EPR functioned: 
Then I had some problems, because the progress report of the night shift appeared between the progress reports of the day and evening shifts.

Usually this is put at the end of the progress notes [in the paper record].

(a nurse)

This nurse did not realise that the electronic progress notes were in chronological order, like on paper, but that for reasons of usability only the last three reports were shown on the screen.

An important complaint concerned the availability of the EPR, which comprised two aspects. One aspect was reduced use now and then due to - real or perceived - software problems. The other aspect was a too small number of workstations. This was cited by both residents and nurses, who indicated that the patient record was needed at the patient's bedside, there where care was delivered:

.... and it is important too that I can bring it [patient record] with me to the patient, since it does not work when I examine the patient at his bedside and have to return to the nurses' station to document my findings. (a resident)

As a last aspect of the system, interviewees cited the lack of integration or linkage with other systems in the hospital. Users had expected more data to be available in the EPR. As an example, they mentioned laboratory results and radiology reports.

\section{Perceived data quality}

The EPR was complete for the domain of stroke, because users could document all relevant data for stroke patients. Moreover, it was clear where to enter what data. However, some interviewees noticed that data presentation was sometimes not accurate and reliable. According to them data appeared at wrong places in the EPR or was not stored at all. In addition, in agreement with the functional requirements saved data could not be changed anymore, which was felt to be impractical in daily work. The accessibility of data at multiple sites was not perceived as a great benefit. Users indicated that the patient records were consulted most at the patient's bedside and not elsewhere in the hospital. Moreover, they stated that the paper records were always available, thus an EPR could not improve availability and accessibility of patient data. 
Five of the EPR users said to have used it less than ten times and twelve of them more than ten times during the whole trial period. When these results were compared with the actual number of logins, nine approximated their real usage, while seven underestimated or overestimated their real usage. On the one hand, interviewees acknowledged that stroke patients were a good group to try. On the other hand, they were reluctant to use the EPR, since it was only for stroke patients, and not for the whole ward or the hospital. In the interviews respondents stressed that they felt urged to use the EPR, and in parallel the paper records. Therefore, many indicated that they hardly consulted the EPR and only entered data. Responses to the questionnaire show that three nurses retrieved data, five residents entered data and three residents retrieved and entered data in the medical part of the EPR. One nurse and three residents retrieved data, while three nurses entered and retrieved data from the nursing part of the EPR.

Two of the interviewed residents had only used the EPR in night and weekend shifts, the other four had used it daily for some time. The interviewed residents indicated that few had used the EPR at the emergency department, which confirmed the questionnaire results. The latter results show that one resident used the EPR in every shift; two others used it in some shifts. Additionally, one resident used the EPR in every shift in the staff rooms at the ward, whereas three did this during some of their shifts. In the inpatient clinic the EPR was used most extensively with three users in every shift and 14 users in some of their shifts. The number of stroke patients at the ward varied each day with some days without any stroke patient, which explained that not in all shifts the EPR was used.

\section{IMPACT ON DAILY WORK}

Interviewees were satisfied with the user friendliness of the screens, and they stated that the EPR was easy to use. Furthermore, they assessed positively that the EPR integrated medical and nursing information into one patient record, although they did not benefit a lot in this project. In the daily routines of ward rounds and shift handovers, the paper medical and nursing records remained the primary source of information. The EPR caused extra work for the nurses and residents, since they kept both paper and electronic records for stroke patients. As main reason respondents cited that back-up facilities were not realised. The second reason was that users did not fully rely 
on the EPR, because of the (perceived) software problems. The third reason that respondents posed was that only part of the ward used the EPR which meant that at handovers paper records needed to be available.

According to the interviewees, consulting physicians refused to use the EPR, because it was unfamiliar to them. In addition, the EPR was too specific and lacked links with other relevant data sources. Some interviewees - who had used the EPR a few times - complained about the difficulty to get an overview of the progress and present state of a patient.

\section{Organisational impact}

None of the interviewees had personally perceived any influence on the communication between nurses and physicians, not in the ward handovers, nor during ward rounds. Moreover, none had experienced a shift in responsibilities between residents and nurses. In addition, not one of the interviewees expected such to occur in the future.

\section{USER NEEDS}

Part of the questionnaire concerned the desired functionality of IT applications in health care. The questionnaire results are shown in the appendix. In general, users' opinions did not change drastically, the majority of the functions or features that were felt important in the baseline study, were so in the evaluation phase. One exception was that the percentage of respondents, who wished that implementing an IS could occur without changes to the established clinical routines, increased from 26 to 42 percent after the EPR implementation.

None of the interviewees expressed additional wishes with respect to the content of the stroke EPR, because in their opinion it was complete for its purpose. Reliability and constant availability were indicated as a primary requirement in interviews and in the questionnaire results. A second basic requirement following from the questionnaires and interviews was accessibility of the EPR. Questionnaire results showed that, like in the baseline questionnaire, most respondents wanted access to the EPR where they needed it. Also in the interviews, respondents repeatedly stressed the necessity of availability at the patient's bedside, illustrated with the next quote. 
It is most convenient to do that at the patient's bedside; to write down the answers of a patient immediately. If I have to go to a computer three doors further or two meters away, it does not work. (a resident)

A third requirement was to have a single EPR for the whole hospital to prevent for example the problems with the consulting physicians who refused to use the EPR. A related request was a link between all availably patient data repositories, like the HIS and an EPR. Furthermore, several users advised to gradually implement a new information system (IS) by starting hospital wide with a limited number of functions and extend the IS function by function.

\section{USER EXPECTATIONS OF IT IN HEALTH CARE}

Expectations users had of IT applications in health care hardly changed after the implementation of the EPR (appendix). Both before and after the implementation respondents did not expect many effects of IT applications on health care.

When asked for their expectations of electronic record keeping in general most interviewed nurses stated to have had few expectations beforehand. The only expectation they had was a reduction of double work and copying of data, which was not realised. One resident regarded legibility and no loss of data as advantages of an EPR. The integration of a nursing and medical record could have an effect on patient care, according to some interviewees. General aspects as multi-site availability, continuous availability, and timeliness of data, however, would not. Two residents expected that their record keeping time, in comparison with paper record keeping, would increase permanently with electronic record keeping. Most respondents supposed that daily routines like the frequency of documenting patient data, ward rounds, shift handover would not change. Additionally, nurses did not expect the quality of care to change, since

the [patient] care must be organised and given, whether I write or type my information. (a nurse)

\section{Management's point of view}

In the baseline measurements and after the trial period of the EPR the head of the department, the head nurse, the department's ICT manager, and a 
senior neurologist (only after implementation) were interviewed about the project and the EPR, and their expectations.

\section{EXPECTATIONS OF ELECTRONIC RECORD KEEPING}

Both heads participated in this project because they strived for higher quality record keeping. Their expectations did not change during the project. In their view paper records were often incomplete, and their expectation had been that an EPR was a possible means to achieve quality improvement. They expected the integration of the medical and the nursing record in the EPR to improve record keeping, to reduce the copying of data and to prevent the transfer of information by telephone or quickly scribbled notes. Particularly for nurses the last aspect would reduce interpretation errors and uncertainty about responsibilities. The ICT manager and the neurologist had been rather sceptical about the chances of success of this project, primarily because the EPR was for stroke only and because they had had negative experiences in the past with ICT projects in daily routines.

\section{Evaluation of the EPR PRoject}

The development approach, prototyping, was considered valuable. The manager who had been closely involved in this process was very satisfied with that way of incrementally building an EPR.

Prior to the implementation, the stability of the database had been a source of concern. However, the database had never become unstable and there had never been a restore of the database during the trial. Nonetheless, most of the problems management had expected beforehand occurred after or during implementation. All agreed that, although all parties had done their best, the project could have been better prepared. Management noted that the project was too much a stand-alone project. The EPR did not really fit into or onto the existing HIS and that made consulting physicians reluctant to use the EPR. They also noted that collaboration with the hospital's EDP department started rather late. Moreover, contrary to initial agreements, back-up facilities could not be realised. Management agreed with EPR users that they had to maintain a paper record to have a back up and to have a patient record for other disciplines, making it extremely difficult to fully exploit the EPR and abandon paper completely. In addition, the project budget was too tight. Afterwards all concluded that a next EPR-project should be better embedded 
in the organisation, meaning that the EDP department and other disciplines should be involved in such a project in a very early stage.

\section{OWN ROLE: THIS TIME, NEXT TIME}

All managers were asked for their role in the project and what they would do differently a next time. None of them was unsatisfied. However, they stressed the importance of embedding such a project in the existing organisational and information structures. A next time they would improve communication within the department and within the organisation to create support for such a project or system, support within the department, but also in the hospital. Management acknowledged that users had few expectations of the EPR, partly because management had insufficiently informed and encouraged them.

\section{We did not enough marketing, you could say. (a manager)}

Also the organisation had not been involved until late in the project. In a next project, the EDP department and other disciplines will be involved earlier and more closely. They will also try to have such a project and such a system embedded in the organisation's information systems and strategy.

\section{Discussion}

In medical informatics the focus of information systems evaluations is shifting from a purely technical focus to studying the interaction of users with the system and their surroundings. Social, organisational, political and other nontechnical factors are often insufficiently addressed in purely quantitative studies, while they may be very important for a successful implementation. Therefore, several authors advocated to alter the approach to health care information system evaluations and to include qualitative methods [8-11]. In agreement with these developments, we adopted an approach that combined quantitative and qualitative methods. As our results show, the different data collection methods yielded rich data, supplementing each other, and providing a rather complete picture. In particular, questionnaire and interview results complement each other well. The questionnaire results reflected the general feeling users had. In the interviews users were stimulated to reflect on specific aspects to refine their general judgements. Just that made our evaluation valuable, 
since it can, for example, explain discrepancies between questionnaire and interview results regarding user friendliness of the EPR. As suggested previously [12], we did not restrict to technical issues. We included a variety of concerns like quality of record keeping, user satisfaction, quality of the EPR, as well as usage behaviour. Not only the point of view of users -nurses and physicians - was included, but also management's opinions were. In addition, the evaluation started before the development of the EPR.

In Chapter 1 we described a framework to evaluate patient care information systems. In our evaluation, we had the opportunity to test the usability of our framework. It was a useful framework to organise our evaluation. The attributes assessed, like completeness of record keeping, collaboration of health care workers, direct benefit, impact on patient care, etc., were systematised clearly and were, in our opinion, relevant aspects.

Furthermore, in this evaluation study we tried to answer several research questions. Our first research question was: what consequences does this EPR have on the completeness of record keeping? As the results showed, the electronic records were more complete than their paper counterparts and than the paper records before the EPR implementation. This seems to be a result of the EPR, since there is no difference between the completeness of paper records before and after implementing the EPR. Given the situation, we had not expected any improvement. After all, the paper record remained the main data source and users were reluctant to use the EPR. Nonetheless, as was reported previously, this shows that an EPR can improve the completeness of record keeping [2]. It also confirms that inconsistencies occur when patient records are kept in parallel [13].

A limitation of our study is that we selected only intake items for completeness analysis. It can be argued that this list could have been extended to several other, general, clinically relevant items. However, we focused on timely and adequate diagnosis upon admission and the neurologist selected the items accordingly. In addition, if the completeness of the already structured intake items improved, an improvement may be expected for other items that were unstructured on paper and structured in the EPR [14]. Further, besides completeness, also correctness could be a valuable attribute of quality of documentation $[15,16]$.

Our second research question was: what consequences does this EPR have on the daily work of nurses and physicians? The integration of medical and nursing record was acknowledged to have potential benefits in an EPR-only situation. However, the double work in documenting data on paper and in the EPR was experienced as a burden, making it very hard to discern any benefits. The extra work was the main impact on daily work. Nevertheless, we 
sustain our expectation of positive results on health care provider efficiency and quality of care in situations without double record keeping [3, 17, 18]. Additionally, it might be expected that an EPR proves useful with a lot of historical information of many (readmitted) patients. This benefit, however, is realised only after a considerable period of regular use. The third research question, what consequences does this EPR have on the opinions of nurses and physicians about electronic record keeping?, was somewhat difficult to answer. In general, users judged the EPR depending on their experience with it. In the interviews a difference existed between frequent and infrequent users regarding the user friendliness. Infrequent users were unfamiliar with the EPR, and therefore, they had to search for the location of items. Once found, also they found data easy to enter and easy to interpret. Possibly the software problems that could not be reproduced were difficulties encountered by users who were not very familiar with the EPR. It is plausible that their expectations of how the EPR would respond to specific actions did not correspond with the true responses. Hence, the structured data entry forms provided potential benefits, but only after users had become familiar with the EPR. The fourth research question was how is the usage behaviour of users? Usage behaviour is likely to depend on the familiarity with the EPR. We had expected that at the start of the trial users would 'collect' many data to enter them all at once and that they would enter more frequently and less data at once toward the end of the trial. We were unable to analyse this carefully, because the paper records remained the primary source of information. Our next research question was what are management's experiences? Management focussed on two themes. The first was that the contribution of others was underestimated. The second issue they addressed and would improve in a future project was the communication within the department and within the entire organisation. According to them, communication had been insufficient. Nevertheless, they were encouraged in their initial expectations that electronic record keeping had potential and was feasible.

The objective of the current evaluation was to study what consequences an EPR would have in daily practice. The explorative character of qualitative methods made them valuable to realise this aim. Furthermore, the intention was to have an incremental and formative design of our EPR. This was realised by the many informal contacts between developers, researchers and users during the trial. These contacts were a source of continuous input to improve the EPR. The most suitable study design in this setting was a before/after study design: the intervention was on a very small group of users and there was no comparable ward available. Nevertheless, we recommend further research to best possible designs to evaluate health care information systems. 


\section{Was the project successful?}

In terms of success and failure, this project may be considered a relative success, although not all initial objectives were met. For example, not all health care providers involved in the care for stroke patients used the EPR and of only part of the stroke patients all data were entered in the EPR. Nevertheless, as a learning trajectory this project was successful. This was illustrated with the following: 1) the EPR had been up and running and contained all essential information, 2) the department had become aware of the problems and pitfalls when introducing an EPR, 3) management had seen that an integrated medical and nursing electronic record could be realised and had users seen actually using this EPR in daily practice, even users who were complete computer-illiterate.

For several reasons the EPR never replaced the paper medical and nursing records. First of all, paper forms were maintained for data collection of other than stroke patients. One choice that influenced the course of the project was to limit the scope of the EPR to one disease, albeit an important one in the field of neurology. During the trial the number of stroke patients varied a lot, and the number of non-stroke patients increased. As a consequence, users had to maintain more paper records than anticipated. Second, without the back up facilities users had to maintain their paper records besides the EPR for legal reasons. In practice, whether or not the EPR was filled in depended on the time left. Third, insufficient communication with other departments in the hospital partly caused the lack of back-up and support facilities. Also the refusal of consulting physicians to use the EPR originated in sub optimal communication. Fourth, a tight budget resulted in a reduction of the initial number of PCs, which, in turn, was perceived as an inadequate availability and accessibility of the EPR by the users. Accessibility of the EPR was limited to five workstations, while users wanted the patient record at the patient's bedside. The consequence was that they had to scribble notes on a piece of paper and copy it into the EPR later. Hence, users lost in this respect. Fifth, a lack of experience with this kind of projects resulted in an underestimation of both costs and efforts that would have been necessary to create the conditions for success.

A set of functional requirements for the EPR was identified prior to the project. More complete requirements resulted from the project. An important addition was the integration of different data sources. Initially, the co-existence of the HIS and the EPR at each PC had been expected to suffice. However, after implementation, management recognised a need for further integration an EPR in the information systems already in use in the hospi- 
tal. Users even requested to have one single EPR for the whole hospital with the HIS data integrated. More likely, the hospital would prefer one user interface and common functionalities in all systems. Regardless the technical realisation, the users need to perceive different systems as one [19]. To achieve this, a gradual expansion of functionality - hospital-wide - might be a better way to full electronic record keeping [20], although this might 'invite' inpatient departments to develop own EPR initiatives.

\section{Conclusions}

The main reason for this project had been the need to support information exchange in the process of care of stroke patients. The expectation was that an EPR could provide enough functionality to fulfil that need. This pilot was started, because hospital developments toward electronic record keeping advanced slowly. Hospital wide electronic record keeping has not been realised five years after the start of the pilot. The results of our evaluation also show that the respondents who were familiar with computers and with the EPR were more positive in their judgements. In other words, it will take some time before users learn to appreciate an EPR and before they can identify possibilities instead of only limitations. Clear short term and long-term benefits that appeal to users can support this trajectory.

This evaluation showed once more that communication is crucial for success $[21,22]$. Communication with all stakeholders, users and the information department is important; in fact, the whole organisation should be adequately and timely informed to create sufficient support.

This pilot yielded requirements for an improved version of an EPR and showed that an integrated EPR can support information exchange. It also provided insight in the problems surrounding electronic record keeping and the opportunities it can create.

\section{References}

1 Dick RS, Steen EB, eds. The Computer-based patient record: an Essential Technology for Health Care. Washington DC: National Academy press 1991.

2 Tang PC, LaRosa MP, Gorden SM. Use of computer-based records, completeness of documentation, and appropriateness of documented clinical decisions. JAMIA. 1999; 6 (3): 245-51. 

ratives and its effect on the speed and completeness of information retrieval. JAMIA. 1998; 5 (6): 571-82.

Tange HJ. Consultation of medical narratives in the electronic medical record. Meth Inform Med. 1999; 38: 289-93.

5 Tange HJ, Dreessen VA, Hasman A, Donkers HH. An experimental electronic medical-record system with multiple views on medical narratives. Comput Methods Programs Biomed. 1997; 54 (3): 157-72.

6 Tange HJ. The paper-based medical record - Is it really obsolete? Comput Methods Programs Biomed. 1995; 48: 127-31.

7 Lewis JR. IBM computer usability satisfaction questionnaires: psychometric evaluation and instructions for use. Int J Human-Comput Interact. 1995; 7: 57-78.

Forsythe DE, Buchanan BG. Broadening our approach to evaluating medical information systems. Proc 15th Annu Symp Comput Appl Med Care. 1991;: 8-12.

9 Kaplan B. Evaluating informatics applications - some alternative approaches: theory, social interactionism, and call for methodological pluralism. Int J Med Inf. 2001; 64: 39-56.

10 Beuscart-Zephir MC, Brender J, Beuscart T, Menager-Depriester I. Cognitive evaluation: How to assess the usability of information technology in healthcare. Comput Methods Programs Biomed. 1997; 54: 19-28.

11 Anderson JG, Aydin CE. Evaluating the impact of health care information systems. Int J Technol Assess Health Care. 1997; 13: 380-93.

12 Kaplan B. Addressing organizational issues to the evaluation of medical systems. JAMIA. 1997; 4: 94-101.

13 Mikkelsen G, Aasly J. Concordance of information in parallel electronic and paper based patient records. Int J Med Inf. 2001; 63: 123-31.

14 Shiffman RN, Brandt CA, Freeman BG. Transition to a computer-based record using scannable, structured encounter forms. Archives of Pediatrics and Adolescent Medicine. 1997; 151: 1247-53.

15 Hogan WR, Wagner MM. Accuracy of data in computer-based patient records. JAMIA. 1997; 4: 342-55.

16 Brennan PF, Stead WW. Assessing data quality: from concordance through correctness and completeness to valid manipulatable representations. JAMLA. 2000; 7 (1): 106-7.

17 Garrett LE, Hammond WE, Stead WW. The effects of computerized medical records on provider efficiency and quality of care. Meth Inform Med. 1986; 25: 151-7.

18 Tang PC, Fafchamps D, Shortliffe EH. Traditional medical records as a source of clinical data in the outpatient setting. Proc Annu Symp Comput Appl Med Care. $1994 ;: 575-9$. 
19 Kuhn KA, Giuse DA. From hospital information systems to health information systems - Problems, challenges, perspectives. In: Haux R, Kulikowski CA, eds. IMIA Yearbook: Schattauer 2001: 63-76.

20 Atkinson CJ, Peel VJ. Transforming a hospital through growing, not building, an electronic patient record system. Meth Inform Med. 1998; 37: 285-93.

21 Lorenzi NM, Riley RT. Managing change: an overview. JAMIA. 2000; 7: 116-24.

22 Lorenzi NM, Riley RT. Organizational aspects of health informatics. Managing technological change. 1st ed. New York: Springer-Verlag 1994 


\section{Two patient care information systems in the same hospital: beyond technical aspects}




\section{Introduction}

In recent years awareness has grown that introducing information technology in the daily routines of health care is more than installing computers. The whole process of design, development and implementation requires participation and influence of the potential users [1-5]. This awareness also implies that not only the end-users themselves, but also their work practices should be considered carefully when designing information systems for health care settings [6]. Since introducing a patient care information system results in changes in work practices, adequately managing these changes is a prerequisite for system success. In this process both the magnitude of change and the organisational culture are very important [5]. Thus, to assess the success of an information system, also organisational and cultural factors should be evaluated.

The authors had the opportunity to concurrently evaluate two different clinical workstations in the same hospital. Both were patient care information systems. In table 1 they are compared with respect to their functionality.

\section{Table 1}

Functionalities of both clinical workstations.

\begin{tabular}{|lll|}
\hline Clinical workstation & A & B \\
Domain & General & Stroke \\
Content & Limited & Complete patient record \\
Use & Data retrieval & Data retrieval + Data entry \\
Availability & Outpatient and inpatient dinic & Inpatient clinic \\
Users & Physicians only & Physicians + Nurses \\
\hline
\end{tabular}

The purpose of this paper is to compare the impact of both systems with respect to organisational, cultural and human factors. To explore these in our study, the following research question was phrased.

How do clinical workstations affect clinical work and what are prerequisites for effective implementation of clinical workstations? 


\section{Background}

The evaluation studies were conducted at the University Hospital Maastricht, the Netherlands. Clinical workstation A was Mirador ${ }^{1}$, a graphical user interface (GUI) to the existing hospital information system (HIS). Clinical workstation B was a disease-specific electronic patient record for stroke (stroke EPR).

\section{Mirador}

Mirador was introduced in 1997 in three outpatient clinics to replace the old character-based HIS interface. At first, only the laboratory results were available, but gradually reports of several examinations as well as discharge letters of different departments have been disclosed. However, up till now the medical narratives have been maintained in paper records. In all outpatient clinics, at the emergency unit, and in most of the inpatient clinics, physicians have access to patient data of the HIS via Mirador. Also the old characterbased HIS-interface is still available. So far, access has been limited to physicians and the system has no data entry facilities. In the outpatient clinic, the physician loads all data of visiting patients before the consulting hour. In the inpatient clinic, physicians search for data of individual patients on a realtime basis.

\section{Stroke EPR}

Additionally to the hospital-wide developments, several departments experimented with department specific information systems. One of these systems is an experimental stroke EPR, which was installed in 2000 for a trial period of one year. This stroke EPR was developed with active user involvement. It is a combined medical and nursing record system that facilitates both data entry and retrieval of data relevant for the care of inpatient stroke patients and has the potential to replace the paper records completely. The stroke EPR was, in addition to Mirador, installed on clinical workstations at the stroke unit, at the emergency department, in the nurses' office, and in the physicians' offices. All residents of the department and the nurses working at the medium care unit (part of the "stroke unit") used the stroke EPR. Stroke patients comprise the vast majority of the neurological patients and they predominantly populated the medium care unit. Therefore, it was expected that after the implementation of the system, paper record keeping 
would be limited to occasional non-stroke patients. It seemed an excellent setting for a pilot study. The stroke EPR and its setting have been described in Chapters 2 and 4.

The trial with the stroke EPR was complicated by the fact that other than stroke patients formed a significant part of the population of the stroke unit during this period. Hence, paper records could not be abolished at the stroke unit.

\section{Method}

The evaluation studies were conducted separately, but concurrently, and similar methods were applied to collect and analyse data.

\section{Data collection}

\section{Mirador}

Four years after the initial implementation the EDP department decided to evaluate Mirador. To this end, a short questionnaire about the use and appreciation of Mirador was distributed among all registered users of the system. The results of this evaluation are shown in appendix II.

Based on usage statistics per department, collected in the first quarter of 2001 , four departments were selected for in-depth interviews. The frequency of use and the distinction between surgical and nonsurgical fields of medicine were decisive selection criteria. From the surgical and nonsurgical disciplines, the department with the most frequent and the least frequent use of Mirador were selected. Three physicians from each department - a resident, a specialist with many years experience and a specialist with a few years experience - were interviewed about their appreciation of Mirador, and problems, needs, and wishes concerning Mirador. These were open-end interviews, conducted by an independent interviewer. All interviews were audio taped and transcribed for subsequent analysis.

\section{STROKE EPR}

Towards the end of the one-year trial period the system was evaluated. This evaluation included chart reviews of electronic and paper patient records, 
analysis of usage logs, and a questionnaire to assess the satisfaction of users with the stroke EPR. In addition, twelve end-users and four key players in the project (the head of the department, the head of nursing, a specialist involved in the project, and an informatician) were interviewed by an independent interviewer. These were in-depth interviews on their satisfaction, problems, expectations and wishes concerning the stroke EPR. We also made an inventory of which features were considered necessary for an ideal stroke EPR.

All interviews were audio taped and transcribed for subsequent analysis. In this paper we concentrate on the results of the interviews with end users. The complete evaluation of the stroke EPR is presented in Chapter 5.

\section{DATA ANALYSIS}

The transcripts of all interviews were coded and analysed with the aid of QSR Nud*IST, a software package for analysis of qualitative data. Coding started with the initial interview topics. The coded sections of the interviews yielded other search terms and key words. In an iterative process relevant sections from different interviews were identified and recurring themes emerged.

\section{Results}

\section{Mirador}

Usage statistics revealed that urology and pediatrics were departments with relatively the most infrequent users, whereas internal medicine and obstetrics and gynaecology were departments with many frequent users of Mirador. Three physicians of those four departments were selected for the interviews. Each interview lasted 30 to 45 minutes. Four main points of interest emerged after coding and analyzing the transcripts: (1) System and information quality, (2) Use, (3) Training and Support, and (4) Communication.

One remark must be made regarding the selection criterion of departments. Interviewees of urology stated to use Mirador frequently, although they were selected for their relative infrequent usage of Mirador. We therefore refer to respondents of urology, internal medicine and obstetrics and gynecology, when speaking about users of frequent users. 


\section{SYSTEM AND INFORMATION QUALITY}

Mirador was user friendly and easy to learn. Respondents benefited from the easy access to relevant data of other specialties. However, the interface of Mirador increased the risk of reduced information awareness according to many respondents. They mentioned as a major advantage of the old HIS interface the low risk to overlook relevant information.

Interviewees had a common complaint about the availability of radiology reports during outpatient encounters. A growing backlog of entering reports by the radiology department meant that many reports were still unavailable via Mirador during patient encounters after radiology examinations. According to respondents this backlog was caused by a lack of personnel.

\section{UsE}

Respondents of pediatrics indicated that they and their colleagues still used the character-based HIS interface. In their opinion, Mirador offered no clear benefits, since the paper record supplemented with the HIS data presented via the old HIS interface accurately provided them the necessary information. They said not to recognize the benefits, but they were unfamiliar with the exact functionality of Mirador. Another important reason for non-use or limited use was a shortage of PCs and of sufficiently powerful PCs, according to the pediatricians. Particularly, in the inpatient clinic and operating theaters the PCs available could not even run Windows.

In contrast, respondents of urology, internal medicine and obstetrics and gynecology were very enthusiastic about Mirador. However, frequent users cited considerable differences in use in different settings. In outpatient clinics and in staff rooms, Mirador had become indispensable. The long startup time was not a problem there, since the physician logged in before starting the consulting hour and logged off before leaving the office. In inpatient clinics, however, the information need was less predictable and the workflow allowed no time to wait for logging on and starting up Mirador. Hence, in the inpatient clinic frequent users oftentimes requested tests again or phoned the laboratory for results, rather than checking whether or not a patient had had a certain test recently. 
None of the interviewed residents received training in using the system. Nevertheless, those who used it indicated that it had been easy to learn. On the other hand, a handout containing the main functionalities of Mirador would have been convenient. Specialists, who received training, were content.

In most cases users knew whom to contact in case of problems. However, they cited that these informaticians were overloaded with work and often had little time to solve a problem. If they received help, they were content with the support provided.

\section{COMMUNiCATION}

Frequent users stated to have high expectations of electronic record keeping - including data entry - and they indicated to be willing to put effort in integrating EPRs in their daily work. Therefore, clinicians who used Mirador welcomed it as a first step towards an EPR. However, uncertainty existed about a next step. None of them was aware of the strategy of the hospital regarding the use of IT in the health care process. Despite the existence of such a strategy, the respondents expressed a feeling of absence of an organisational policy.

First, a resident expressed surprise that the hospital did not- at least not to his knowledge - explicitly encourage physicians to use the new Mirador instead of the old character-based HIS interface.

Second, users regretted that there was no working group investigating the requirements or wishes of the daily users. Several interviewees noted that a working group could help to further develop and expand the current system toward a complete EPR. In such a working group all parties should be represented. In the present situation, the communication between the informaticians and physicians was limited to the problems to be solved.

Third, departments like radiology and the EDP department had insufficient capacity, the first to enter reports timely and the second to adequately solve all problems encountered. This caused one frequent user to conclude that the hospital did not aim at increasing efficiency. In addition, the number and power of the PCs were insufficient at certain departments.

Fourth, one frequent user had the impression that, at present, many departments had their own policies concerning electronic record keeping: "No, I do not have the feeling that there is one central policy. I think that it differs for every 
department.." (a resident). Another user supported this with "[A policy] yes, locally, at the ICU, but according to me it stopped there.." (a specialist).

\section{Stroke EPR}

Each interview lasted 30 to 45 minutes. From the analyses of the interviews the following three themes appeared to be of high importance to the respondents: (1) System and information quality, (2) Use, (3) Communication in the project.

\section{SYSTEM AND INFORMATION QUALITY}

In general respondents noted that the stroke EPR was very user friendly. Both nurses and physicians perceived the system to be easy to use. Residents even stated that data entry in the medical admission form was faster than in its paper counterpart. Physicians entered data of patients at the emergency department so nurses had access to these data before the patient arrived on the ward. One nurse and two physicians assessed this positively. In addition, both the medical and the nursing record were easily accessible and always available together. This was perceived as an advantage:

the advantage is, all information is centralized with the patient, so you have no need to search for the nursing record, it [the nursing record] is there ( a resident).

Nevertheless, most physicians observed no immediate tangible benefits of the system and preferred the paper records. Paper records gave them more overview, they said, although some expected it to be a matter of time before having the same level of comfort with a stroke EPR. Also the interviewed nurses perceived no clear benefits of this stroke EPR in comparison to the paper records, although it was easy to use for data entry as well as for data retrieval.

An important point of criticism was the availability of the system. The stroke EPR was available at those locations where nurses and residents did most of their administrative work and held the shift handover. Many respondents, however, wished to use it at the patient's bed, like they did with the paper records. 


\section{UsE}

According to the end-users the stroke EPR was not always available or fully functional. For instance, sometimes a new patient could not be admitted or the data entered disappeared to reappear the next day. One nurse acknowledged that computer illiteracy could explain some problems:

..probably we could have resolved them [problems with the computer] ourselves, but it could have been ignorance from our side [users].. (a nurse).

However, respondents understood that not all problems could be solved immediately.

Several residents complained that they used the stroke EPR too infrequently to get experienced. Only three of them worked daily with the stroke EPR, while the other three used it only during their evening and night shifts, only four times a year a one-week period.

\section{COMMUNICATION IN THE PROJECT}

Residents felt adequately informed about the stroke EPR project, they also felt that their group had been sufficiently involved in system development. Most of the nurses felt adequately trained, but they did not remember any clear involvement of nurses during system development. Communication with the developers was satisfactory to all respondents, whether it concerned technical problems or content related issues.

Users did not have a clear vision of the objectives management had with this EPR. This was illustrated with different views concerning the purpose of the stroke EPR project. One view was that the stroke EPR should have made life easier for them, by decreasing the time spent on administrative tasks and by improving the overview of data. Another was that it was meant to provide easy access to research data.

The consulting clinicians from other departments had been expected to use the stroke EPR as well, but they refused, which meant unanticipated extra work for the residents and nurses. According to the interviewees, this refusal was due to the fact that consultants perceived the stroke EPR to be yet another system in the hospital. 


\section{Discussion}

In the next two paragraphs the differences between and similarities of both workstations are summarized. The lessons learnt section draws upon the main themes that the evaluations had in common. These themes concern important aspects of clinical workstations: the support of daily work, an organisational and culturally defined issue like communication, and a distinction in requirements of clinical workstations for inpatient and outpatient clinics.

\section{Differences between workstations}

As expected, considerable differences existed between the two systems. First of all, the number of workstations for the stroke EPR was too limited, whereas the PCs for use of Mirador did not always meet the requirements. Second, the stroke EPR contained all required functionality, while the functionality of Mirador was not complete and it was not extended fast enough according to the respondents. Third, consulting physicians from other departments refused to use the stroke EPR, although we initially assumed that they would. The stroke EPR was very specific and consultants were confronted with it, only at the stroke unit. In contrast, Mirador had little functionality, contained a lot of information that was relevant to many health care workers and was hospital-wide available. All that might have made it easy to accept.

\section{Similarities between workstations}

Based on the interviews the following similarities between both systems were observed. First of all, most users considered both systems to be very user friendly. Second, users had information collected by other disciplines readily available and identified that as an improvement of the coordination between disciplines. Third, users stressed that immediate support was a prerequisite in health care practice, since patients should not need to and often cannot wait. In other words, the ever-increasing dependence on technology poses new challenges to resolve. Fourth, communication between the informaticians, management and the end-users was insufficient. Users were unaware that both Mirador and the stroke EPR were only a first step in a process. Also, the benefits of either system were unclear to some of the respondents. 


\section{Lessons learnt}

Clinical workstations are installed with various purposes and in various forms. All are intended to contribute to health care work. Both workstations in the present study were perceived to contribute positively to health care work. The results indicated that benefits need to outweigh the extra efforts before users decide to use a certain workstation. It is plausible that in case of Mirador this situation was reached sooner than for the stroke EPR.

Previously, the integration of information from different sources has been reported to improve coordination and communication between health care providers [7]. Our results also indicated that coordination between health care providers is enhanced. Mirador provides easy access to data previously difficult to obtain like discharge summaries of other specialties, and users reported to benefit from that. Users of the stroke EPR identified benefits of the combination of medical and nursing records: they always had both records available, and at admission, the time before relevant data became available was reduced. Thus, disclosing data from different disciplines had a positive effect on the communication between them irrespective the functionality of the clinical workstation.

Effective communication between parties, however, influences the diffusion of an innovation $[8,9]$. In the stroke EPR project we inferred the insufficient communication from the diversity of goals that were identified. To those who perceived Mirador and the stroke EPR to have no direct benefits, the potential benefits - short term or long term - apparently had not adequately been communicated. Likewise, to some respondents the necessity of Mirador was not evident, since more familiar alternatives were still available. More importantly, they were unaware of all functionality of Mirador. Most users of the stroke EPR had no clear view on its purpose and experienced no immediate benefit. The persistence of a paper record for other than stroke patients and the perceived technical problems provided excellent excuses for not using the stroke EPR.

Also, communication about future goals and intended benefits between management and end-users was not optimal. The interviewees were unaware of the existing organisational policy towards computerizing paper records. They were interested in it, but failed to notice it. Thus, had there been a better dialogue between management, users and developers/ implementers, then expectations, plans, fears and wishes could have been exchanged. In addition, the opportunities of the clinical workstations could have been exploited to a much larger extent.

Another interesting point that emerged from the results relates to differences 
in requirements between inpatient and outpatient settings. Stroke EPR users preferred the paper records, although the system was easy to use and easy to learn to use, like Mirador. It suggests that the stroke EPR had more impact on users' work than Mirador. The trajectories of patients in inpatient clinics can be unpredictable, in contrast to the relatively well-organised patient encounters in outpatient clinics. As described in the literature, managing these trajectories requires adequate response to unexpected events, and inventive coordination and collaboration [10]. Adding up that the long startup time of Mirador only in the inpatient clinic appeared problematic, suggests that the fit between task and technology apparently was not sufficient for work in the inpatient clinic [11]. From these findings, we construe that requirements for EPRs for inpatient and outpatient settings differ, which may be an interesting subject of future research.

\section{Conclusions}

We evaluated two patient care information systems in one hospital. From our findings we inferred that both systems had similar effects on daily work and had similar prerequisites for implementation. Patient care information systems, even with limited functionality, can enhance coordination between health care providers. Inpatient and outpatient systems have different requirements to support the respective health care practices. Effective communication between management, implementers and users is crucial for user commitment. It should include the purpose of the system, potential benefits, anticipated changes in workflow, and (future) policy.

\section{Acknowledgements}

We would like to thank M. Hébert [12] for providing her interview guide. It helped us a great deal to select and phrase our interview topics. Then, we thank Mrs. Ippel for her help with transcribing interviews and Perry Hünen for his valuable contribution during the research project. 


\section{References}

1. Ash JS. Managing change: Analysis of a hypothetical case. JAMIA 2000; 7 (2): 125 34.

2. Aydin CE, Rice RE. Social worlds, individual differences, and implementation.

Predicting attitudes toward a medical information system. Information \& Management 1991; 20: 119-36.

3. Franz CR, Robey D. Organizational context, user involvement, and the usefulness of information systems. Decision Sciences 1986; 17: 329-56.

4. Brooke C, Maguire S. Systems Development: A Restrictive Practice? Int J Inform Manag 1998; 18 (3): 165-80.

5. Lorenzi NM, Riley RT. Organizational aspects of health informatics. Managing technological change. 1st ed. New York: Springer-Verlag 1994.

6. Berg M. Considerations for sociotechnical design: experiences with an electronic patient record in a clinical context. Int J Med Inf 1998; 52: 243-51.

7. Kaplan B, Lundsgaarde H. Toward an evaluation of an integrated clinical imaging system: identifying clinical benefits. Meth Inform Med 1996; 35 (3): 221-9.

8. Ash J. Organizational factors that influence information technology diffusion in academic health science centers. JAMLA 1997; 4: 102-11.

9. Martin-Baranera M, Planas I, Palau J, Miralles M, Sancho JJ, Sanz F. Assessing physician's expectations and attitudes toward hospital information systems. The IMASIS experience. MD Comput 1999; (2): 73-6.

10. Strauss A, Fagerhaugh S, Suczek B, Wiener C. Social organization of medical work. 2nd ed. New Brunswick, New Yersey: Transaction Publishers 1997.

11. Goodhue DL, Thompson RL. Task-technology fit and individual performance. MIS Quarterly 1995; 19: 213-36.

12. Hebert MA. Impact of IT on health care professionals: changes in work and the productivity paradox. Health Serv Manage Res 1998; 11: 69-79. 


\section{General Conclusions and Discussion}




\section{General Conclusions}

The studies in this thesis reported on several aspects related to the development, implementation, use and evaluation of an EPR. This Chapter presents conclusions, discusses the results of the studies and relates them to the objectives of this thesis.

The first objective of this thesis - to develop, implement and evaluate an electronic patient record for stroke - is addressed in Chapters 2 to 5 . Chapter 2 and 3 describe the phases of information and situation analysis and how users were involved in the development. Chapter 4 presents the EPR that was developed and the results of the evaluation are described in Chapter 5. The first research question was phrased as follows. What does a successful approach to EPR development and implementation comprise?

We conclude that

- Active user participation is difficult to achieve, but is crucial.

- Close co-operation between prospective users, management, developers and implementers is crucial and should start in a premature stage of the project.

- It is feasible to develop and implement a small-scale EPR, but the assumption that small-scaled is synonym to less complicated will prove untrue in most cases.

The second research question, what are important aspects of an EPR evaluation study?, led to the following conclusions:

- The rate of success depends on the choice of the success factors and the interests of the stakeholders (users, managers, developers, etc.)

- An EPR evaluation should include multiple concerns: technical issues, human factors and organisational issues.

- Data for evaluation are best collected with various, both qualitative and quantitative data collection methods that supplement each other.

- An EPR evaluation should preferably start before the implementation and be continued at least $6-12$ months after the implementation.

The second objective of this thesis - to investigate electronic record keeping in daily practice - was discussed in Chapters 2, 5 and 6. Chapter 3 describes 
how user involvement was realised in the EPR project. Chapter 5 presents the results of the evaluation of the EPR. In Chapter 6 the EPR is compared with the hospital wide Mirador with respect to technical, human, organisational and culture factors.

What consequences does an EPR have on health care professionals and on their daily work?, was the last research question and it led us to conclude:

- A multidisciplinary EPR can improve the completeness of record keeping.

- A multidisciplinary EPR can enhance coordination between health care professionals.

- Direct benefits need to outweigh the investments needed to adapt work routines.

In the following paragraphs some of the conclusions are discussed. To start with, several aspects of electronic patient records will be addressed: their development, implementation and evaluation and their impact on health care work. Subsequently, the focus is on the methodological strengths and weaknesses of the research. Finally, the practical implications and recommendations for future research are discussed.

\section{Discussion}

\section{Development, implementation and evaluation of an EPR}

Key issues in system development and implementation relate to a system's success. These include, among others, user involvement and communication. Without user involvement it is impossible to develop a high quality EPR and to create support for the implementation of an EPR. Our study showed that the quality of the EPR was satisfactory not only to the users, but also to management and developers. Whether we created support for the project is doubtful. Users were cooperative, but seemed not really interested in the project.

Effective communication regarding information technology between management, system developers and implementers, and health care workers is of utmost importance (Chapter 6). Several factors related to sub optimal communication. First of all, the direct benefits of the innovation were not clear to prospective users. As a consequence, they felt no need for an EPR. Second, for users and the EDP department this project might have seemed purely a 
scientific research project that was started to gain experience with a trajectory of development and introduction of an EPR (both for the department and for the researchers). Thus, what the organisation aimed at with the install of the EPR was not quite clear, which caused the users' reluctance to use the EPR. Third, the finiteness of the project made users hesitant to use the EPR. The last two aspects made it less interesting to discover their possible gains. Better marketing might have prevented this to happen, although it could also be that for the users this project arrived early; that they were not ready for electronic record keeping. Nevertheless, their experiences with electronic record keeping prepared them for an EPR in the future, which is a step ahead, many others.

Given the intention of the project, to investigate the aspects relating to the introduction and use of an EPR, the choice to develop a complete EPR for a specific domain was a logical one. It certainly has advantages: 1) it has relatively few users, 2) it is easily adapted to specific desires, and 3) full functionality can be implemented relatively easy. However, it also has advantages to implement an EPR hospital-wide: 1) well-known to all, 2) it is available in the whole organisation, and 3) the need to realise technical support is high. The advantages of each option are disadvantages for the other. Reflecting on the results in Chapters 6 and 7, the question arises how to approach an implementation when considering the hospital-wide introduction of an EPR. One could choose to implement different functions incrementally where the order of adding different functionality depend on the organisation [1]. This option provides users the opportunity to gradually adapt to a new situation. It might provide flexibility to pace the implementation, but it might lead to individual, departmental initiatives of inpatient departments. Still, it seems more likely to provide a solid basis to proceed than a departmental approach.

In most cases an EPR will be evaluated to study the rate of success and the factors relating to success. To conclude whether or not an EPR was successfully implemented the premises need to be clear and the focus of the evaluation should not be limited to technical factors. It is important to include also relevant aspects of the process of development and implementation, human factors and organisational and cultural issues. The literature review (Chapter 1) showed that for all these issues attributes could be defined and assessed. These are for example the coordination between health care workers, changed clinical work patterns, and direct benefits.

Another aspect of an evaluation study is the inclusion of viewpoints of different stakeholders. In the EPR evaluation the interviews of both end users and management elicited interesting results. Management, for example, 
expected higher quality of record keeping due to the EPR. This expectation, however, appeared unknown with the end users. Thus, by including the different viewpoints the situation was analysed more carefully.

The combination of diverse data collection methods is essential in an evaluation study. Data were collected by means of in-depth interviews, chart reviews, a logging of user actions, and questionnaires. The results showed that questionnaires and interviews supplemented each other very well (Chapter 2, 3 and 5). In other words, the results of one data collection method were investigated further by means of another method providing better insight in the situation. These results concur with previous research that included two additional recommendations, namely to evaluate formative and to have a longitudinal design [2].

\section{An EPR in daily practice}

The structured paper records served as a starting point for the EPR, and therefore, we had expected that the inevitable changes in daily practice would be limited to the organisation of work (Chapter 4). In addition, in Chapter 3 we argue that an EPR may support record keeping by avoiding copying of data and by structuring data more than in paper records.

Users, however, did not replace the paper record with the EPR. This increased the workload of nurses and physicians, which was the main, unanticipated, impact on daily work. It also caused that users had no need to adapt daily routines of record keeping. Moreover, the EPR users did not recognise direct benefits of the EPR, which made them reluctant to use the EPR.

The quality of the system was not a real objection. What, then, was their main objection? First of all, the lack of back-up facilities was obviously a critical issue that caused extra work. Second, when asked for their expectations of electronic record keeping, many users were rather indifferent. Adopting the EPR implies adapting their way of working, which is known to be difficult. Possibly their indifference caused that they would have been willing to adopt the EPR only in case of very obvious and very large immediate benefits for them, like automatically incorporating vital signs recordings in the EPR or direct order communication to the laboratory or the radiology department. Third, as previously mentioned, the fact that this project was to gain experience with the development and introduction of an EPR as well as to do research, and that it was known to be finite, might have caused users to dissociate themselves from the project and the EPR. 
Another issue that might have prevented the discard of paper records is that for non-stroke patients, paper records had to be maintained. During the project the number of stroke patients was less than initially anticipated. This provided an easy escape to paper records, since the majority was not electronic but paper records. To what extent this influenced the participation of users is not known, but it shows that certain risks can arise with two different, concurrent systems of record keeping.

\section{Methodological strengths and weaknesses}

This section discusses methodological strengths and limitations of the present study. One of the most important strengths is the fact that the EPR was evaluated in daily practice. Users used the EPR in their natural working environment and not in a laboratory setting. This elicited relevant and sometimes unanticipated aspects of the introduction and use of an EPR in daily practice. For instance, a seemingly trivial issue like the co-operation of consulting physicians showed to be a real barrier to a complete implementation of the EPR.

Another strength of the evaluation is the use of different data collection methods, the focus on a variety of concerns, and the interests of different stakeholders. Questionnaire results and interview results provided insight in the users' satisfaction with paper patient records and electronic patient records. Complementary, the logging module enabled a quantitative analysis of the users' behaviour. Furthermore, the viewpoints of end users as well as management were included both before and after the trial period. Diverse concerns were included in the evaluation. These comprised technical issues like information and system quality, but also usage, user satisfaction, individual impact and organisational impact. It generated a complete picture of the situation during the development, implementation and trial period.

Several outcome measures (user satisfaction, system quality, individual impact, organisational impact) relied on self-reports. These offered a richness and diversity of results that other methods could not have provided. It might be argued that self-reports are not fully reliable, since respondents may give socially desirable responses and their memory may not be infallible. The same objection could be uttered with regard to the in-depth interviews. To a certain extent these objections were met in the design of the study, for example by emphasizing anonymity and an independent interviewer.

Generalizability of the results needs commenting. The study was conducted in a small-scale setting, the stroke unit of the neurology department. The 
intention of this study was to investigate the aspects relating to the introduction and use of an EPR; to attain to an indication of the effects rather than quantifying them. Experimental approaches may not have elicited fully the diverse aspects pertaining to such study. Therefore, the best alternative was to conduct an in-depth study in a limited domain and a small-scale setting. Nevertheless, the results provide a basis for further exploration in experimental studies. This should be considered when generalising the results of this study to other settings. However, we have no reason to believe that a comparable study would yield entirely different results in other domains or settings, because the results concern general issues rather than domain or setting specific issues.

\section{Implications and future research}

To what extent do the research findings of this study contribute to the introduction of electronic record keeping? The present study may have implications for development, implementation and evaluation of EPRs in daily practice. Furthermore, several findings created new research questions to be investigated.

\section{IMPLICATIONS}

We developed and evaluated an integrated medical and nursing EPR for the stroke unit of an academic hospital. To what extent do the results have significance for other domains or settings?

At the neurology department, the medical and nursing intake of stroke patients and the nursing paper record were structured to a large extent. We regarded this as an advantage and it made the development of the EPR relatively easy, since the content was clear to developers as well as users. Probably, structuring paper forms is a relevant step toward electronic record keeping. It is said that structuring of data might be easier for more technically fields of medicine like surgery or cardiology than for internal medicine or neurology. The experiences with the stroke intake form, however, showed that all essential information could be collected in a systematised way. According to the head of the department, intake forms of other neurological diseases could be structured as well. The general part of the EPR (progress notes, recording of vital signs, overview of requested tests and the results) could, with some adjustments, be useful for other disciplines as well. 
The evaluations of both the EPR and Mirador show that prospective users need to recognize immediate, tangible benefits of an EPR before they start using it. We identified at least one aspect that can provide such benefits, which is disclosing relevant data from other disciplines. This comprises not only the exchange of information between different medical specialties, but also the information exchange between physicians and nurses. Possibly this can be extended to other health care providers within and outside the hospital, for example physical therapists or GPs. The results indicate that users appreciate that, but they prefer all data to be presented in one interface (Chapters 5 and 6). This requires flexible interfaces with personalised views, since not all data are relevant for every health care professional. It also requires standardised data sets and integration of data repositories, at least visually. In current developments towards shared and multidisciplinary treatment and care of patients a team of health care providers of several disciplines needs to be able to share relevant patient information [3].

\section{Future RESEARCH}

An issue that we consider worth exploring is the requirement for inpatient and outpatient EPRs. The comparison of the EPR and Mirador revealed that requirements differ for work in inpatient and in outpatient clinics (Chapter 6). In comparison to the situation in outpatient clinics, in inpatient clinics the patient trajectory is less predictable, making also the information need less predictable. Nurses recorded more data than residents, and they regularly recorded many data at once, like vital signs, whereas residents recorded data whenever necessary. Interfaces should be adapted to the specific needs of different health care workers. Further research in this area is needed.

With a well-established framework for evaluation studies of EPRs, the evaluations can zoom in on specific attributes that are relevant to health care. The evaluation framework in Chapter 1 yielded a list of attributes of different success factors, but further research is needed to refine the framework and identify essential criteria for success.

\section{Concluding remark}

An EPR has potential to improve record keeping and to support the health care process. Its development and implementation require active user involvement and adequate communication with all participants. In addition, 
adequate and effective communication between all parties involved is a prerequisite for successful introduction and use. EPRs in daily practice need to be evaluated thoroughly, including technical factors, human factors and organisational issues. Further research, however, is needed to identify specific benefits for end users and to measure quality improvements of patient records with electronic record keeping.

\section{References}

1 Atkinson CJ, Peel VJ. Transforming a hospital through growing, not building, an electronic patient record system. Meth Inform Med. 1998; 37: 285-93.

2 Kaplan B. Evaluating informatics applications - some alternative approaches: theory, social interactionism, and call for methodological pluralism. Int J Med Inf. 2001; 64: 39-56.

3 Stefanelli M. The socio-organizational age of artificial intelligence in medicine. Artif Intell Med. 2001; 23: 25-47. 



\begin{tabular}{|c|c|c|c|c|c|c|c|c|c|}
\hline \multirow{3}{*}{ Satisfaction } & \multicolumn{3}{|c|}{ satisfied ( $(\mathbf{6})$} & \multicolumn{3}{|c|}{ neutral (\$) } & \multicolumn{3}{|c|}{ dissatisf $(\mathbf{x})$} \\
\hline & \multicolumn{2}{|c|}{ baseline } & \multirow[t]{2}{*}{ EPR } & \multicolumn{2}{|c|}{ baseline } & \multirow[t]{2}{*}{ EPR } & \multicolumn{2}{|c|}{ baseline } & \multirow[t]{2}{*}{ EPR } \\
\hline & MR & NR & & MR & NR & & MR & NR & \\
\hline \multicolumn{10}{|l|}{ General aspects } \\
\hline overall satisfaction & 59 & 89 & 6 & 31 & 4 & 29 & 10 & 7 & 65 \\
\hline easy to learn & 54 & 59 & 18 & 27 & 26 & 35 & 19 & 15 & 47 \\
\hline availability at any time & 60 & 79 & 12 & 23 & 11 & 18 & 17 & 11 & 71 \\
\hline $\begin{array}{l}\text { availability on any location } \\
\text { completeness of: }\end{array}$ & 60 & 75 & 24 & 20 & 14 & 18 & 20 & 11 & 59 \\
\hline diagnostic interventions ${ }^{+}$ & 53 & 46 & 44 & 23 & 42 & 19 & 23 & 12 & 44 \\
\hline therapeutic interventions ${ }^{+}$ & 59 & 46 & 47 & 24 & 42 & 13 & 17 & 12 & 40 \\
\hline decisions made & 53 & 52 & 25 & 30 & 37 & 38 & 17 & 11 & 38 \\
\hline orders made ${ }^{+}$ & 47 & 70 & 41 & 40 & 30 & 24 & 13 & 0 & 35 \\
\hline plans made ${ }^{+}$ & 47 & 52 & 40 & 37 & 37 & 20 & 17 & 11 & 40 \\
\hline \multicolumn{10}{|l|}{ Data entry } \\
\hline ease of data entry & 70 & 78 & 53 & 19 & 7 & 18 & 11 & 15 & 29 \\
\hline speed of data entry & 73 & 69 & 12 & 23 & 15 & 29 & 4 & 15 & 59 \\
\hline $\begin{array}{l}\text { lay-out of the record is adequate } \\
\text { to enter data }\end{array}$ & 46 & 63 & 35 & 46 & 26 & 35 & 7 & 11 & 29 \\
\hline $\begin{array}{l}\text { flexibility in deciding which data to } \\
\text { register where, and in which words }\end{array}$ & 61 & 67 & 35 & 25 & 26 & 18 & 14 & 7 & 47 \\
\hline \multicolumn{10}{|l|}{ Data retrieval } \\
\hline ease of information retrieval & 53 & 68 & 13 & 20 & 21 & 25 & 27 & 11 & 63 \\
\hline ease of retrieving own data & 70 & 70 & 6 & 23 & 15 & 56 & 7 & 15 & 38 \\
\hline $\begin{array}{l}\text { ease of retrieving others data } \\
\text { understanding data: }\end{array}$ & 21 & 46 & 13 & 34 & 27 & 38 & 45 & 27 & 50 \\
\hline own entriest & 85 & 81 & 80 & 7 & 8 & 20 & 7 & 12 & 0 \\
\hline others' entries+ & 39 & 63 & 38 & 36 & 22 & 56 & 25 & 15 & 6 \\
\hline \multicolumn{10}{|l|}{$\begin{array}{l}\text { speed of getting an overview of } \\
\text { state/progress of treatment: }\end{array}$} \\
\hline first impression & 41 & 37 & 6 & 24 & 33 & 25 & 34 & 30 & 69 \\
\hline full impression & 18 & 33 & 0 & 36 & 30 & 19 & 46 & 37 & 81 \\
\hline \multicolumn{10}{|l|}{ lay-out of the record is adequate } \\
\hline to retrieve data & 36 & 52 & 25 & 43 & 37 & 50 & 21 & 11 & 25 \\
\hline speed of finding specific data & 17 & 26 & 0 & 14 & 22 & 25 & 69 & 52 & 75 \\
\hline speed of identifying missing datat & 17 & 22 & 31 & 17 & 37 & 38 & 66 & 41 & 31 \\
\hline $\begin{array}{l}\text { information retrieval not impeded } \\
\text { by: }\end{array}$ & & & & & & & & & \\
\hline overload of irrelevant detailst. & 17 & 33 & 33 & 41 & 26 & 40 & 41 & 41 & 27 \\
\hline overlooking relevant data & 38 & 52 & 29 & 45 & 15 & 47 & 17 & 33 & 24 \\
\hline \multicolumn{10}{|l|}{ User interface } \\
\hline dear screen messages & & & 0 & & & 25 & & & 75 \\
\hline easy to undo mistakes & & & 0 & & & 18 & & & 82 \\
\hline quick to undo mistakes & & & 0 & & & 12 & & & 88 \\
\hline dear manual & & & 25 & & & 56 & & & 19 \\
\hline dear on-line help & & & 0 & & & 64 & & & 36 \\
\hline data are easy to understand 9 & & & 53 & & & 29 & & & 18 \\
\hline data support daily work & & & 12 & & & 35 & & & 53 \\
\hline organisation of data on screens $\$$ & & & 53 & & & 35 & & & 12 \\
\hline user friendly screens $\$$ & & & 47 & & & 35 & & & 18 \\
\hline \multicolumn{10}{|l|}{ functionality } \\
\hline general user friendliness & & & 6 & & & 18 & & & 76 \\
\hline $\begin{array}{l}- \text { MR = paper medical record, NR = pape } \\
\text { record; } 5 \text { positive aspects of user interfac }\end{array}$ & & stu & $P R \in q$ & & 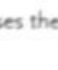 & per me & and & & \\
\hline
\end{tabular}




$\begin{array}{llll}\text { Before } & \text { After } & \text { Before } & \text { After } \\ \text { EPR } & \text { EPR } & \text { EPR } & \text { EPR }\end{array}$

I can enter information in my own words and not need to know any

33

26

3

special codes

I can learn to use the system in less than 2 hours

I can access the system at any place in the clinical setting

The system always responds to my queries in less than 5 seconds

The system can be implemented with no changes whatsoever to existing clinic routines

When a system provides medical advice on the care of specific patients, it always provides multiple alternative recommendations

When a system provides medical advice on the care of specific patients, it can quantify the level of certainty inherent in its recommendations

The system takes a patient's own preferences into account when giving advice to clinicians

The system can clearly explain the rationale for advice it gives on the care of patients

Users can browse the information in a system as well as asking it to provide advice about care of specific patients

The system has been demonstrated in research studies to make

diagnoses at least as accurate as human consultants

The system has been demonstrated in research studies to provide treatment recommendations at least as accurate as human consultants

\section{Expected Effects}

\section{Before After}

Costs of health care

Clinician autonomy

Quality of health care

Interactions within the health care team

Role of the government in health care

Management of medical/ethical dilemmas

Enjoyment of the practice of medicine

Status of medicine as a profession

Continuing medical education

The self-image of dinicians

Humaneness of the practice of medicine

The rapport between clinicians and patients 


\section{Appendix II}

This appendix shows methods and results of the evaluation of Mirador that were not included in Chapter 6. The selection of the four departments that were interviewed was based on these results.

\section{Methods}

A short questionnaire (figure 1) of six items was sent to all registered users to assess self-reported usage (dichotomised), and perceived ease of use (3 items on a 5-point Likert scale). In addition usage statistics were collected in the first quarter of 2001. For this purpose periods of 10 minutes that users were logged in were counted during 8 weeks. These results were grouped by specialty.

1. Do you use Mirador ?

$$
\text { Yes - No }
$$

If 'Yes' please continue with question 3.

If 'No', please comment here on your answer:

2. Do you think Mirador is easy to use?
Very difficult
$\begin{array}{llllll}1 & 2 & 3 & 4 & 5 & \text { Very easy }\end{array}$

3. Data in Mirador are presented more conveniently arranged than in the paper records

$\begin{array}{llllllll}\text { Completely agree } & 1 & 2 & 3 & 4 & 5 & \text { Completely disagree }\end{array}$

4. Data are quicker to retrieve from Mirador than from the paper records

$\begin{array}{lllllll}\text { Completely agree } & 1 & 2 & 3 & 4 & 5 & \text { Completely disagree }\end{array}$

5. Do you use Mirador

During the outpatient consultations?

never $1-2-3-4-5$ always

At staff rooms?

never $1-2-3-4-5$ always

In the inpatient dinics?

never 1 - 2-3-4-5 always

At the Emergency department?

never $1-2-3-4-5$ always

Any comments:

\section{Figure 1}

Short questionnaire to assess use and perceived ease of use. 


\section{Results}

\section{Short questionnaire}

The response rate of the short questionnaire was about $40 \%$ (215 respondents). A majority of $93 \%$ used Mirador. Non-users (7\%) had several reasons for non-use: no understanding of Mirador, a departmental systems providing sufficient data for daily care, no need to use Mirador, or unavailability of clinical workstation because of the high costs.

Only 15 of the 200 users indicated that they never used Mirador in the outpatient clinics, wheras 120 of them responded to use it always there (table 1). Thirty percent of the users always used Mirador at the emergency department, while 24.5 percent never used it there.

\section{Table 1}

Use of Mirador at different locations. Table shows what percentage of the respondents used Mirador at the given locations.

\begin{tabular}{|lll|}
\hline Location & $\begin{array}{l}\text { Use } \\
\text { Always (\%) }\end{array}$ & Never (\%) \\
outpatient clinic & 60 & 7.5 \\
inpatient clinic & 41 & 16,5 \\
staff rooms & 38 & 12.5 \\
emergency dept & 30 & 24.5 \\
\hline
\end{tabular}

The other questionnaire results are presented in table 2. Mirador was easy to use according to 176 respondents (88\%). Seventy-six users $(38 \%)$ disagreed with the statement that Mirador presented data more conveniently than the paper records, while $92(46 \%)$ agreed. The speed of data retrieval was higher than in the paper records according to 86 respondents ( $43 \%)$, whereas thirty-eight percent disagreed with that statement. 


\section{Table 2}

Number of respondents per question per option. Total number of respondents was 200.

\begin{tabular}{|lll|}
\hline Ease of use & Overview data is better & $\begin{array}{l}\text { Speed of data retrieval is } \\
\text { higher }\end{array}$ \\
0 (very difficult) & 57 (fully agree) & 60 (fully agrec) \\
4 & 35 & 26 \\
19 & 29 & 35 \\
86 & 42 & 42 \\
90 (very easy) & 34 (fully disagree) & 34 (fully disagrec) \\
1 (no data) & 3 (no data) & 3 (no data) \\
\hline
\end{tabular}

\section{Usage statistics}

During eight weeks of the first quarter of 2001 logging data of users of Mirador, grouped by specialty, were collected. The periods of 10 minutes that a user was logged in were counted. Table 3 shows the results, grouped by specialty. Obstetrics\&Gynaecology and Urology were the two chirurgical specialties with most and least logged-in periods, a mean of 42 and 24 periods of 10 minutes a week respectively. The two non-surgical specialties with most and least logged-in periods were Internal medicine and Pediatrics. Pediatrics had a mean periods of 10 minutes a week of 11 , while internal medicine physicians were most active with 67 periods of 10 minutes a week on average. Based on the results Urology, Obstetrics and Gynaecology, Internal medicine and Pediatrics were selected for in-depth interviews. 


\section{Table 3}

Counts per individual per department per week.

\section{Department}

LabHLE

Lab-KCH

Lab-KLF

Lab-KNF

Lab-MMB

Nucleair Medicine

Lab-PAT

Lab-WTP

Radiology

Anesthesia

Cardiol

SCPC

Dermatology

\section{Gynaecology}

SHEE

ICU

ICU-ANE

ICU-HEE

ICU-INT

ICU-LON

Internal Medicine

SKAM

\section{Pediatrics}

Ear-Nose-Throat

Pulmonology

Surgery

Neurology

Eyc

Orthopedia

SPCH

Psychiatry

Revalidation

Urology

\section{Counts per user per department per week}

34,54

59,50

0,06

3.25

0,00

61,78

26,95

0,00

9,04

6.42

60.91

42,33

31,23

42,26

43,73

0,00

0,00

21,75

0,00

12,50

66,60

45,58

10,69

29,55

62,41

21,24

74,14

9.73

27,22

32,01

34,10

56,47

23.73 


\section{Summary}

Stroke, or a cerebrovascular accident (CVA), can lead to irreversible damage of brain tissue and loss of function. Immediate diagnosis and treatment are crucial for further prognosis. Different health care providers are involved in this process and therefore, adequate communication is vital. Electronic record keeping is believed to be a solution in improving and supporting this communication. This thesis reports on the development, implementation and evaluation of an experimental electronic patient record (EPR) for stroke. In addition, the consequences of electronic record keeping in daily health care practice were investigated.

Chapter 1 presents an overview of the literature on evaluations of patient care information systems (PCIS) that require data entry by health care professionals. This review aimed at identifying attributes that were used to assess success and to test a framework to systematise them. This framework contained six success factors: system quality, information quality, usage, user satisfaction, individual and organizational impact. We added three contingent factors: system development process, the implementation process and organizational culture and characteristics. Thirty-three papers that included study design and attributes of success were selected for complete review. These papers described evaluations of general, hospital-wide information systems or specific systems like an information system at an intensive care unit. Several study designs were identified: descriptive, correlational, comparative studies with randomised and non-randomised controls, and multiple and single case studies. In the evaluation studies the attributes that related to success were identified and were assigned to one of the success or contingent factors. The attributes of the latter were identified predominantly in evaluation studies of failures. We conclude that the presented framework with several attributes for each success factor is useful in evaluations of PCISs. Moreover, the contingent factors seem important to assess, because they may play a role in success as well. In addition, we recognise the need for thorough evaluation studies and suggest how to design them. 
In Chapter 2 the situation at the neurology ward of the University Hospital Maastricht prior to the EPR was analysed with the aims: (1) to identify system requirements, (2) to determine advantages and disadvantages of the paper record situation, and (3) to identify the potential of an EPR for stroke. The paper medical and nursing records were investigated as well as a typical patient's route through the hospital. It is concluded that the paper medical records show three types of incompleteness: (1) clinical items that were not filled in, (2) not copied data; the necessity to copy data from one sheet of paper to another leads to data loss, and (3) misplaced or missing reports of diagnostic tests: these reports were hard to trace in the paper records. This missing information needed to be retrieved from other data repositories. Furthermore, an increasing need for communication and information exchange was identified. New legislation and changing social values result in

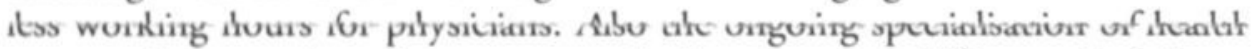
care workers requires frequent consultation between different disciplines. These developments introduce the need for more patient handovers

Prudent predictions were made on the chances of a successful introduction of the EPR for stroke. These were based on the five attributes of adoption of innovations: relative advantage, compatibility, perceived complexity, trialability, and observability. It was expected that the EPR for stroke would have a fair chance, because (a) users would benefit from single data entry, (b) wherever possible EPR data entry forms were based on existing paper forms and familiar terms and headings were used, and (c) everyone could see the EPR being used, which maximised observability. Only the trialability was a source of minor concern, since users would need to use the EPR only for stroke patients. Meanwhile, however, they needed to maintain paper records for other than stroke patients, providing an easy escape from the EPR.

Chapter 3 describes the participation of users in the design and development of the EPR. On the one hand we aimed at further eliciting systems requirements, on the other hand we aimed at increasing support for the EPR. By means of questionnaires, complemented with interviews, the attitude toward computers, the satisfaction with the paper records, the knowledge of computers, and needs and expectations of users were assessed. Users' attitude toward computers in health care was neither negative nor positive. However, experienced computer users -self-rated - had a more positive attitude than inexperienced users. Experienced users were less satisfied with the paper records than inexperienced computer users. However, all respondents were more satisfied with data entry than with data retrieval in the paper records. The main expectation users had of electronic record keeping was more concise reporting. 
Chapter 4 describes the EPR for stroke that was developed. This EPR was a combined medical and nursing patient record, complete for the domain of stroke, which was developed in Visual Basic 5.0 and had an MsAccess database. Since both medical and nursing paper records contained already structured forms, several data entry screens reflected the format of their paper counterparts. In addition to the data entry screens, a time-oriented summary screen presented the entered data. Besides patient data, the EPR contained the clinical guidelines for stroke and a context sensitive on-line help module to support users. Demographic patient data and admission data were retrieved from the hospital information system by the EPR. Other relevant information could be viewed in the hospital information system at the same workstation.

In Chapter 5 the results of the evaluation of the EPR are presented. First of all, the research setting and the intervention are described. Before and after the implementation several issues were assessed. The user evaluation comprised user satisfaction, data and system quality, use, user needs and expectations, the impact on daily work of users, organisational impact, and usage. In addition, the completeness of the patient records, the actual usage and the management's point of view were assessed. Data were collected by means of different quantitative and qualitative methods, that complemented each other whenever possible. The results showed that (1) electronic patient records were more complete than their corresponding paper records, (2) the users were rather satisfied with the EPR, which is remarkable, since the paper records remained the primary data source for nurses and physicians, (3) users were, despite the limited use and double work, content with the user friendliness of the EPR and with the fact that the medical and nursing record were integrated, and (4) users expressed the need to have an EPR at the bedside. Conclusively, as a learning trajectory, the project was a success, since the EPR had been up and running for a considerable period of time, the department had become aware of the problems and pitfalls when introducing an EPR, and management had seen that integration of medical and nursing record was possible and that nurses and physicians actually used the EPR in their working environment, even those who had a computer phobia.

In Chapter 6 the EPR is compared with Mirador, a hospital widely available GUI to the HIS with respect to technical, organisational, cultural and human factors. Data were collected via in-depth interviews with end-users of both clinical workstations. Analysis of the transcripts showed several common themes in the two evaluations. End users assessed both clinical work- 
stations as user friendly. Coordination between health care workers was perceived to be enhanced. However, in both situations poor communication between management, implementers and users resulted in uncertainty and scepticism about future perspectives. Furthermore, it appeared that inpatient and outpatient settings needed clinical workstations with different requirements for an optimal fit between work practices and information system.

Chapter 7 presents the main conclusions of this study. Summarising, a successful introduction of an EPR starts before the development phase, requires many efforts of and benefits for users, and depends not only on the EPR itself. This chapter also discusses the findings concentrating on the processes of development and implementation, and on EPRs in daily practice. Furthermore, the methodology is discussed. This thesis ends with the implications of this study for electronic record keeping in other settings and domains and recommendations for future research. 


\section{Samenvatting}

Een beroerte of hersenbloeding, ofwel cerebrovasculair accident (CVA), kan onherstelbare schade toebrengen aan het hersenweefsel en verlies van functies tot gevolg hebben. Snelle diagnostiek en behandeling zijn van groot belang voor de verdere prognose. Hierbij zijn diverse zorgverleners betrokken en dus is adequate communicatie van vitaal belang. De verwachting is dat een electronisch patiëntendossier (EPD) de communicatie zou kunnen ondersteunen en verbeteren. Dit proefschrift beschrijft de ontwikkeling, implementatie en evaluatie van een experimenteel EPD voor het registreren en het raadplegen van gegevens van patiënten met een CVA. Daarnaast werden de gevolgen van electronische dossiervoering voor de dagelijkse praktijk onderzocht.

Hoofdstuk 1 geeft een overzicht van de literatuur over evaluaties van patiëntgerelateerde informatiesystemen in de gezondheidszorg, waarin de zorgverleners zelf gegevens vastleggen. De attributen die in de evaluaties gebruikt werden voor het meten van succes werden geïdentificeerd en vervolgens gesystematiseerd met behulp van een set succes- en beïnvloedende factoren. De succesfactoren waren systeem-, datakwaliteit, gebruik, gebruikerstevredenheid, impact op de individuele zorgverlener en impact op de organisatie. De beïnvloedende factoren waren systeem-, implementatietraject en cultuur en karakteristieken van de organisatie. De attributen die in deze categorie geplaatst werden, bleken veelal afkomstig uit evaluaties van mislukte implementaties.

We concluderen dat de set gepresenteerde succes- en beïnvloedende factoren bruikbaar is voor de evaluaties van zorginformatiesystemen en dat een breed scala aan attributen voorhanden is voor evaluaties. Bovendien geven we aan dat gedegen evaluatiestudies noodzakelijk zijn en doen we suggesties voor het opzetten van dergelijke studies.

In Hoofdstuk 2 werd de situatie op een neurologie afdeling van het Academisch Ziekenhuis Maastricht geanalyseerd met als doelstellingen (1) de systeemeisen beschrijven, (2) de voor- en nadelen van de papieren dossiers achterhalen en (3) de mogelijk toegevoegde waarde van een EPD voor CVA 
identificeren. De papieren, medische en verpleegkundige dossiers werden onderzocht en de gang door het ziekenhuis van een 'doorsnee' CVA patiënt werd geanalyseerd. Het bleek dat de papieren medische dossiers drie vormen van incompleetheid vertoonden: (1) klinische gegevens die niet ingevuld werden (2) niet gecopieerde gegevens; de noodzaak om gegevens van het ene vel papier naar het andere te copieren leidt tot verlies van gegevens en (3) ontbrekende de verslagen van diagnostische testen, zoals bijvoorbeeld CTscans. Daarnaast werd een groeiende behoefte en noodzaak tot communicatie en het uitwisselen van gegevens gesignaleerd. De werktijd van artsen wordt korter onder invloed van wetgeving en veranderende sociale verhoudingen. Daarnaast vereist de verregaande specialisatie van zorgverleners regelmatige afstemming tussen de betrokken disciplines. Dit alles heeft tot gevolg dat patiëntgegevens frequenter overgedragen worden van zorgverlener op zorgverlener.

De kans op een succesvolle introductie van het EPD voor CVA werd gebaseerd op de vijf zaken die een rol spelen bij de adoptie van innovaties; het relatieve voordeel, de verenigbaarheid met de eigen situatie, de verwachte complexiteit, de mogelijkheid om uit te proberen, en de zichtbaarheid van de innovatie. De verwachting was dat het EPD een redelijke kans van slagen had aangezien de gebruikers gegevens nog slechts eenmalig zouden invoeren, de invoerschermen waar mogelijk zouden worden gebaseerd op de bestaande papieren formulieren met dezelfde termen en onderverdeling, en iedereen zou op de afdeling de computers en hun gebruikers kunnen zien. Een punt van zorg lag in het feit dat gebruikers het EPD zouden moeten gebruiken voor CVA patiënten en voor alle andere patiënten het bekende papieren dossier.

Hoofdstuk 3 beschrijft de participatie van gebruikers tijdens het ontwerpen en ontwikkelen van het EPD. Aan de ene kant was het doel de eisen voor het systeem verder uit te werken, aan de andere kant was het een manier om draagvlak voor het EPD en het project te creëren. Middels vragenlijsten, aangevuld met interviews werd de attitude ten aanzien van computers, tevredenheid met de papieren dossiers, computerkennis, systeemeisen en verwachtingen van toekomstige gebruikers gemeten. De attitude bleek over het geheel genomen noch positief noch negatief. Wel hadden ervaren computer gebruikers een positievere attitude dan onervaren computergebruikers en waren zij minder tevreden met de papieren dossiers. Voor beide groepen was de tevredenheid met de papieren dossiers groter voor het invoeren van gegevens dan voor het opzoeken van gegevens. De belangrijkste verwachting van toekomstige gebruikers was dat electronische dossiervoering zou resulteren in beknoptere rapportages. 
Hoofdstuk 4 beschrijft het EPD dat ontwikkeld werd. Dit EPD was een gecombineerd medisch en verpleegkundig dossier en inhoudelijk volledig voor CVA. Het is ontwikkeld in Visual Basic 5.0 en de gegevens werden opgeslagen in een MsAccess database. Aangezien zowel het papieren medisch dossier als het papieren verpleegkundig dossier al gestructureerde formulieren bevatten, leken verschillende invoerschermen van het EPD sterk op hun papieren variant. Niet alleen via invoerschermen, maar ook op een tijdgeorienteerd werkblad konden de gegevens van een patiënt geraadpleegd worden. Naast patiëntgegevens bevatte het EPD ook de klinische richtlijnen voor CVA en een on-line, context-gevoelige help om gebruikers te ondersteunen. Demografische gegevens konden uit het ziekenhuisinformatiesysteem (ZIS) worden geladen, terwijl voor overige relevante informatie, zoals laboratoriumuitslagen, het ZIS zelf geraadpleegd diende te worden om redundante informatie in het EPD te voorkomen. Het EPD en het ZIS waren beiden op de PC's beschikbaar.

In Hoofdstuk 5 worden de resultaten van de evaluatie van het EPD besproken. Zowel voor als na de implementatie zijn diverse variabelen gemeten. Onderwerp van studie waren de volledigheid van de papieren en electronische dossiers, gebruikerstevredenheid, data- en systeemkwaliteit, gebruik, gebruikerssysteemeisen, verwachtingen van een EPD, impact op het dagelijks werk van zorgverleners en impact op de organisatie. Bovendien werd middels een logging module het gebruik gemeten en werd het standpunt van het management van de afdeling onderzocht. De data werd verzameld middels kwantitatieve en kwalitatieve methoden. Uit de resultaten bleek dat (1) electronische dossiers vollediger werden ingevuld dan overeenkomstige papieren dossiers, (2) gebruikers, ondanks beperkt gebruik van het EPD, redelijk tevreden waren over de gebruikersvriendelijkheid ervan, (3) dat de integratie van het medisch en verpleegkundig dossier positief beoordeeld werd en (4) gebruikers niet meer of minder tevreden waren met het EPD dan met het papieren dossier. Dit laatste was opmerkelijk, aangezien het papieren dossier primair bleef dienen als patiëntendossier en het EPD ernaast werd ingevuld. Zij hadden één duidelijke wens aangaande het gebruik van een EPD in de kliniek en dat was een computer aan het bed, de plaats waar de gegevens ingevoerd of geraadpleegd worden.

In Hoofdstuk 6 wordt het EPD vergeleken met Mirador, een ziekenhuisbreed beschikbare grafische gebruikers-interface van het ZIS. Deze vergelijking richt zich op technische, organisatorische, culturele en menselijke factoren. Diepte-interviews met eindgebruikers van beide systemen toonden diverse overeenkomsten tussen beiden: (1) beiden systemen waren gebruikersvriendelijk en (2) elk van de systemen had een positieve invloed op de 
coordinatie tussen zorgverleners. Echter, in beide gevallen resulteerde onvoldoende communicatie tussen management, eindgebruikers en de verantwoordelijken voor de introductie in onzekerheid en skepsis over toekomstige ontwikkelingen. Daarnaast bleek dat de vereisten voor werkstations in poliklinische en klinische settings aan andere eisen zouden moeten voldoen voor een optimale afstemming tussen werkroutines en informatiesysteem. Tenslotte worden in Hoofdstuk 7 de belangrijkste conclusies van het onderzoek gepresenteerd en bediscussieerd. Samengevat kan geconcludeerd worden dat een succesvolle introductie van een EPD start voor de ontwikkelfase of aanschaf, veel input van en voordelen voor eindgebruikers vereist en niet alleen afhangt van de kwaliteit van het EPD. Daarnaast worden de onderzoeksbevindingen bediscussieerd waarbij het ontwikkel- en implementatieproces en het EPD in de dagelijkse praktijk centraal staat. Een deel van de discussie is gewijd aan de methodologie. Dit proefschrift wordt afgesloten met de implicaties van deze studie voor electronische dossiervoering in andere settings en domeinen en aanbevelingen voor vervolgonderzoek. 


\section{Dankwoord}

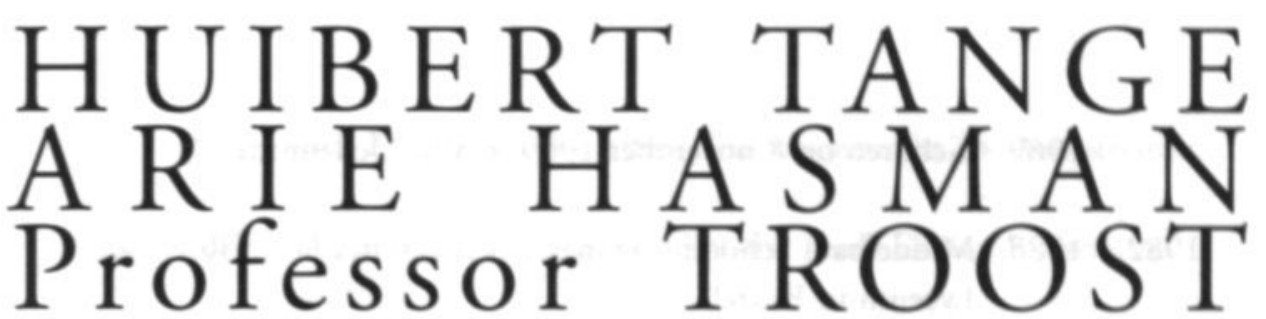

VERPLEEGKUNDIGEN C5/MEDIUM CARE ARTSEN EN ARTSASSISTENTEN C5 ROB ROGGEVEEN JOS THIJSSEN ROBERT van OOSTENBRUGGE PERRY HÜNEN JELIS BOITEN (EX)COLLEGA'S VAN MEDISCHE INFORMATICA VRIENDEN EN FAMILIE

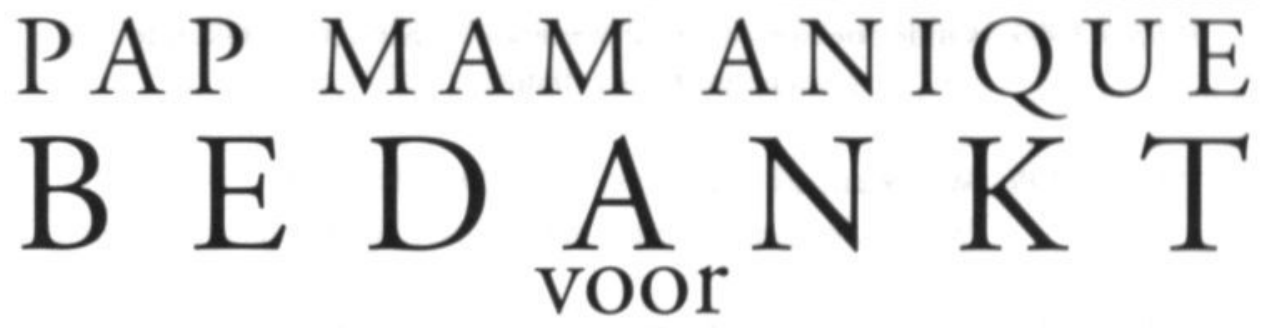

HET VERTROUWEN • DE SAMENWERKING - DE ONDERSTEUNING - DE KAN $\mathrm{SEN} \bullet \mathrm{DE} \mathrm{HUMOR} \bullet \mathrm{HET}$ GEDULD • DE BELANGSTELLING • DE AFLEIDING

TOT SLOT:

Meebeleefd en Meegeleefd

mijn lief,

\section{GER}

$\&$

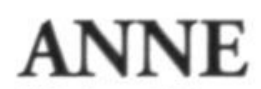

mijn altijd vrolijke meiske 


\section{Curriculum Vitae}

1969 Geboren op 8 november 1969 te Sint Oedenrode

1982 - 1988 Middelbare School: Gymnasium B aan het Jacob Roelands Lyceum in Boxtel

1988 - 1993 Doctoraalstudie Biomedische Wetenschappen aan de Rijksuniversiteit Leiden

1993 - 1994 Onderzoeksproject naar vetzuren bij Kindergeneeskunde aan de Universiteit van Padua, Italië

1994 - 1995 Werkzaam als interviewer bij de Dienst Sociaal Wetenschappelijk Onderzoek van de Rijksuniversiteit Leiden

1996 - 1997 Werkzaam als software engineer bij ELC Information Services in 's- Hertogenbosch

1997 - 2002 Werkzaam als Assistent in Opleiding bij de capaciteitsgroep Medische Informatica aan de Universiteit van Maastricht, onderzoek naar electronisch patiëntendossier

2001 - heden Werkzaam bij de afdeling Automatisering van het Elkerliek Ziekenhuis in Helmond 


\section{Curriculum Vitae}

1969 born November, 8th 1969, Sint Oedenrode, the Netherlands

1982 - 1988 Highschool, Gymnasium B at the Jacob Roelands Lyceum, Boxtel

1988 - 1993 University education, Biomedical Sciences at the State University Leiden

1993 - 1994 Research project concerning fatty acids at the department of Pediatrics, University of Padova, Italy

$1994-1995$ Worked as an interviewer at the Institute of Social Scientific Research, State University Leiden

1996 - 1997 Worked as a software engineer at ELC Information Services, 's-Hertogenbosch

1997 - 2002 Worked as a PhD student at the department of Medical Informatics, Maastricht University; research on electronic records

2001 - heden Currently working at the EDP department of the Elkerliek Hospital, a general hospital, Helmond 


\section{Publications}

\section{Full papers}

Van der Meijden MJ, Tange HJ, Boiten J, Troost J, Hasman A.

An experimental electronic patient record for stroke patients. Part 1: Situation analysis. Int J Med Inform 2000; 58-59 111-125.

Van der Meijden MJ, Tange HJ, Boiten J, Troost J, Hasman A.

An experimental electronic patient record for stroke patients. Part 2: System description. Int J Med Inform 2000; 58-59 127-140.

Van der Meijden MJ, Tange HJ, Troost J, Hasman A.

Development and implementation of an EPR: how to encourage the user. Int J Med Inform 2001; 64 173-186.

Van der Meijden MJ, Solen I, Hasman A, Troost J, Tange HJ.

Two patient care information systems in the same hospital: beyond technical aspects. Meth Inf Med; in press.

\section{Abstracts}

Van der Meijden MJ, Tange HJ, Boiten J, Troost J, Hasman A.

An experimental electronic patient record for stroke patients. In: Kokol, P., Zupan, B., Stare, J, Premik, M, Engelbrecht, $R$, editors. Proc Medical Informatics Europe, Ljubljana: IOS Press; 1999, p. 795-798.

Van der Meijden MJ, Tange HJ, Boiten J, Troost J, Hasman A.

The user in the design process of an EPR. In: Hasman A, Blobel B, Dudeck J, Engelbrecht R, Gell G, Prokosch, H.U., editors. Proc Medical Informatics Europe, Hannover: IOS Press; 2000, p. 224-228.

Van der Meijden MJ, Solen I, Hasman A, Tange HJ.

Twee verschillende zorg-gerelateerde informatiesystemen in hetzelfde ziekenhuis vergeleken: niet alleen technische aspecten tellen. In: Helder, J.C., editor. Proc Medisch Informatica Congres, Noordwijk; 2001 (CD-rom).

Van der Meijden MJ, Tange HJ, Solen I., Hasman A.

User evaluation of two patient care information systems compared: beyond technical aspects. In: Berg, M., van der Lei, J., editors. IT in Health Care: Sociotechnical Approaches, Rotterdam: Erasmus University; 2001, p. 44. 


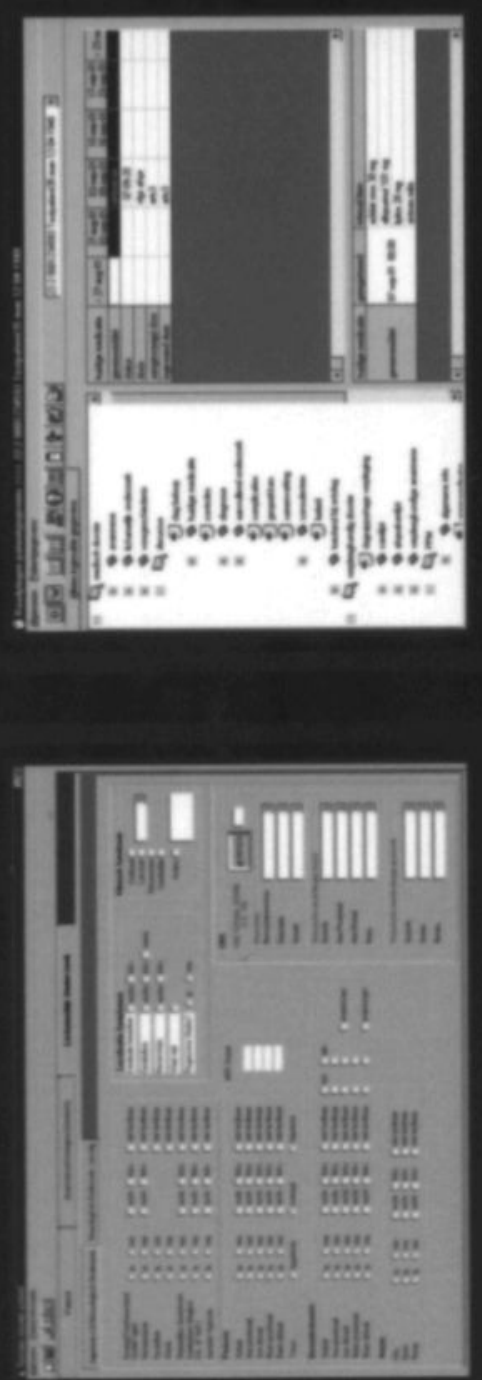